\title{
Le Laborien récent de la grotte-abri de Peyrazet (Creysse, Lot, France). Nouvelles données pour la fin du Tardiglaciaire en Quercy
}

Recent Laborian of the Peyrazet cave-rock shelter (Creysse, Lot, France). New data for the end of Lateglacial in Quercy

Mathieu Langlais, Véronique Laroulandie, Jérémie Jacquier, Sandrine Costamagno, Pierre Chalard, Jean-Baptiste Mallye, Jean-Marc Pétillon, Solange Rigaud, Aurélien Royer, Luca Sitzia, David Cochard, Laure Dayet, Célia Fat Cheung, Olivier Le Gall, Alain Queffelec et François LacrampeCuyaubère

\section{OpenEdition}

Journals

Édition électronique

URL : http://journals.openedition.org/paleo/2917

DOI : $10.4000 /$ paleo.2917

ISSN : $2101-0420$

Éditeur

SAMRA

Édition imprimée

Date de publication : 1 décembre 2015

Pagination : 79-116

ISSN : 1145-3370

Référence électronique

Mathieu Langlais, Véronique Laroulandie, Jérémie Jacquier, Sandrine Costamagno, Pierre Chalard, Jean-Baptiste Mallye, Jean-Marc Pétillon, Solange Rigaud, Aurélien Royer, Luca Sitzia, David Cochard Laure Dayet, Célia Fat Cheung, Olivier Le Gall, Alain Queffelec et François Lacrampe-Cuyaubère, " Le Laborien récent de la grotte-abri de Peyrazet (Creysse, Lot, France). Nouvelles données pour la fin du Tardiglaciaire en Quercy », PALEO [En ligne], 26 | 2015, mis en ligne le 26 avril 2016, consulté le 07 juillet 2020. URL : http://journals.openedition.org/paleo/2917 ; DOI : https://doi.org/10.4000/paleo. 2917

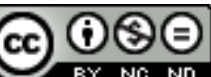

PALEO est mis à disposition selon les termes de la licence Creative Commons Attribution - Pas d'Utilisation Commerciale - Pas de Modification 4.0 International. 


\title{
Le Laborien récent de la grotte-abri de Peyrazet (Creysse, Lot, France). Nouvelles données pour la fin du Tardiglaciaire en Quercy
}

\author{
Mathieu LANGLAIS ${ }^{(a, d)}$, Véronique LAROULANDIE ${ }^{(a)}$, Jérémie JACQUIER ${ }^{(b)}$, \\ Sandrine COSTAMAGNO ${ }^{(c)}$, Pierre CHALARD ${ }^{(c)}$, Jean-Baptiste MALLYE ${ }^{(a)}$, \\ Jean-Marc PÉTILLON ${ }^{(c)}$, Solange RIGAUD ${ }^{(e)}$, Aurélien ROYER ${ }^{(a)}$, \\ Luca SITZIA(a), David COCHARD ${ }^{(a)}$, Laure DAYET(a), Célia FAT CHEUNG(c), \\ Olivier LE GALL (†), Alain QUEFFELEC ${ }^{(a)}$, François LACRAMPE-CUYAUBÈRE ${ }^{(t)}$
}

\author{
En hommage à Olivier Le Gall, \\ Paléo-ichtyologue et Chasseur, 1954-2014
}

\begin{abstract}
Résumé : Découverte en 1990, la grotte-abri de Peyrazet (Creysse, Lot, France) se situe dans le Haut-Quercy en bordure du causse de Martel, à quelques centaines de mètres du cours actuel de la Dordogne. Les fouilles menées depuis 2008 livrent une archéoséquence du Tardiglaciaire qui permet de combler certaines lacunes documentaires régionales et plus largement du Sud-Ouest de la France. Au Magdalénien supérieur succède un niveau ayant donné des indices d'un Azilien sensu lato stratigraphiquement séparé du Laborien, ensemble supérieur qui fait l'objet de cet article. Jusqu'alors ce technocomplexe de la fin du Pléistocène et des débuts de l'Holocène demeurait mal connu dans la région. En effet, seuls des travaux anciens menés dans deux gisements permettaient de noter sa présence en Quercy. La découverte d'un ensemble laborien récent (ou Épilaborien) à Peyrazet est l'occasion de conduire une étude collective des divers vestiges dans un cadre archéostratigraphique mieux maîtrisé. L'analyse géoarchéologique met en évidence l'action conjointe du ruissellement et de l'éboulisation comme principaux responsables de la mise en place des dépôts. Dans la partie S-O du site, un lithofaciès de remaniement indique une bioturbation importante en lien avec le creusement de terriers. Bien que leur origine ne soit pas liée aux activités humaines, les rongeurs, les oiseaux, les poissons et les mésomammifères (excepté le lièvre) apportent des données concernant l'environnement des chasseurs-cueilleurs. La grande faune est dominée par le cerf dont les carcasses pourraient avoir été introduites incomplètes sur le site puis traitées pour en extraire la viande et la moelle. Nous avons bénéficié d'une analyse fonctionnelle croisée à l'étude typo-
\end{abstract}

(a) Laboratoire PACEA (UMR 5199), CNRS, MCC, univ. Bordeaux, Université de Bordeaux, Allée Geoffroy Saint-Hilaire, CS 50023 33615 PESSAC cedex - mathieu.langlais@u-bordeaux.fr ; véronique.laroulandie@u-bordeaux.fr ; jb.mallye@u-bordeaux.fr ; aurelien_royer@hotmail.com ; ca3bigio@gmail.com ; david.cochard@u-bordeaux.fr ; laure.dayet@gmail.com ; alain.queffelec@u-bordeaux.fr

(b) CReAAH (UMR 6566), université de Rennes I - jacquier.jeremie@gmail.com ;

(c) Laboratoire TRACES (UMR 5608), CNRS, MCC, univ. de Toulouse Jean Jaurès - costamag@univ-tlse2.fr ;

pierre.chalard-biberson@culture.gouv.fr ; petillon@univ-tlse2.fr

(d) SERP - universitat de Barcelona

(e) Laboratoire CIRHUS - UMI 3199, CNRS, New York University - srigaud17@gmail.com

(f) Société Archéosphère - f.lacrampe@archeosphere.com 
technologique des vestiges lithiques composés pour l'essentiel de silex locaux et régionaux. Ce double regard a permis de mettre en évidence une diversité d'activités mise en œuvre dans la cavité. Une pièce d'ocre rouge, quelques vestiges d'industrie osseuse et des éléments de parure participent également à la description d'une large gamme de tâches effectuées lors d'un séjour prolongé ou de plusieurs occupations successives. La comparaison des pointes de chasse microlithiques avec d'autres gisements sur une vaste échelle géographique conduit à discuter l'attribution de cet ensemble supérieur à différentes phases du Laborien. L'hypothèse d'un Laborien récent (ou Épilaborien) conduit à réfléchir à une perduration de morphotypes ancestraux parallèlement à de nouveaux types d'armatures, observation déjà réalisée notamment à La Borie del Rey dans le Haut-Agenais mais qui demande encore des précisions et de nouvelles découvertes.

Mots-clés : Quercy, Préboréal, Laborien, Épilaborien, typotechnologie, analyse fonctionnelle, gibier, armement de chasse.

Abstract: Recent Laborian of the Peyrazet cave-rock shelter (Creysse, Lot, France). New data for the end of Lateglacial in Quercy. Discovered in 1990, Peyrazet cave-rock shelter (Creysse, Lot) lies in the Haut-Quercy region at the limits of the Martel limestone plateau, several hundred meters from the current Dordogne River valley. Excavations begun in 2008 produced a Late Glacial archaeo-sequence that sheds new light on several still poorly understood aspects of the archeological record in both the Haut-Quercy region and southwestern France in general. The level overlying the Late Magdalenian occupation produced limited evidence for the Azilian and is stratigraphically separated from the Laborian. This latter techno-complex, dated to the end of the Pleistocene and early Holocene, remains poorly documented in the region, having only been previously identified from two sites in the Quercy. The discovery of a recent Laborian (Epilaborian) occupation at Peyrazet presented the ideal occasion for a collaborative study of the diverse archaeological material recovered from this well-understood archaeo-stratigraphic context. A geoarchaeological analysis produced evidence for both surface runoff and the accumulation of coarse deposits (éboulis) as the principal site formation processes. In the southwest area of the site, a reworked lithofacies demonstrates substantial bioturbation in connection with animal burrowing. Although the presence of rodent, bird, fish, and medium-sized mammals (except hare) cannot be definitively connected to human activity, they nevertheless provide important information concerning the environments exploited by hunter-gatherer groups. Larger species are dominated by red deer whose carcasses were partially processed before being introduced to the site, where meat was subsequently removed and marrow consumed. A functional analysis combined with a typo-technological study of the primarily locally- and regionally-procured lithic material revealed evidence for diverse activities having taken place on-site. An ochre fragment, several bone tools and ornaments equally indicate a large variety of tasks to have been carried out during a single, long occupation or several successive visits. A typo-technological comparison of hunting weaponry (microliths) from sites across a substantial area suggests the assemblage to represent either a Laborian/Epilaborian mix or a unique Epilaborian occupation. This latter case would indicate the persistence of older morphotypes alongside the development of new tools forms, a situation already identified at Borie del Rey in the Haut-Agenais but which requires more detailed study supported by new discoveries.

Key-words: Quercy, Preboreal, Laborian, Epilaborian, Technotypology, Functional analysis, Game, Hunting weaponry.

\section{Introduction}

Interface du Bassin aquitain et du Massif central, le HautQuercy préhistorique forme un domaine bien connu historiographiquement pour son peuplement tardiglaciaire (Lorblanchet 1972). Néanmoins, mises à part les fouilles récentes effectuées dans le Lot à l'abri Murat (Rocamadour ; Lorblanchet 1989, 1996), au Sanglier (Reihac ; Séronie-Vivien dir. 2001) ou à Pégourié (Caniacdu-Causse ; Séronie-Vivien dir. 1995) et actuellement au Cuzoul de Gramat (Valdeyron et al. 2011), la fin du Paléolithique de cette région demeurait essentiellement documentée par des collections provenant de travaux anciens (fin $X I X^{e}$ - début $X X^{e}$ siècle), en particulier ceux de F. Bergougnoux, A. Viré et l'abbé Lemozi (fig. 1a). Bien que le Laborien ne fut pas reconnu en tant que tel à l'époque les auteurs préférant parler d'Azilien ou de Magdalénien final - deux gisements seulement avaient livré jusqu'alors des vestiges de cette période dans la région : l'abri Malaurie à Rocamadour (Niederlander, Lacam, Sonneville-Bordes 1956), site éponyme d'une pointe à dos et base tronquée qui deviendra un des marqueurs principaux du Laborien (Coulonges 1963 ; Le Tensorer 1979 ; Célérier 1998), et le Roc d'Abeilles à Calviac (Champagne et Espitalié 1970). La révision récente de ces deux séries replacées dans leur contexte aquitain a permis de proposer l'attribution d'une partie du matériel au Laborien (Langlais et al. 2014a).

Dans ce contexte, la découverte d'un ensemble attribué au Laborien à la grotte-abri de Peyrazet (Creysse, Lot), gisement sondé par P. Chalard en 1991 et qui fait l'objet de fouilles programmées depuis 2008 (ibid.), est l'occasion d'apporter de nouvelles données concernant le peuplement régional au cours de la transition Pléistocène / Holocène. Le site de Peyrazet est localisé entre les causses de Martel 


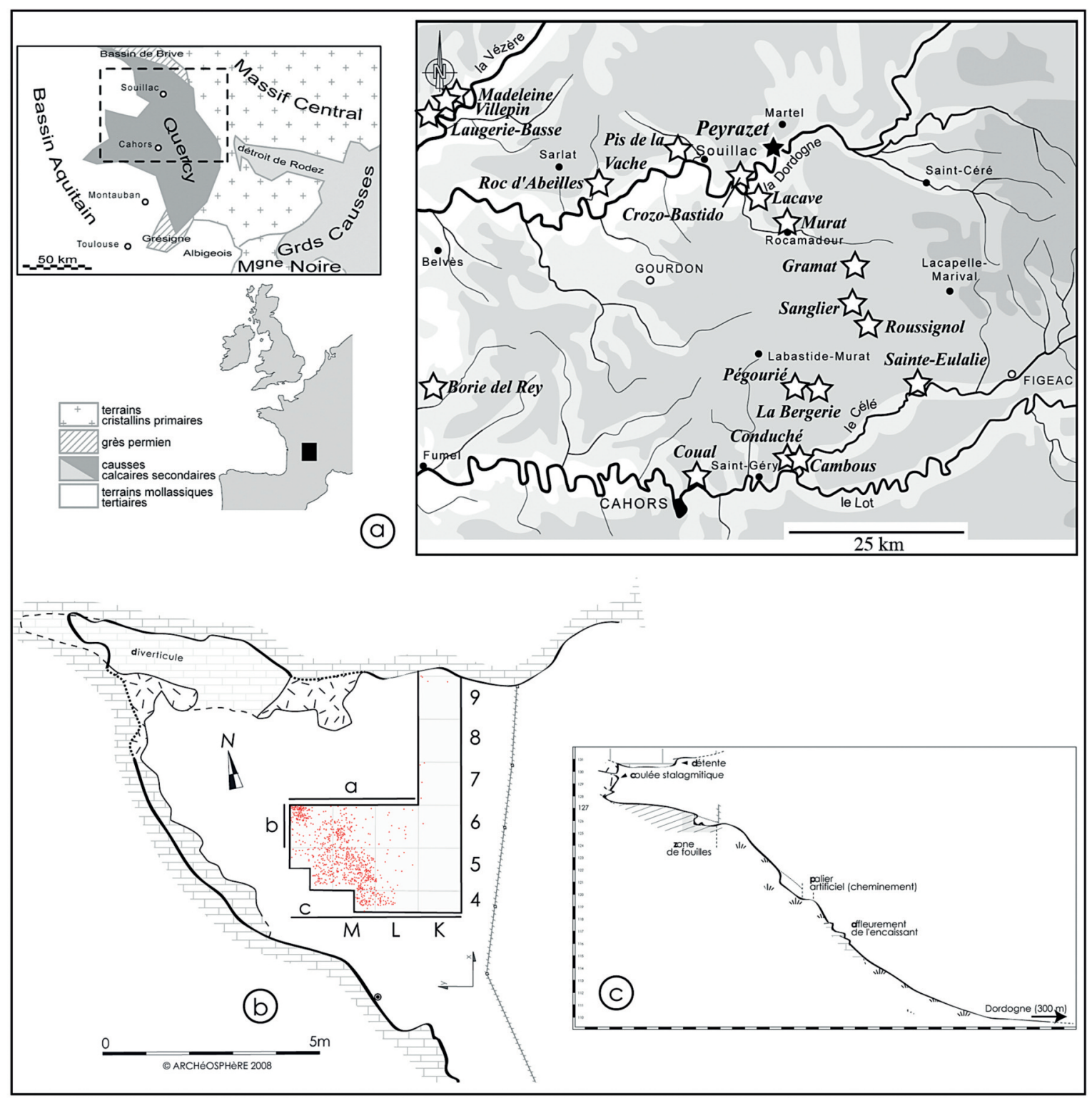

Figure 1 - a : Peyrazet dans son contexte tardiglaciaire régional (fond de carte M. Jarry, INRAP ; DAO ML), b : plan de la cavité avec emprise des fouilles, projection horizontale des vestiges coordonnés dans l'ensemble supérieur et localisation des coupes, $c$ : transect sagittal de la cavité ( $b-c$ : DAO Archéosphère).

Figure 1 - a: Peyrazet and other regional Late Glacial sites (base map by M. Jarry, INRAP, Illustration ML), b: plan of the cave-rock shelter with the excavated area indicated, c: sagittal transect (b-c: Illustration Archéosphere).

au Nord et Gramat au Sud, à $300 \mathrm{~m}$ de la rive droite de la Dordogne (fig. 1a). La cavité, située à une altitude NGF de $127 \mathrm{~m}$, s'ouvre vers le S-E et domine le fond de vallée d'une vingtaine de mètres environ (fig. 1c). II s'agit d'une ancienne galerie karstique creusée dans les calcaires massifs du Dogger (Bajocien supérieur et Bathonien inférieur) qui a été recoupée suite à l'incision de la vallée de la Dordogne. Au niveau du site, la galerie est large d'environ 1,50 $\mathrm{m}$ dans le secteur amont. Elle s'évase très rapidement en direction du versant, donnant ainsi une morphologie d'abri dont la largeur à l'aplomb du porche actuel est d'environ $10 \mathrm{~m}$ (fig. 1b). L'ensemble laborien repose sur un important complexe du Magdalénien supérieur, les deux étant séparés par une interface livrant des éléments aziliens (Langlais et Laroulandie et coll. 2009). L'ensemble supérieur laborien (couches 1 et 2) a été fouillé sur une surface de $12 \mathrm{~m}^{2}$ (fig. 2a). Plus ou moins dilatés en épaisseur selon les secteurs (fig. 2b), les niveaux laboriens n'ont pas été trouvés sur l'ensemble de la fenêtre de fouilles, se concentrant dans la partie haute du gisement (fig. 2a). 

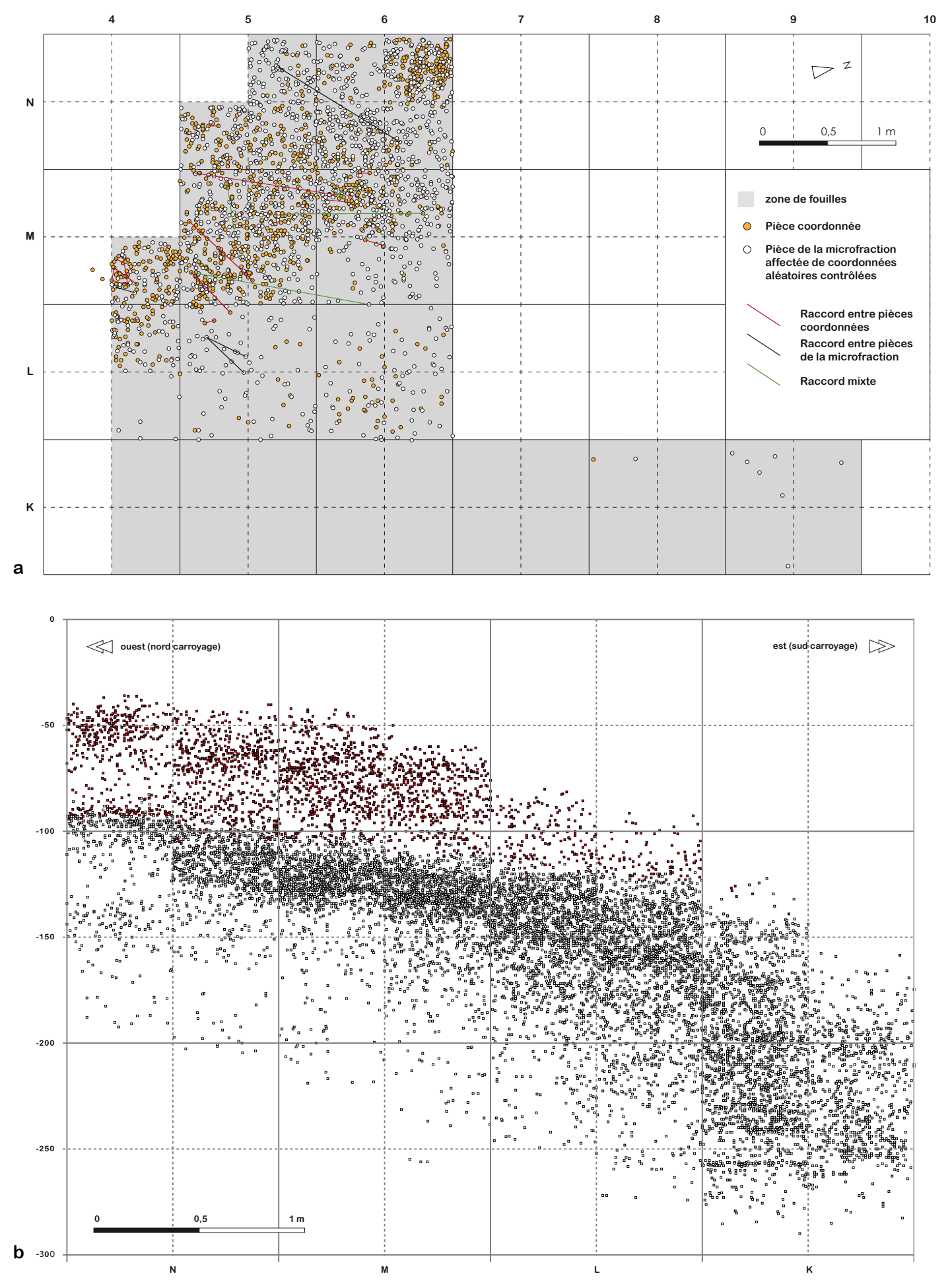

Figure 2 - a : projection en plan des vestiges des couches 1 et 2 et remontages lithiques; $b$ : projection verticale de l'ensemble des vestiges coordonnés et des refus de tamis (campagnes 2008-2014, en rouge : couches 1 et 2).

Figure 2 - a: projection (plan view) of the pieces from levels 1 \& 2; b: vertical projection of pieces plotted and sieved fraction from all levels (excavation seasons 2008-2014, in red: levels 1 \& 2). 


\section{Géoarchéologie}

À l'heure actuelle, la puissance du remplissage sédimentaire peut-être estimée à au moins $150 \mathrm{~cm}$. La fouille a permis de dégager une coupe frontale orientée N-S ainsi que deux coupes sagittales (nord et sud, fig. 1). La séquence principale est visible au niveau de la coupe sagittale nord et consiste, de haut en bas, en trois unités principales.

\section{Coupe sagittale nord (fig. 3a)}

L'unité 1 est épaisse d'environ $60 \mathrm{~cm}$ et faiblement inclinée vers l'est. Au sommet se développe un horizon A calcaire biomacrostructuré épais d'environ $10 \mathrm{~cm}$ et correspondant à un rendosol d'âge holocène. Le système racinaire pénètre jusqu'à la base de l'unité dont la limite inférieure est diffuse. Le lithofaciès principal est un diamicton massif à support matriciel. En direction du porche, l'unité s'enrichit rapidement en fraction grossière et le diamicton présente plutôt un support clastique. La matrice correspond à une argile limoneuse jaune-brunâtre (10YR 6/8) à gravillons calcaires (1 à $2 \mathrm{~cm}$ ). La fraction grossière est dominée par des cailloux calcaires anguleux de moins de $10 \mathrm{~cm}$ en moyenne et par de rares blocs de 10 à $40 \mathrm{~cm}$. Le faciès diamictique est typiquement observé dans les dépôts de pente et peut résulter de l'action de plusieurs processus sédimentaires tels que la solifluxion, les coulées de débris ou encore le ruissellement (Bertran 2004). Dans la mesure où la bioturbation affecte l'ensemble de l'unité, les structures sédimentaires typiques du ruissellement (figures de tri, litage) ne sont pas visibles et son identification comme principal agent sédimentaire reste délicate. En milieu fossile, ce cas de figure est récurrent (Lenoble 2005). Par ailleurs, si le faciès diamictique est observé pour la solifluxion et les coulées de débris, l'organisation stratigraphique globale de l'unité ne s'accorde pas aux descriptions données en milieu actif pour les dépôts associés à ces agents sédimentaires (Bertran 2004). Ainsi, l'hypothèse plus vraisemblable est que le ruissellement depuis l'endokarst et l'éboulisation des parois de l'abri soient les principaux processus responsables de la mise en place de cette unité. L'ensemble laborien (couches 1 et 2) qui fait l'objet de cet article est contenu dans cette unité géologique.

L'unité 2 apparaît sur l'ensemble de la coupe et son pendage est d'environ $8^{\circ}$ vers l'est. Dans le secteur ouest, elle fait $30 \mathrm{~cm}$ d'épaisseur et s'accroît rapidement en direction du versant. En raison de l'avancement de la fouille, la base de l'unité n'est pas totalement visible en partie est : son épaisseur est d'au moins $100 \mathrm{~cm}$. Le lithofaciès correspond à un diamicton massif à support matriciel à clastique. Les cailloux et les plaquettes sont anguleux et généralement de taille inférieure à $10 \mathrm{~cm}$. La matrice est sablo-limoneuse et de couleur brun foncé jaunâtre (10YR 4/6). Trois sous-unités ont été identifiées. La sous-unité $2 b$ se distingue par un enrichissement en matière organique et une couleur brun très foncé (10YR $2 / 2$ ). Elle passe graduellement à l'unité $2 c$ identifiée par un support plutôt matriciel avec une fraction fine limoneuse plus abondante et moins carbonatée. Dans le secteur est, la quasi-totalité des sédiments est fortement imprégnée de carbonates secondaires. L'unité 2, présentant globalement le même faciès que l'unité 1 , résulte de l'action conjointe du ruissellement et de l'éboulisation. La sous-unité $2 b$ témoigne de la formation d'un horizon humifère. L'ensemble de cette unité 2 correspond aux couches archéologiques c.3 : interface azilienne et c.4 : Magdalénien supérieur.

L'unité 3 est constituée d'un dépôt de blocs et de dalles de taille variant entre 10 et $50 \mathrm{~cm}$ et montrant vers sa partie inférieure des blocs métriques à plurimétriques. La base de cette unité n'a pas été atteinte. En partie sommitale, la structure est à support matriciel constitué de limons sabloargileux carbonatés jaune-brunâtre (10YR 6/8), sans trace macroscopique d'activité biologique. La structure devient semi-ouverte à ouverte dans les secteurs riches en gros blocs. L'inclinaison de ces derniers varie entre environ $22^{\circ}$ et $29^{\circ}$ en direction de l'est, ce qui est conforme au pendage global de l'unité vers la vallée. Toutes les informations convergent pour suggérer que l'unité 3 correspond à un niveau d'éboulis dont la mise en place est vraisemblablement liée à une phase de rééquilibrage de la voûte. Cette unité correspond à la couche 5 de l'archéostratigraphie.

\section{Coupes frontale et sagittale sud (fig. $3 b$ et c)}

Nous présentons brièvement ces deux coupes complémentaires en raison des différences stratigraphiques significatives par rapport à la sagittale nord.

La coupe frontale est située à l'extrémité ouest de la bande 6 (fig. 1b) et est orientée N-S. Elle représente le trait d'union des sagittales nord et sud. La succession des unités 1, 2 et 3 précédemment décrites (fig. $3 b$ ) est visible dans sa moitié nord. Elle n'est pas observée en partie sud de la coupe et ce changement est marqué par une limite d'érosion nette, d'allure irrégulière et traversant verticalement les unités 1 et 2 (fig. 3b). La succession stratigraphique qui s'observe au sud de la limite d'érosion s'organise en deux ensembles. Un horizon de surface $(0-30 \mathrm{~cm})$, constitué par des sables limono-argileux brun-gris (2.5Y $5 / 2)$, avec une structure en agrégats sub-arrondis clairement identifiables. De nombreux cailloux calcaires anguleux à sub-anguleux sont dispersés dans l'horizon. Les racines sont abondantes et des microcharbons sont présents. Sous cet horizon $(30-150 \mathrm{~cm})$, s'observe une succession de lits infradécimétriques jaunes et de lits d'épaisseur variant entre 10 et $30 \mathrm{~cm}$ de couleur brun-jaunâtre clair. Des cailloux et plaquettes calcaires dispersés ou disposés en alignements mal exprimés sont visibles. On note également la présence de lentilles caillouteuses à support clastique épaisses d'environ $10 \mathrm{~cm}$. Les lits ont un faible pendage vers le sud et sont constitués par un mélange d'agrégats de couleurs différentes, allant du jaune brunâtre au brun foncé. Leur forme est sphérique à sub-sphérique et la taille inférieure à $1 \mathrm{~cm}$ en moyenne. Dans le coin inférieur droit de l'unité, une plage altérée se note clairement à l'affleurement. Elle se marque notamment par un enrichissement en carbonates, qui recouvrent les cailloux sous forme de croûtes, et par le fait que le sédiment y est très meuble. 
A

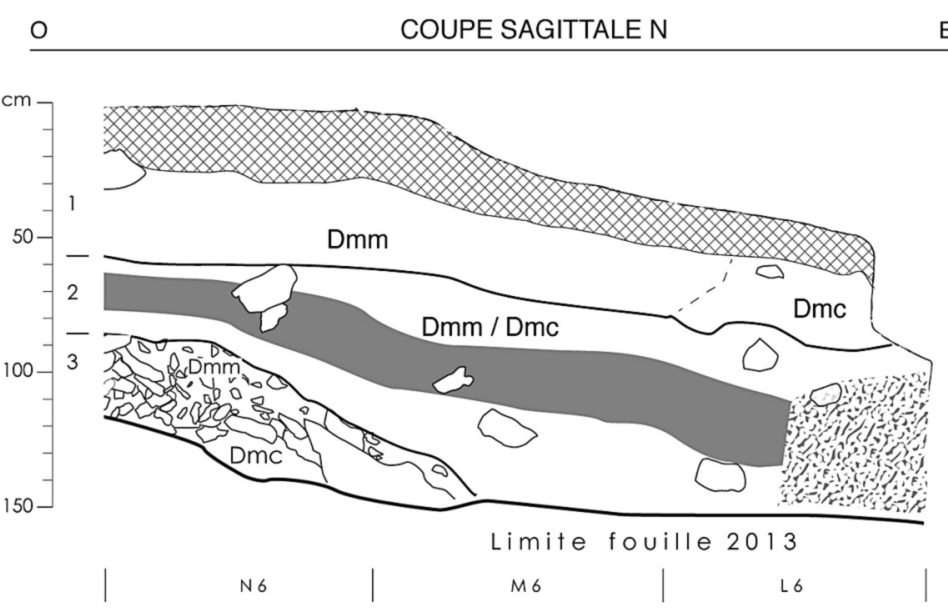

C E COUPE SAGITTALE S
B E

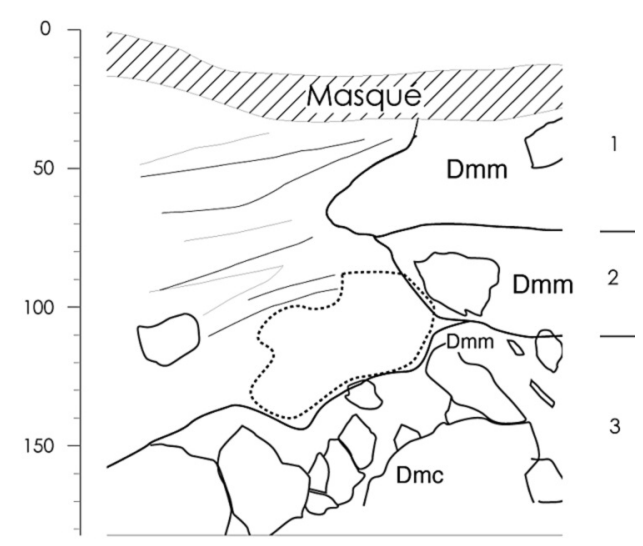

N6

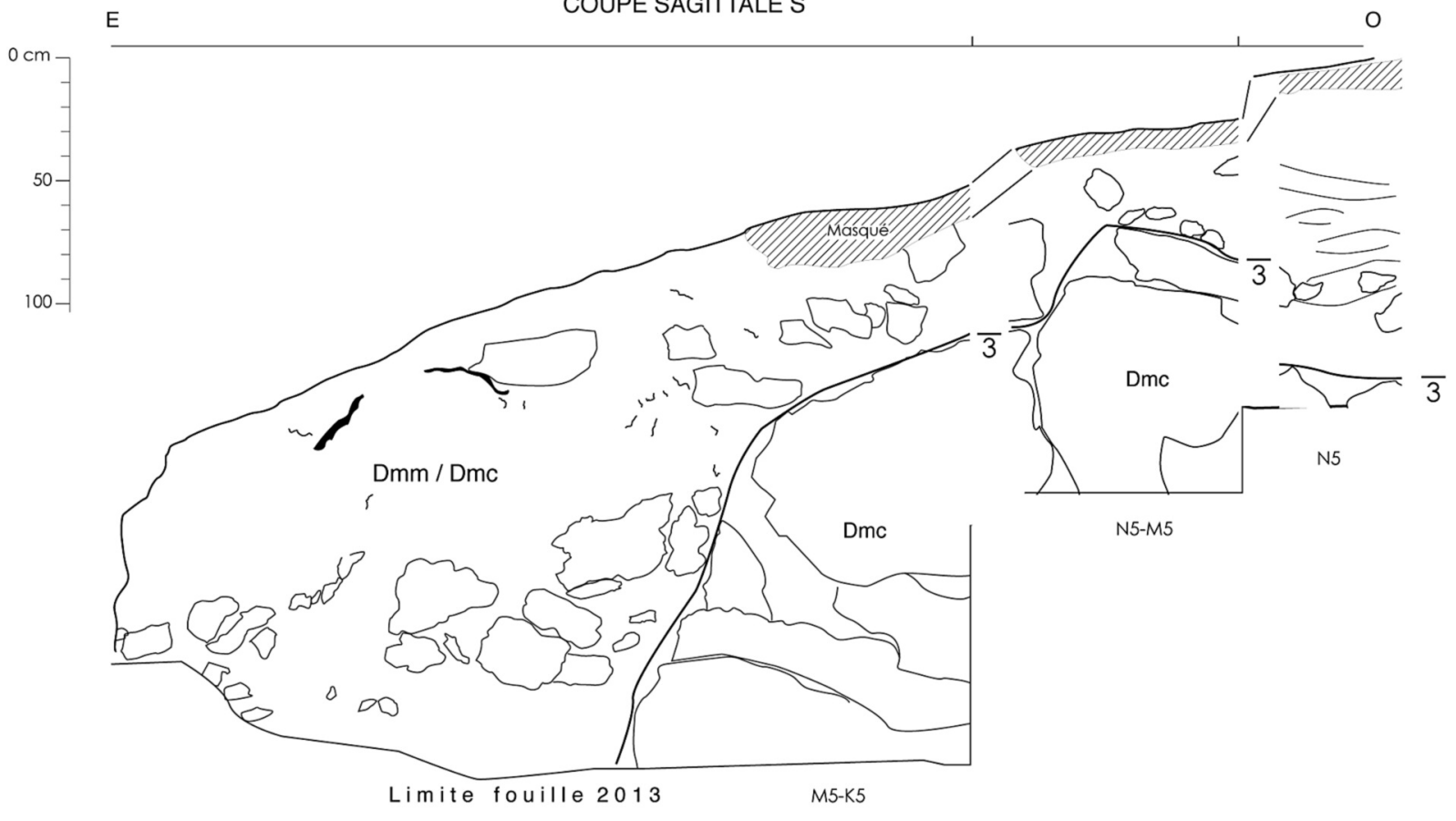

\section{Légende}

Rendosol

Horizon humifère Imprégnation par carbonates

Plage altérée

$\mathrm{Dmm}=$ diamicton à support matriciel

$\mathrm{Dmc}=$ Diamicton à support clastique

Figure 3 - Levé des coupes A : sagittale nord, B : frontale est, $C$ : sagittale sud.

Figure 3 - Profiles A: sagittal north, B: frontal east, C: sagittal south. 
La coupe sagittale sud (fig. 3c) se caractérise dans sa partie ouest par l'absence des unités 1 et 2 . Ces unités sont remplacées, comme pour la moitié sud de la coupe G, par des alternances de lits sablo-limoneux brun-jaune clair et jaune, un mélange d'agrégats de couleurs différentes, ainsi que la présence de lentilles caillouteuses. La partie inférieure de la coupe correspond à l'unité 3 et montre une continuité tout le long de l'ensemble fouillé dans la moitié sud du site. En partie est, on retrouve la succession des unités 1, 2 et 3 décrites sur la coupe sagittale nord, bien que la forte imprégnation en carbonates et une bioturbation racinaire intense rendent moins net le passage entre les différentes unités.

La stratigraphie des coupes sagittale sud et frontale atteste de la présence d'une discontinuité stratigraphique à caractère érosif dans le secteur sud-ouest du site. Située environ au milieu de la bande 6 dans le secteur plus à l'ouest (fig. 3c), elle affecte uniquement la partie supérieure de la séquence. Le lithofaciès observé en coupe frontale, et notamment la présence au sein des lits d'un mélange d'agrégats de couleurs différentes correspondant vraisemblablement aux unités 1 et 2 , suggèrent qu'en partie S-O du site ces deux unités ont été remaniées. Par ailleurs, l'absence du rendosol holocène au sommet de la séquence atteste d'un âge relativement récent pour ce remaniement. Le lithofaciès de remaniement est interprété comme le résultat d'une bioturbation importante en lien avec le creusement de terriers par des fouisseurs de grande taille (renard ou blaireau). Nous retiendrons comme critères principaux la déstructuration des unités stratigraphiques originelles et la structure en agrégats arrondis des dépôts avec un mélange de sédiment provenant de ces deux unités. Ces critères rejoignent en partie les observations faites lors de l'étude des biofaciès caractérisant les terriers actuels de blaireau (Mallye 2007). Au sein des lits à faible pendage, nous n'avons pas pu observer le granoclassement de particules typique des cônes de déblais à l'entrée de terriers (ibid.). Nous pensons que le faciès observé témoigne plutôt du comblement d'une ou plusieurs galeries internes du/des terrier(s). Ce comblement a pu s'effectuer en lien avec l'activité des blaireaux (aménagement et nettoyage des galeries) et l'effondrement progressif des galeries. Les lentilles caillouteuses pourraient être liées à l'aménagement de l'entrée de galeries secondaires. Cette interprétation reste à confirmer dans la mesure où il n'existe pas à l'heure actuelle de description détaillée des lithofaciès caractéristiques des aires internes des terriers de blaireau. Néanmoins, l'hypothèse du/des terriers nous paraît cohérente, également au vu de l'étude de la mésofaune qui montre la présence de restes de jeunes carnivores (y compris de blaireau, voir ci-dessous). Des faciès de remaniement comparables à celui observé à Peyrazet peuvent également être observés dans des comblements de fosses archéologiques ou dans des remblais d'anciennes fouilles. Néanmoins, au moins trois arguments vont à l'encontre d'une telle interprétation : absence de vestiges d'âge historique dans la zone fouillée ; absence de témoins d'une ancienne fouille ; cohérence spatiale significative des couches archéologiques entre les différents secteurs du site (remontages entre les deux bandes 5 et 6 , fig. $2 a$ ).

\section{Spectre faunique}

L'ensemble laborien livre un spectre macrofaunique largement dominé par le cerf (Cervus elaphus, 73,6 \% du NRD ongulés : tabl. 1). Il est complété par quelques restes de chevreuil (Capreolus capreolus), sanglier (Sus scrofa), Bovinés, cheval (Equus caballus), chamois (Rupicapra rupicapra) et bouquetin (Capra ibex). La présence du renne (Rangifer tarandus, NR=5) dans ce contexte est sujette à caution. Cet ongulé étant dominant dans les niveaux sousjacents du Magdalénien supérieur, les phénomènes de bioturbation relevés précédemment et l'existence d'une discontinuité stratigraphique de la couche azilienne font que sa présence doit être considérée ici avec beaucoup de prudence. D'autant que les dates directes effectuées sur cette espèce dans le sud-ouest de la France témoignent de sa disparition autour de 14 ky (millénaires) cal. BP (Costamagno et al. 2009 ; Szmidt et al. 2009 ; Drucker, Madelaine, Morala 2011 ; Langlais et al. 2012). Bien que le mauvais état de préservation de ces pièces ait rendu impossible une datation directe, nous considérons le renne comme intrusif dans l'ensemble supérieur de Peyrazet.

Les mésomammifères sont représentés par quatre genres de Carnivores et deux de Léporidés (tabl. 1). L'état fragmenté des restes de renard n'a pas permis d'en déterminer l'espèce. II s'agit de dents de lait qui présentent une forte résorption radiculaire. Le seul reste de blaireau déterminé est une première molaire supérieure dont les racines ne sont pas encore formées et qui renvoie à un individu âgé de quelques mois. Les six restes du genre Martes sont immatures et pourraient appartenir à un même individu. Les épiphyses des os sont manquantes et les dents sont des déciduales. Concernant le putois, le faible nombre de restes et l'absence d'éléments diagnostiques ne permet pas de distinguer le putois commun (Mustela (Putorius) putorius), du putois des steppes (Mustela (Putorius) eversmanni) ou du vison d'Europe (Mustela lutreola). Trois restes de belette / hermine, sept de lapin de garenne (Oryctolagus cuniculus) et cinq de lièvre (Lepus $s p$.) ont également été identifiés.

L'avifaune de l'ensemble supérieur appartient à plusieurs ordres taxinomiques, inégalement représentés (tabl. 1). Les Passériformes sont nombreux et forment près des deux tiers du corpus. Au sein de cet ordre, cinq pièces ont été rapportées à la famille des Corvidés et en particulier, au choucas des tours (Corvus monedula), ainsi qu'à une espèce de plus grande taille, la corneille noire ou le corbeau freux (Corvus corone/frugilegus). Les autres ossements de Passériformes, bien qu'indéterminés, appartiennent à plusieurs espèces dont la taille est proche de - ou inférieure à - celle du merle. A minima, trois espèces de Galliformes sont documentées : la perdrix grise ( $P$. perdix), la caille des blés ( $C$. coturnix) et la poule domestique ( $G$. Gallus domesticus), dont la présence est vraisemblablement intrusive (voir infra). Dans cet ordre, un fragment proximal de carpométacarpe pourrait appartenir au lagopède 


\begin{tabular}{|c|c|c|c|}
\hline TAXONS & $N R$ & TAXONS & $N R$ \\
\hline Bovinés & 3 & Anatidés & 6 \\
\hline Rupicapra rupicapra/Chamois & 9 & Rapace diurne & 4 \\
\hline Capra ibex/Bouquetin & 2 & Falco sp. & 1 \\
\hline Caprinés-Ovicaprinés & 1 & Galliformes & 3 \\
\hline Cervus elaphus/Cerf élaphe & 95 & cf. Lagopus & 1 \\
\hline Rangifer tarandus/Renne & $5 *$ & Perdix perdix, Perdrix grise & 4 \\
\hline Capreolus capreolus/Chevreuil & 5 & cf. Perdix perdix & 1 \\
\hline Cervidés & 4 & Coturnix coturnix, Caille des blés & 2 \\
\hline Sus scrofa/Sanglier & 3 & cf. Coturnix coturnix & 1 \\
\hline Equus caballus/Cheval & 2 & Gallus domesticus* & 2 \\
\hline Total NRDt Ongulés & 129 & Strigiformes & 1 \\
\hline Mammifères de grande taille & 9 & Charadiriiformes & 1 \\
\hline Mammifères de moyenne ou grande taille & 14 & Passériformes & 118 \\
\hline Mammifères de moyenne taille & 357 & Corvidés & 2 \\
\hline Mammifères de petite ou moyenne taille & 51 & Corvus monedula & 1 \\
\hline Mammifères de petite taille & 30 & Corvus corone/frugilegus & 2 \\
\hline Mammifères de petite ou très petite taille & 4 & Aves & 41 \\
\hline Mammifères de très petite taille & 11 & Total aves & 191 \\
\hline Mammifères & 14718 & Cyprinidés (cf. Chevaine/Vandoise) & 29 \\
\hline Total Ongulés & 15323 & Anguillidés (cf. Anguille) & 20 \\
\hline Vulpes sp./Renard s.l. & 3 & Salmoninés (cf. Truite/Saumon) & 15 \\
\hline Meles meles/Blaireau & 1 & Esocidés (cf. Brochet) & 2 \\
\hline Martes sp./Martre ou Fouine & 6 & indet & 28 \\
\hline Mustela (Putorius) sp./Putois s.l. & 4 & Total ichyofaune & 94 \\
\hline Mustela nivalis/erminea/Belette ou Hermine & 3 & \multirow{4}{*}{\multicolumn{2}{|c|}{$\begin{array}{l}\text { Tableau } 1 \text { - Spectre faunique de l'ensemble supérieur de } \\
\text { Peyrazet (exceptés les rongeurs). Les taxons suivis de * sont } \\
\text { considérés comme intrusifs à l'ensemble archéologique. }\end{array}$}} \\
\hline Petit carnivore indét. & 2 & & \\
\hline Lepus sp./Lièvre s.l. & 5 & & \\
\hline Oryctolagus cuniculus/Lapin & 7 & & \\
\hline Léporidé indét. & 1 & \multirow{2}{*}{\multicolumn{2}{|c|}{$\begin{array}{l}\text { Table } 1 \text { - Faunal spectrum of the upper Peyrazet sequence } \\
\text { (excluding rodents). Taxon with * are intrusive. }\end{array}$}} \\
\hline Total Mésofaune & 32 & & \\
\hline
\end{tabular}

(cf. Lagopus). Les rapaces, diurnes et nocturnes, sont attestés par quelques vestiges dont un petit faucon indéterminé. Les Anatidés sont présents sous la forme de quelques fragments. Enfin, un reste de Charadriiforme a été identifié.

Les couches 1 et 2 ont livré 94 restes de poissons dont 66 sont déterminés (tabl. 1). L'estimation des tailles a été faite sur les vestiges de Salmoninés $(25-30 \mathrm{~cm})$ et de Cyprinidés
(10-30 cm, 1 individu de 45-50 cm). Les saisons de capture observées ( $\mathrm{N}=22)$ signent pour les Salmoninés, le brochet et les Cyprinidés une mort au cours de la bonne saison. Quelques restes de batraciens ont également été trouvés au tamisage.

L'ensemble supérieur a livré une faible quantité de restes de micromammifères, en comparaison avec les couches inférieures. L'échantillon analysé n'est pas exhaustif et 
provient d'environ 1250 litres de sédiment. Le matériel a été récupéré par un tamisage à l'eau avec une maille de 1,6 $\mathrm{mm}$. Au total, un minimum de 77 individus a été identifié, appartenant à dix espèces de rongeurs et cinq insectivores. La couche 2 se différencie de la couche 1 par l'absence de loir gris ( $G$. glis) et de rat noir ( $R$. rattus, intrusif), ainsi que de la présence de mulot à collier (Apodemus flavicollis) et de musaraignes (Crocidura russula et Sorex minutus). Par ailleurs, trois fragments de molaires d'hamster européen ( $C$. cricetus) ont été identifiés à la base de c. 1 et au sommet de c. 2. Ces deux spectres fauniques fossiles présentent de nombreuses différences avec le spectre faunique actuel, obtenu à partir de pelotes collectées à Martel (environ à $7 \mathrm{~km}$ du site ; tabl. 2).

\section{Taphonomie des vertébrés}

Sur les 385 pièces de grande faune observées d'un point de vue taphonomique, une seule pourrait présenter une trace de carnivore. Les vestiges osseux comportent de nombreuses altérations post-dépositionnelles et sur près de $50 \%$ des ossements, plus de la moitié de la surface corticale n'est pas observable. Les traces de racines, de corrosion/dissolution, de desquamation et de concrétionnement sont majoritairement responsables de cette altération. Les fissures et le délitement pourraient être liés à une alternance de phases humides et de phases sèches. La faiblesse de l'échantillon et la mauvaise conservation des surfaces limitent l'étude archéozoologique.

Le nombre restreint d'ossements de mésomammifères, la mauvaise préservation de certains d'entre eux et le peu de

\begin{tabular}{|c|c|c|c|}
\hline TAXONS & Actuel & Couche 1 & Couche 2 \\
\hline Apodemus sylvaticus/Mulot sylvestre & $\mathrm{x}$ & $\mathrm{x}$ & $\mathrm{x}$ \\
\hline Apodemus flavicollis/Mulot à collier & & & $\mathrm{x}$ \\
\hline Arvicola terrestris/Campagnol terrestre & & $\mathrm{x}$ & $\mathrm{x}$ \\
\hline Cricetus cricetus/Hamster européen & & $\mathrm{x}$ & $\mathrm{x}$ \\
\hline Glis glis/Loir gris & & $\mathrm{x}$ & \\
\hline Microtus agrestis/Campagnol agreste & $\mathrm{x}$ & $\mathrm{x}$ & $\mathrm{x}$ \\
\hline Microtus arvalis/Campagnol des champs & $\mathrm{x}$ & $\mathrm{x}$ & $\mathrm{x}$ \\
\hline Microtus oeconomus/Campagnol nordique & & $\mathrm{x}$ & $\mathrm{x}$ \\
\hline Microtus (Terricola) pyrenaicus/Campagnol des Pyrénées & $\mathrm{x}$ & & \\
\hline Myodes glareolus/Campagnol roussâtre & $\mathrm{x}$ & $\mathrm{x}$ & $\mathrm{x}$ \\
\hline Mus musculus/Souris domestique & $\mathrm{x}$ & & \\
\hline Rattus rattus/Rat noir* & $\mathrm{x}$ & $\mathrm{x}$ & \\
\hline Crocidura russula/Musaraigne musette & $\mathrm{x}$ & & $\mathrm{x}$ \\
\hline Crocidura indet./Crocidure indet. & & $\mathrm{x}$ & $\mathrm{x}$ \\
\hline Sorex coronatus-araneus/Musaraigne couronnée-carrelet & $\mathrm{x}$ & $\mathrm{x}$ & $\mathrm{x}$ \\
\hline Sorex minutus/Musaraigne pygmée & $\mathrm{x}$ & & $\mathrm{x}$ \\
\hline Talpa europaea/Taupe d'Europe & & $\mathrm{x}$ & $\mathrm{x}$ \\
\hline Myotis nattereri/Vespertilion de Natterer & & $\mathrm{x}$ & \\
\hline
\end{tabular}

Tableau 2 - Liste taxinomique des petits mammifères de l'ensemble supérieur de Peyrazet et de l'actuel (données provenant de LPO Lot, obtenues à partir de pelotes récoltées dans la commune de Martel), ${ }^{*}=$ intrusif.

Table 2 - List of small mammals from the upper Peyrazet sequence and modern data from owl pellets collected around Martel (data from LPO Lot), ${ }^{*}=$ intrusive. 
traces de prédation n'ont pas permis d'identifier l'ensemble des modalités d'accumulation des différents taxons. Néanmoins, la présence de restes osseux et dentaires de petits carnivores (renard, blaireau, martre/fouine, belette/hermine), en particulier de jeunes, laisse penser que le site a fonctionné comme un lieu de refuge pour ces différents taxons pendant une partie de l'année (fin du printemps - début de l'été). Ce résultat pourrait également être corrélé avec la reconnaissance d'un terrier à la fouille (voir supra). À côté des petits carnivores et du lapin de garenne dont l'origine demeure problématique, deux restes de lièvre présentent des traces anthropogéniques (voir infra).

Au sein de l'avifaune, la présence de deux ossements de poule au sommet du remplissage est sans nul doute imputable à une pollution de cet ensemble. Un des deux fragments porte des traces de manducation indiquant l'apport par un carnivore, vraisemblablement de petite taille. Le nettoyage effectué lors de la première campagne avait livré quelques vestiges à la patine récente également marqués par ce type de stigmates. Ces deux pièces se rangent aux côtés d'autres indices marquant une contamination récente du sédiment contenant le matériel laborien (voir infra). II est actuellement impossible d'écarter l'hypothèse d'une contamination plus large, concernant d'autres taxons. Plusieurs vestiges présentent des traces de digestion légères qui rappellent celles qui sont produites par des rapaces nocturnes. Elles se rencontrent sur des ossements de Passériformes, perdrix, caille et rapace diurne. Un humérus de petit passereau montre par ailleurs des traces de manducation. Malgré l'observation attentive des surfaces osseuses, aucun argument n'indique une exploitation des Oiseaux par les chasseurs-cueilleurs.

L'étude taphonomique des restes de poissons demeure à faire et, en l'attente de ces analyses, il est difficile de trancher sur le caractère anthropogénique de tout ou partie des vestiges ichtyologiques. La présence de petits carnivores, d'oiseaux et de rongeurs accumulés par des prédateurs non humains pourrait néanmoins laisser présager que certains poissons n'ont pas été pêchés par les occupants laboriens.

Avant de réaliser des reconstitutions climatiques et environnementales sur les rongeurs, il est nécessaire de se poser la question de l'intégrité des ensembles microfauniques. Nos résultats mettent en évidence deux espèces en c. 1 - $R$. rattus $(\mathrm{NR}=1)$ et $M$. oeconomus $(\mathrm{NR}=2)$ - qui n'ont jamais cohabité dans le Sud-Ouest de la France (Le Louarn et Quéré 2003). Les premières traces de $R$. rattus en France sont datées des premiers siècles avant $\mathrm{J}$.-C, tandis que les dernières traces du $M$. oeconomus dans le Sud-Ouest de la France ont été reportées dans des couches de l'Abeurador (Hérault), datées du début de l'Holocène vers 7-8 ky BP non cal (Marquet 1993). Le reste de $R$. rattus, ainsi d'ailleurs que ceux de $G$. glis, sont trouvés dans les tout premiers décapages de l'ensemble supérieur qui ont livré par ailleurs quelques restes de céramiques protohistoriques. Au contraire, les individus de $M$. oeconomus ont été identifiés à la base de c. 1 tandis que la c. 2 a livré sept dents supplémentaires de ce taxon.
L'absence de différence dans les patines des os ne permet pas de distinguer les perturbations. En outre, il ne semble pas exister de corrélations spatiales, selon le carroyage et les décapages, entre les restes lithiques ou fauniques perturbés et les restes de $M$. oeconomus. En conséquence, au vu de ces résultats et des quantités de restes déterminés, et bien qu'il reste difficile de confirmer la présence « réelle » du Campagnol nordique en c. 1, sa présence en c. 2 confirmerait une survivance de ce taxon au début de l'Holocène dans le Sud-Ouest de la France.

\section{Implications environnementales}

Au sein des Ongulés, outre la présence vraisemblablement intrusive du renne (voir ci-dessus), aucune espèce glaciaire n'est documentée dans l'ensemble supérieur. Le chevreuil et le sanglier attestent de conditions climatiques tempérées. La présence discrète de Bovinés et du cheval et la dominance du cerf signent des espaces plutôt ouverts. Chamois et bouquetin indiquent un milieu rupicole.

Comme pour les mésomammifères, peu d'informations environnementales peuvent être tirées de la liste avifaunique car le taux de détermination spécifique est faible et les aires de répartition des espèces déterminées larges. Mise à part la pièce rapprochée du lagopède, il n'y a aucun taxon typique de conditions climatiques glaciaires. Cet unique vestige pourrait provenir de l'ensemble magdalénien où cette espèce est bien représentée aux côtés du renne. La présence d'Anatidés et du choucas est compatible avec l'environnement immédiat du site, offrant respectivement des milieux humides et rocheux à ces taxons. La perdrix grise et la caille des blés indiquent quant à elles un paysage présentant des espaces ouverts.

Pour les micromammifères, l'environnement autour du gisement a été reconstitué à partir de la méthode de Jeannet (2010) qui se fonde sur le spectre taxinomique. Les couches 1 et 2 présentent des couverts végétaux à fortes composantes boisées. La couche 1 tend à avoir un couvert végétal de type « futaie » tandis que la couche 2 présente des pourcentages plus importants des couverts végétaux de types "broussaille » et « taillis ». Les deux couches présentent une humidité importante du sol. La couche 2 tend à se différencier de la couche 1 par un environnement légèrement plus humide, avec des sols « frais » et marécageux et une présence moins importante " d'eaux vives ». Les spectres de petits mammifères des couches 1 et 2 permettent, à partir de la méthode BioClim (Hernández Fernández 2001, 2006; Hernández Fernández et Peláez-Campomanes 2003), de définir un climat typiquement tempéré (zone climatique $\mathrm{VI}$ ) avec deux probabilité maximales $\left(P_{1}=1.000\right)$. Cette méthode BioClim, combinée au modèle climatique QnBMs (Hernández Fernández et Peláez-Campomanes 2005), permet de quantifier la moyenne annuelle de température. Une moyenne annuelle de température est estimée à $11,1 \pm 3,6^{\circ} \mathrm{C}$ pour la couche 1 , tandis que la couche 2 présente une moyenne annuelle de température plus basse estimée à $7,6 \pm 3,6^{\circ} \mathrm{C}$. Ce contraste peut être pondéré par des bioturbations récentes surtout en c. 1 . 
Quant au Hamster européen, reconnu en c. 2 et c. 1 base, il habite actuellement les steppes et les champs de céréales d'Europe centrale et de l'Est et est pour la première fois identifiée dans le Sud-Ouest de la France durant cette période, suggérant ainsi un événement frais (Dryas récent ou oscillation froide du Préboréal ?).

\section{Bilan sur les ressources animales laboriennes}

\section{La grande faune}

Parmi les restes dentaires identifiés, certains proviennent d'animaux adultes (cerf, chevreuil, cheval, bouquetin, chamois), d'autres d'individus immatures (cerf, chamois, sanglier). La présence de jeunes est également attestée par des fragments diaphysaires d'os longs présentant un aspect fibreux. II faut également signaler la découverte de deux restes de fœtus non identifiés. Pour le cerf, à l'exception des bois, des vertèbres, des carpiens/tarsiens et des troisièmes phalanges, tous les éléments squelettiques ont été identifiés. Les côtes semblent nettement sousreprésentées relativement aux os des membres. Cette observation se confirme si l'on considère également les restes déterminés anatomiquement. En tenant compte de ces pièces, les fragments de vertèbres sont toujours absents. Les dents sont également rares. Sur les onze restes dentaires identifiés, une rangée presque complète d'incisives provenant d'un même individu - soit sept dents a été mise au jour en connexion. Les autres dents correspondent à de petits fragments. À l'exception d'un fragment travaillé (voir ci-dessous), les éléments en bois de cervidé sont absents.

Malgré la mauvaise conservation des surfaces osseuses, quelques pièces livrent des traces de boucherie. Elles correspondent soit à des stries $(\mathrm{NR}=28)$, soit à des traces de percussion $(N R=16)$. Ces marques ont été principalement observées sur des fragments de diaphyse d'os longs. Elles concernent le cerf, les Caprinés et les grands Bovinés. Un fragment de métatarsien de cerf porte une trace longitudinale en face postérieure qui pourrait attester du prélèvement des tendons fléchisseurs d'une patte arrière. Parallèlement, les os brûlés sont abondants ; ils représentent plus de la moitié des vestiges osseux (utilisation en combustible ?). Les os complets sont très rares : seuls deux sésamoïdes de cerf, une première phalange de chamois, une deuxième phalange de chevreuil et l'humérus de fœtus sont entiers. D'après l'étude des bords de fracture des diaphyses d'os longs, en plus d'une fracturation sur os frais, une fragmentation secondaire sur os sec affecte plus de $30 \%$ des bords.

Le faible nombre de restes osseux pourrait indiquer des séjours relativement courts et l'absence de bois (exception faite du fragment travaillé) des chasses menées sur des biches ou à la fin de l'hiver et/ou au printemps, saisons à laquelle les cerfs sont dépourvus de bois. Une autre hypothèse envisageable est l'abandon de ces parties sur les sites d'abattage, abandon qui pourrait être mis en relation avec la désaffection pour l'industrie en bois de cervidé à cette période. Bien que le squelette axial postcrânien soit nettement sous-représenté, sans doute en raison de la mauvaise conservation de ces ossements, il est difficile de conclure sur les modalités d'introduction des carcasses de cerfs (complètes ou certains quartiers ?). Quoi qu'il en soit, les carcasses ont été exploitées pour leur viande et leur moelle qui ont été consommées sur place.

\section{Le(s) Lièvre(s)}

Des traces produites par l'homme ont été identifiées sur deux restes de lièvre. Un fragment de diaphyse de tibia porte des stries de découpe et de raclage. Une extrémité distale d'humérus gauche est marquée sur l'épicondyle latéral par des traces de découpe qui témoignent vraisemblablement de la désarticulation du bras et de l'avant-bras de l'animal (Cochard 2004 ; Lloveras, MorenoGarcia, Nadal 2009). Cet os présente en outre des traces de brûlure renseignant d'une éventuelle cuisson à proximité d'une source de chaleur (Vigne et al. 1981 ; Vigne et Marinval-Vigne 1983), néanmoins d'autres découvertes similaires seraient utiles pour confirmer cette hypothèse. Rappelons que trois restes de lièvre ont été identifiés dans la c. 7 de La Borie del Rey (Langlais et al. 2014b).

\section{L'industrie osseuse}

Dans les couches supérieures de Peyrazet, l'industrie osseuse est représentée par quelques objets seulement. Une pièce se présente comme un ensemble d'au moins 49 fragments, pour la plupart infracentimétriques. Seize d'entre eux ont pu être raccordés, pour former cinq éléments dont le plus grand mesure $45 \times 19 \times 4 \mathrm{~mm}$. L'objet était vraisemblablement, à l'origine, un tronçon de côte (mammifère de taille moyenne ou grande) dont les faces médiale et latérale ont été entièrement raclées. Les stries de raclage sont encore nettement visibles sur chacun des fragments. La pièce a ensuite été soumise à l'action du feu, ce qui a entraîné, outre un changement de coloration, la destruction de la surface travaillée à plusieurs endroits, ainsi qu'une fragilisation du tissu osseux qui a sans doute accéléré le processus de fragmentation. Cette pièce est trop fragmentaire pour que son attribution typotechnologique puisse être précisée ; il pourrait s'agir d'un bloc osseux préparé (« nettoyé ») en vue d'une exploitation future. L'utilisation du bois de cervidé est représentée par une pièce travaillée de section subquadrangulaire $(26 \times 10 \times 5 \mathrm{~mm})$ qui présente des fractures postdépositionnelles à ses deux extrémités et sur l'un des bords ; le bord restant montre un pan de stries régulières et parallèles qui signalent un débitage par rainurage longitudinal. L'attribution taxinomique (renne ou cerf ?) reste indéterminée, tout comme le statut typotechnologique de cet objet : il pourrait s'agir d'un fragment d'objet fini sur baguette, d'un fragment de baguette brute, voire d'un fragment de déchet de débitage par rainurage. Sauf à y voir une contamination du niveau magdalénien sous-jacent, il s'agirait ici du second exemple archéologique pour lequel la pratique du débitage de bois de cervidé par rainurage longitudinal est attestée au 
Laborien - la seule autre mention à notre connaissance étant la couche 2 du Pont-d'Ambon (extraction de baguettes par double rainurage sur bois de cerf : Célérier 1996, p. 90-91 et fig. 20). Enfin, notons la mise au jour au sein du terrier d'une barbelure de harpon plat et d'un poinçon sur os obtenu par raclage (proche de pièces des couches 7 et 3 du site éponyme : Langlais et al. 2014b). Ces deux objets ne peuvent être attribués avec certitude à l'ensemble supérieur, notamment du fait de la présence d'éléments aziliens dans l'ensemble sous-jacent.

\section{Les équipements lithiques}

Le silex domine largement les roches exploitées par les chasseurs-cueilleurs du Laborien de Peyrazet. Néanmoins, d'autres roches ont également été apportées sur le site sous la forme de galets issus des plages de la Dordogne. Parmi elles, seuls les quartz/quartzites $(\mathrm{N}=13)$ documentent des actions de débitage vraisemblablement sur enclume sous la forme de quelques éclats. Toutefois, le faible corpus ne permet pas d'être plus précis. Pour le reste, il s'agit de galets de roches métamorphiques fragmentés $(\mathrm{N}=65)$ et de quelques basaltes $(\mathrm{N}=4)$ vraisemblablement utilisés entiers en macro-outils ou comme charge d'un foyer. Sur ce dernier point, deux petites zones de concentration démantelée de galets, plus ou moins rubéfiés et associés à des microcharbons ont été mises au jour. L'importante arénisation des roches métamorphiques, en particulier des micaschistes, oblitère souvent toute information. Quatre pièces en cristal de roche complètent l'ensemble.

\section{Matières premières siliceuses}

Pour le silex, mises à part les esquilles infracentimétriques $(\mathrm{N}=2887)$, un ensemble de 1490 pièces se répartissent en différents supports et matériaux (tabl. 3). L'examen systématique des pièces à la loupe binoculaire a permis de déterminer plusieurs provenances. Les silex locaux (environ $12 \%$ ) regroupent les matériaux jaspéroïdes et en Bajocien (fig. 4, $n^{\circ} 3-6$ ), 3 pièces en Bathonien ainsi que plusieurs silex tertiaires. Les galets en jaspéroïde sont disponibles à proximité dans les alluvions de la Dordogne situées en contrebas de l'abri et dans les anciennes terrasses mais aussi au sein de silicifications hettangiennes localisées en rive droite. Le silex du Bajocien affleure dans des gîtes très proches (altérites des calcaires des causses de Gramat ou de Martel, notamment le Puy d'Issolud).

\begin{tabular}{|c|c|c|c|c|c|c|c|c|c|c|c|c|}
\hline SUPPORT/MP & SENgn & TER & $J S P$ & $B A J$ & SENbd & GDM & BAT & $B V$ & indet & marin & $N R$ & $\%$ \\
\hline éclat & 180 & 20 & 4 & 13 & 1 & & 1 & & 49 & 2 & 270 & \\
\hline éclat cortical & 12 & 3 & & & 2 & & & & & & 17 & 20,3 \\
\hline éclat SC & 12 & & & & 1 & & & & 1 & 1 & 15 & \\
\hline EL & 37 & 6 & 2 & 1 & 1 & & 1 & & 2 & 1 & 51 & \\
\hline ELSC & 16 & 2 & 1 & 1 & 1 & & & & 2 & & 23 & 5,1 \\
\hline EL cortical & 2 & & & & & & & & & & 2 & \\
\hline ELL & 52 & 8 & 1 & 5 & & 2 & 1 & & 8 & & 77 & 57 \\
\hline ELLSC & 7 & 1 & & & & & & & & & 8 & \\
\hline Lame & 115 & 17 & & 3 & 6 & & & 1 & 7 & 1 & 150 & 113 \\
\hline Lame SC & 14 & & & & 3 & & & & 1 & & 18 & \\
\hline PL & 72 & 7 & & 1 & 3 & & & 1 & 9 & & 93 & 66 \\
\hline PLSC & 5 & & & & & & & & & & 5 & 0,0 \\
\hline lamelle & 132 & 10 & 10 & 5 & 2 & 3 & & & 39 & & 201 & 136 \\
\hline lamelle SC & 1 & & & & & & & & 1 & & 2 & 10,0 \\
\hline fragment & 357 & 30 & 17 & 5 & 1 & 1 & & & 120 & 1 & 532 & \\
\hline fragment cortical & 14 & 1 & & & & & & & & & 15 & 37,3 \\
\hline fragment SC & 9 & & & & & & & & & & 9 & \\
\hline rognon & 2 & & & & & & & & & & 2 & 0,1 \\
\hline NR & 1039 & 105 & 35 & 34 & 21 & 6 & 3 & 2 & 239 & 6 & 1490 & \\
\hline$\%$ & 69,7 & 7,1 & 2,3 & 2,3 & 1,4 & 0,4 & 0,2 & 0,1 & 16,1 & 0,4 & & \\
\hline
\end{tabular}

Tableau 3 - Décompte des matières premières (SEN : Sénonien, gn : gris-noir, bd : blond, TER : Tertiaires, JSP : Jaspéroïdes, BAJ : Bajocien, GDM : grain-de-mil, BV : Belvès, BAT : Bathonien) par catégories de supports (SC : semi-cortical, EL : éclat laminaire, ELL : éclat lamellaire, $P L$ : petite lame).

Table 3 - Representation of different raw materials (SEN: Senonian, gn: grey-black, bd: blond, TER: Tertiairy, JSP: “Jaspers", BAJ: Bajocian, GDM: "grain-de-mil", BV: Belvès, BAT: Bathonian) by blank type (SC: semi-cortical, EL: laminar flake, ELL: bladelet by-products, PL: small blade). 

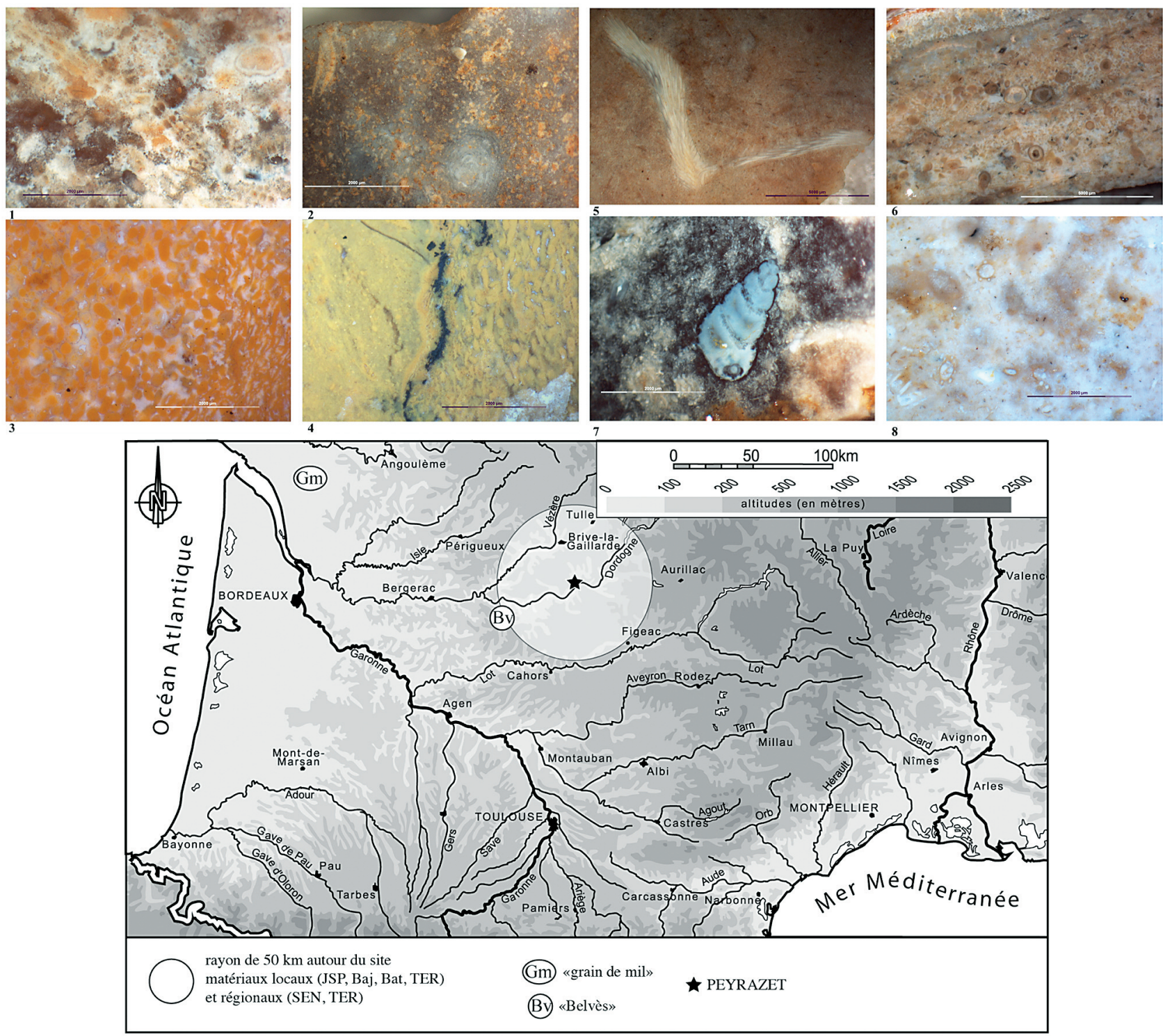

Figure 4 - Caractères micropaléontologiques de certains matériaux (1 : "grain-de-mil », 2 : Belvès à subalvéolines et orbitoides tissoti ; 3-4: structure oolithique des jaspéroïdes de l'Hettangien, 5-6: Bajocien, 7-8: Tertiaires à gastéropodes et characées), Carte de provenance des matériaux exploités dans l'ensemble supérieur de Peyrazet (JSP : jaspérö̈des, Bat : bathoniens, Baj : bajociens, TER : tertiaires, SEN : sénoniens).

Figure 4 - Micropalaeontological characters of specific lithic raw materials (1: "grain-de-mil", 2: Belvès subalveolina and orbitoides tissoti; 3-4: oolithic structure of Hettangian "jaspers", 5-6: Bajocian, 7-8: Tertiary gastropodes and Chara). Raw materials exploited in the upper Peyrazet sequence (JSP: "jaspers", Baj: Bajocian flints, Bat: Bathonian flints, TER: Tertiary flints, SEN: Senonian flints).

Le silex du Bathonien - dont les sources se trouvent sur les plateaux calcaires environnants - est identifié seulement à l'unité dans cet ensemble. Enfin, des galets en silex tertiaire, également disponibles dans les terrasses alluviales aux environs du site, complètent ce cortège des matières premières locales (fig. $4, n^{\circ} 7-8$ ).

En ce qui concerne les matières premières allochtones (environ $72 \%$ ), les silex du Sénonien périgourdin dominent largement. Les composantes « gris-noir » et « blond » sont disponibles au plus près à quelques dizaines de kilomètres à l'ouest du site sans nécessairement franchir la Dordogne (Turq et Morala et coll. 2014). La présence de quelques pièces en silex « grain-de-mil » (Simonnet et coll. 2007 ; Caux 2014 ; fig. 4, $\mathrm{n}^{\circ}$ 1) souligne une provenance plus lointaine à $250 \mathrm{~km}$ vers l'ouest, en Charente. Le seul matériau pour lequel il a fallu nécessairement franchir la Dordogne est un silex à grandes alvéolines et orbitoides tissoti (fig. $4, \mathrm{n}^{\circ} 2$ ) qui provient de la région de Belvès au sud-ouest du gisement (Turq 2000 ; fig. 4). 
Du point de vue techno-économique (tabl. 3), le Sénonien gris-noir, les Tertiaires et le Bajocien ont été débités sur place pour la réalisation de la production lamino-lamellaire. Le Sénonien gris-noir a fourni l'essentiel des supports d'outils et d'armatures. En revanche, les jaspéroïdes sont exploités uniquement pour la composante lamellaire, sans doute du fait des volumes initiaux de dimension relativement réduite. Quant au silex de Belvès, il est documenté par une lame brute et une pointe à dos. Enfin, le silex « grain-de-mil » est présent sous la forme de chutes de burin et d'un fragment, témoignant d'un apport d'outils sur le site.

\section{Équipement et activités domestiques}

La série lithique a été soumise, de manière presque exhaustive ${ }^{1}$, à une analyse fonctionnelle suivant les principes méthodologiques définis par S. A. Semenov (1964) et désormais appliqués par la plupart des spécialistes (e.g. Plisson 1985 ; Van Gijn 1989 ; Gassin 1996). Malgré les altérations mécaniques dont il a souffert, l'assemblage lithique présente un état de conservation satisfaisant pour l'étude des traces d'usage. Des écaillures, isolées ou en petits groupes, probablement générées par une combinaison de plusieurs phénomènes postdépositionnels sont fréquentes mais n'impliquent qu'une perte d'information mineure. La fragmentation des vestiges a constitué un problème plus important. En effet, près de la moitié des zones utilisées (ZU) identifiées sont recoupées par une cassure d'origine indéterminée. Cette fragmentation a parfois rendu difficile la reconstitution du fonctionnement des outils. L'état de conservation des surfaces et des polis d'utilisation s'est par contre révélé être très bon. Un lustré de sol qui s'exprime ici par un poli fluide à luisance relativement forte) est visible sur la plupart des pièces mais n'altère pas le microrelief et ne constitue ainsi qu'un bruit de fond parasite gênant pour la lecture des microtraces les plus ténues. Le voile de patine blanche qui affecte régulièrement les vestiges se révèle surtout problématique pour le rendu des clichés micro-photographiques.

À travers cette approche "typo-techno-fonctionnelle ", 57 pièces ont été considérées comme des outils (tabl. 4 ; fig. 5, fig. 6). Les deux gammes principales sont les couteaux et les grattoirs. S'y ajoutent les 36 chutes de burin dont certaines portent des traces (antérieures au coup de burin), les cinq burins, quelques pièces esquillées et des lames tronquées (couteaux à extrémité aménagée). L'essentiel de l'outillage est réalisé sur des lames rectilignes de plein débitage (voir ci-dessous). L'analyse fonctionnelle a permis de mettre en évidence au moins six grands types d'activités : traitement des carcasses (10 ZU), des peaux (24 ZU), de matières osseuses (2 ZU) et de plantes (5 ZU), raclage de matières minérales (3 ZU), percussion lancée directe ou indirecte sur une matière dure organique (6 ZU).

Les couteaux correspondent à des supports laminaires bruts (fig. 7), tronqués (fig. 5, $n^{\circ} 4-5$ ) ou présentant un bord abattu (fig. $5, n^{\circ} 2$ ). Ils sont de profil rectiligne et présentent un ou deux tranchant(s) naturel(s) aigu(s) mis en jeu dans trois registres principaux d'activité : le traitement des carcasses, le travail de la peau et le travail des plantes.

Le premier registre regroupe probablement plusieurs opérations techniques distinctes. À l'échelle macroscopique, les outils présentent des usures comparables. Les esquillements sont discrets, initiés en flexion ou plus rarement en cône, bifaciaux, rasants à semi-abrupts, espacés à chevauchants, leur longueur n'excède pas $2 \mathrm{~mm}$. En revanche, l'observation au microscope métallographique permet de distinguer deux types de traces.

\begin{tabular}{|c|c|c|c|c|c|}
\hline TYPES & $L A M E$ & LAMELLE & $E C L A T$ & $E L L$ & $N R$ \\
\hline couteau $\&$ fgt & 15 & & & 5 & 20 \\
\hline grattoir & 5 & & 4 & 1 & 10 \\
\hline lame retouchée \& $f g t$ & 6 & & & & 6 \\
\hline burin & 5 & & & & 5 \\
\hline pièce esquillée $\&$ fgt & 1 & & 2 & 2 & 5 \\
\hline lame tronquée & 4 & & & & 4 \\
\hline microperçoir & 2 & & & 1 & 3 \\
\hline couteau à dos & 1 & & & & 1 \\
\hline pièce tronquée & & & 1 & & 1 \\
\hline grattoir-burin & & & 1 & & 1 \\
\hline lamelle tronquée & & 1 & & & 1 \\
\hline NR & 39 & 1 & 8 & 9 & 57 \\
\hline chute de burin & & 13 & & 23 & 36 \\
\hline
\end{tabular}

Tableau 4 - Inventaire des outils domestiques de l'ensemble supérieur de Peyrazet (en italique, lames retouchées mais ne présentant pas de traces fonctionnelles).

Table 4 - Domestic tools from the upper Peyrazet sequence (retouched blades without traces of use in italics).

(1) À l'exception de quelques pièces brutes en silex bajocien et d'une partie des éléments d'armatures, écartés faute de temps, tous les éléments conditionnés en sachets individuels, qu'ils soient issus de la fouille ou du tamisage, ont été analysés. Ainsi 716 pièces (665 pièces brutes et 51 éléments retouchés) ont été étudiées dont 16 éléments d'armatures. 

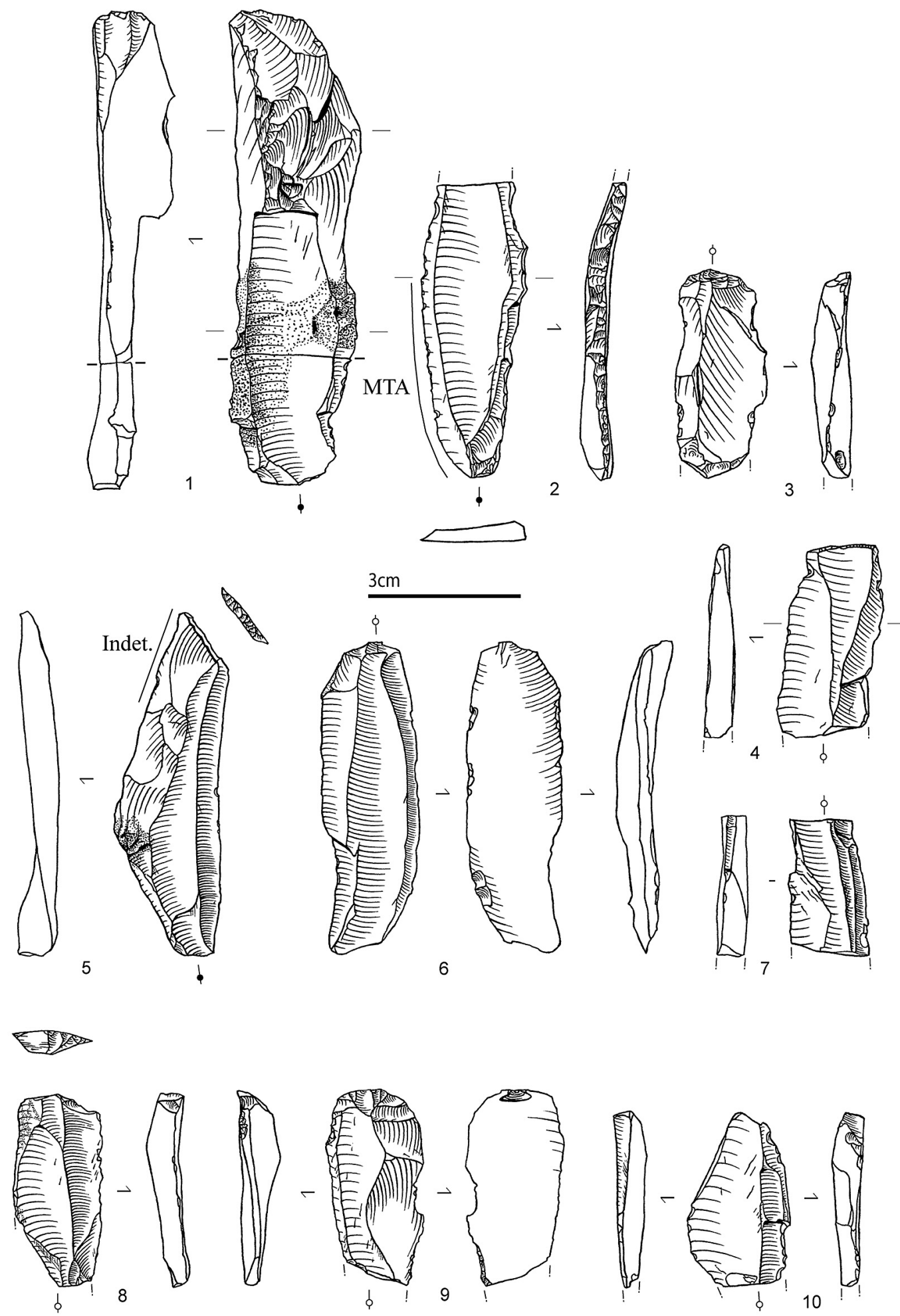

Figure 5 - Exemples d'outils domestiques $(1,7,10$ : burins ; 2 : couteau à dos ; 3,8,9: grattoirs ; 4-5: lames tronquées ; 6 : lame à esquillement inverse; dessins C. Fat Cheung, informations tracéologiques MTA : matière tendre animale).

Figure 5 - Domestic tools (1,7,10: burins; 2: backed knives; 3,8,9: end scrapers; 4-5: truncated blades; 6: blade with inverse chipping; Drawings $C$. Fat Cheung, Use-wear information MTA: soft animal materials). 


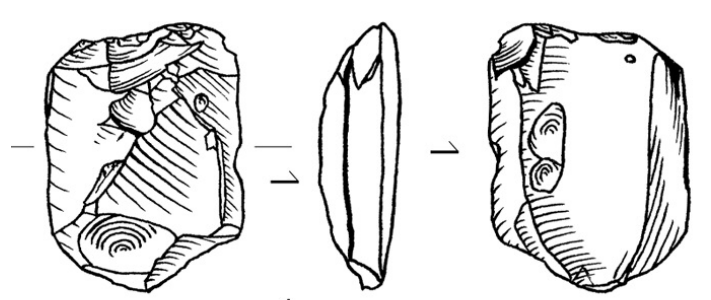

1
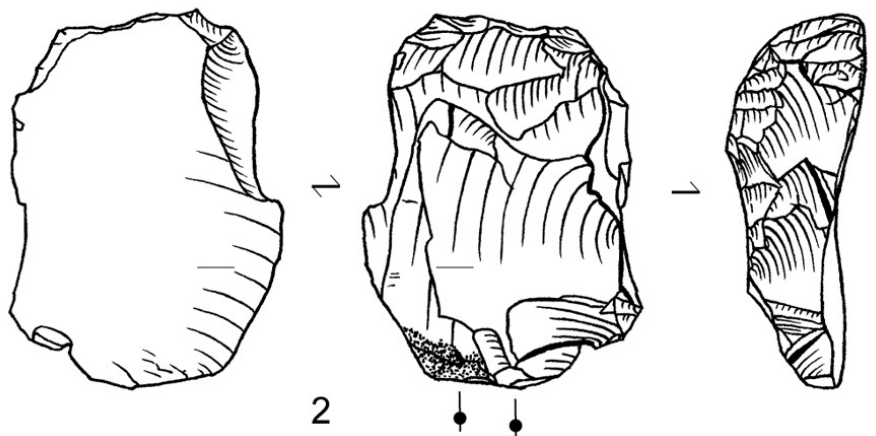
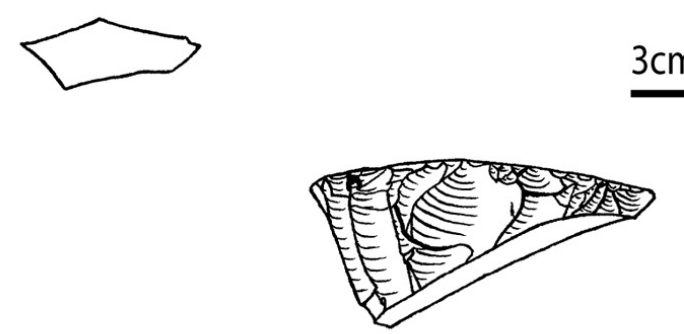

$3 \mathrm{~cm}$
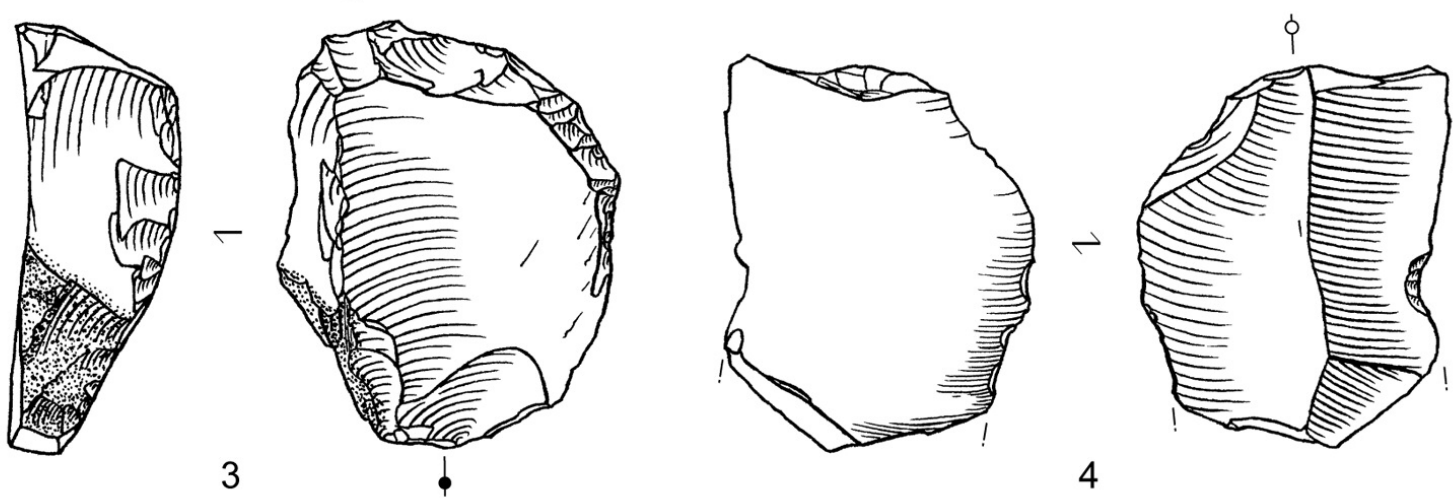

4

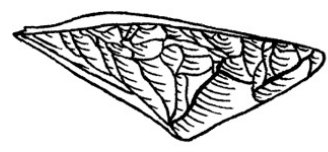

Figure 6 - Exemples d'outils domestiques (1: pièce esquillée ; 2,3 : grattoirs ; 4 : pièce tronquée ; dessins C. Fat Cheung).

Figure 6 - Domestic tools (1: splintered piece; 2,3: end scrapers; 4: truncated piece; Drawings C. Fat Cheung).

Une partie des usures observées est compatible avec des étapes de dépeçage ou de décharnement. Les microtraces évoquent le contact avec la viande. Le fil présente un micro-arrondi lisse et brillant, discontinu et imperceptible à la binoculaire. Celui-ci affecte parfois également la base des nervures des enlèvements d'usage. II est prolongé sur les faces par un micropoli fluide et brillant, marginal, arborant par endroit des coalescences douces. Quelques rares stries fines et discrètes, parallèles au bord, accompagnent ces micro-usures (fig. 8, $\mathrm{n}^{\circ} 1-2$ ).

Les autres traces, beaucoup plus développées, ont été générées par des contacts en coupe longitudinale avec des matières animales peut-être plus résistantes mais dont la nature reste indéterminée (tendons, boyaux, peau fraîche ou humide ?). À l'échelle macroscopique, l'arrondi du fil actif est déjà perceptible. Les micropolis envahissent plus largement les faces et leur modelé a tendance à doucir plus généreusement les sommets de la microtopographie. L'aspect des zones polies est grenu mais la luisance reste relativement forte. Les stries fines et parallèles au bord sont plus abondantes (fig. 8, $\mathrm{n}^{\circ} 3$ ).

Les traces de travail des peaux observées sur les bords bruts montrent une importante diversité. Les opérations de raclage dominent. Certaines usures sont très proches de celles observées sur les fronts des grattoirs et témoignent d'opérations réalisées sur des peaux à l'état sec. C'est notamment le cas d'une pièce utilisée sur deux zones anguleuses (fig. $9, \mathrm{n}^{\circ} 3$ ) et d'une lame utilisée en coupe positive sur son bord gauche (fig. $9, n^{\circ} 2$ ). D'autres bords bruts aigus semblent avoir été employés au travail de peau humide. Les émoussés sont moins prononcés, les polis s'insinuent au plus profond des négatifs des enlèvements d'usage, ils sont plus brillants et ne revêtent pas nécessairement un aspect grenu. Les stries sont généralement peu fréquentes. Au sein des usures regroupées dans le travail des peaux humides, les micropolis ne sont pas homogènes. Certains affectent les zones hautes comme les zones basses de la 


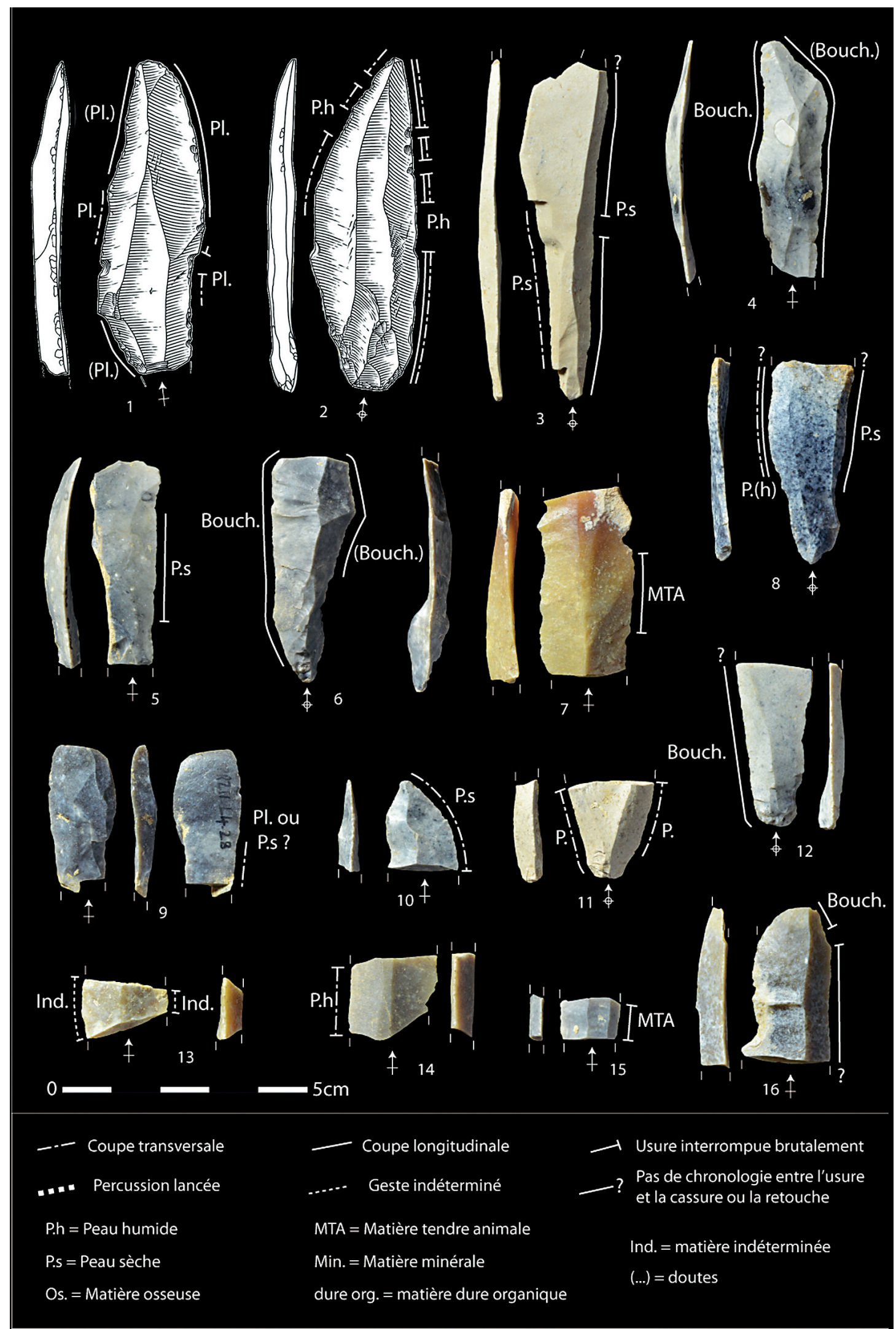

Figure 7 - Supports laminaires bruts ayant livré des traces d'usage.

Figure 7 - Laminar blanks with traces of use. 


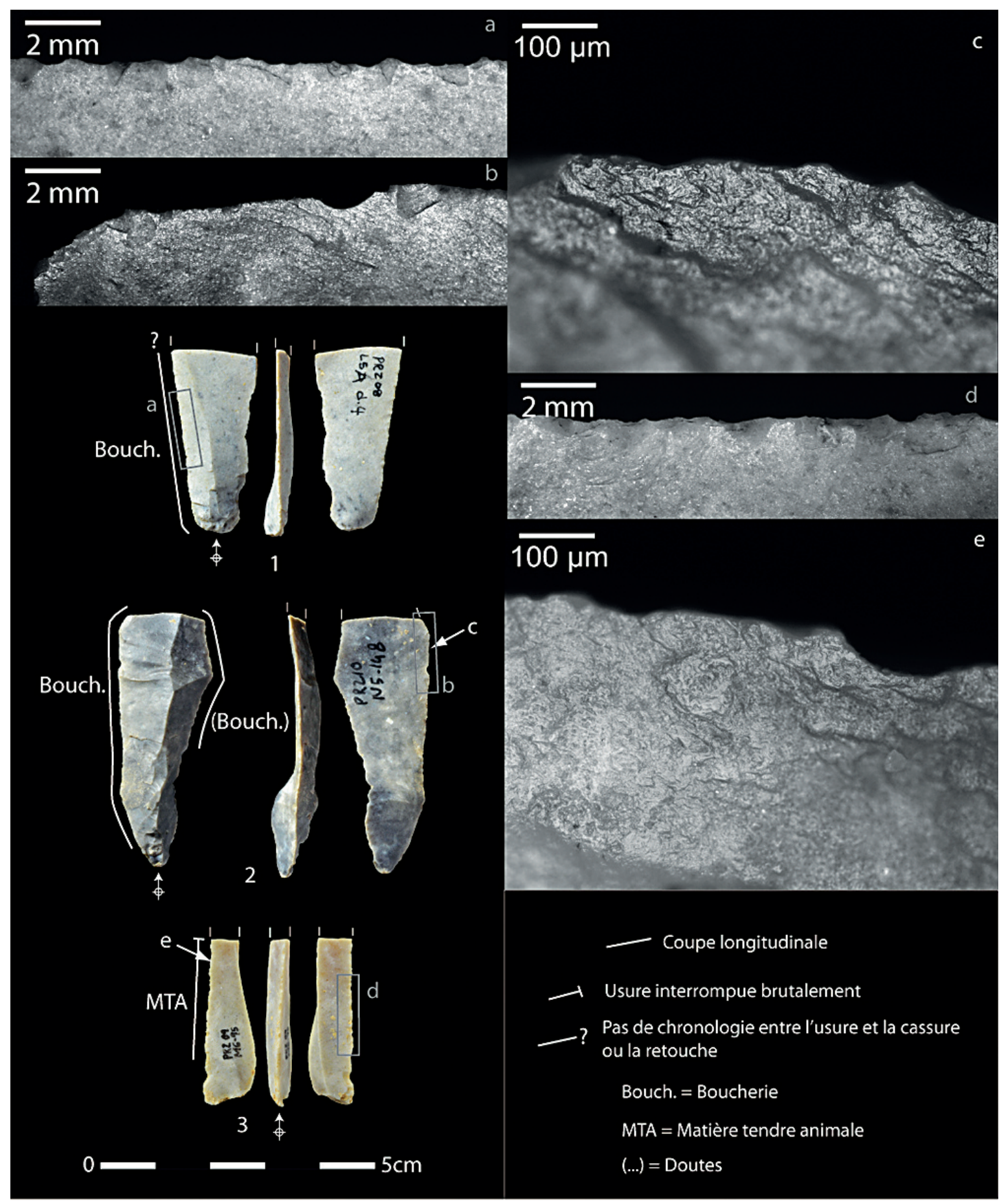

Figure 8 - Exemples de supports bruts employés à la décarnisation et à la découpe de matières tendres animales. 1 et 2 : fragments de supports laminaires avec traces macro et microscopiques compatibles avec des opérations de décarnisation ; 3 : fragment proximal de chute de burin avec traces macro et microscopiques renvoyant à une utilisation en découpe de matières tendre animale indéterminée.

Figure 8 - Unmodified blanks used for defleshing and cutting soft animal materials. 1 and 2: fragments of laminar blanks with macro- and microscopic traces compatible with defleshing; 3: proximal fragment of a burin spall with macro- and microscopic traces referable to cutting an unidentified soft animal material. 


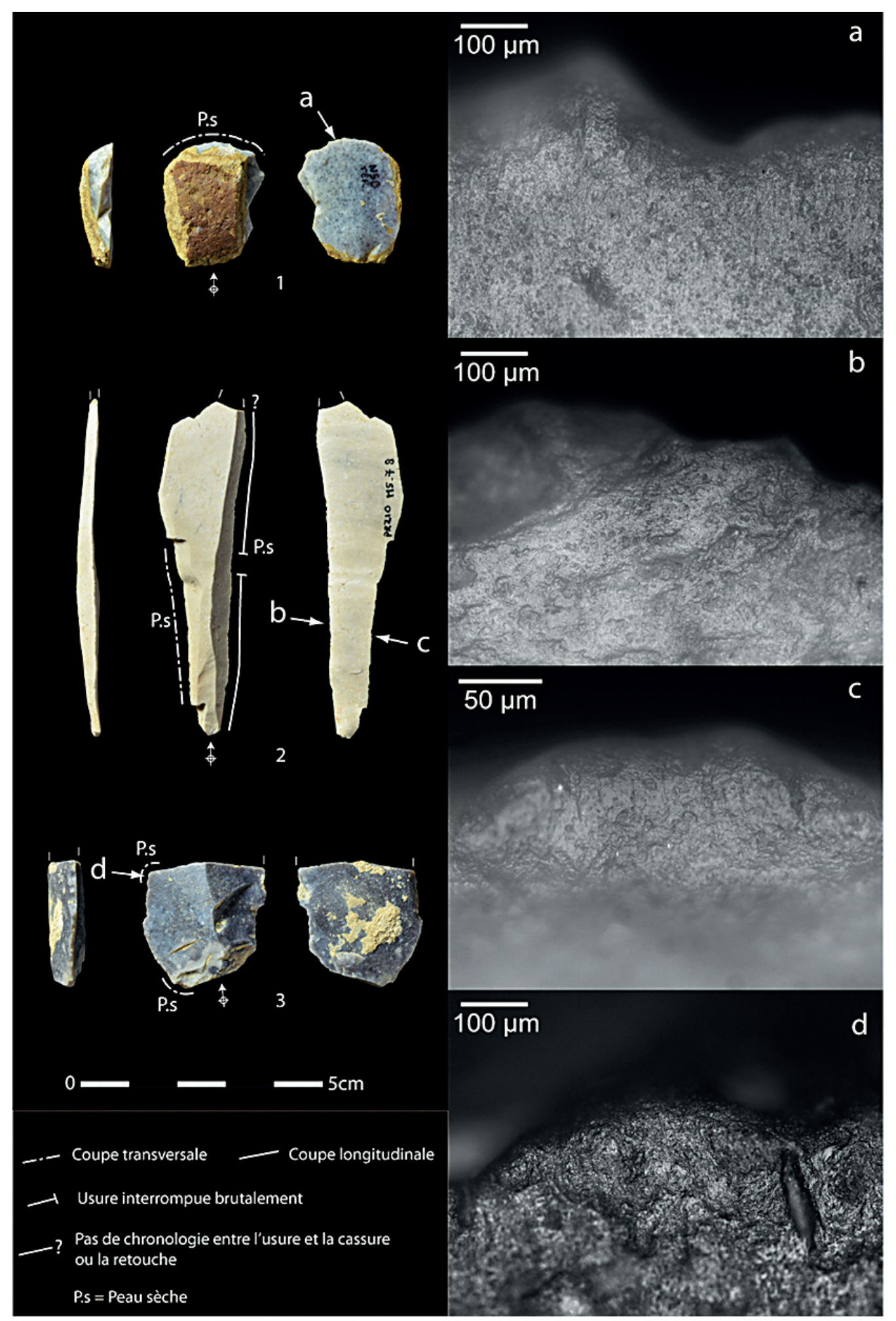

Figure 9 - Exemples d'outils ayant été utilisés au travail de peaux à l'état sec. 1 : grattoir présentant des traces de raclage de peau sèche sur son front $; 2$ : lame brute utilisée à la découpe et au raclage (coupe positive) de peau sèche ; 3 : fragment de support probablement laminaire utilisé par deux appointements naturels au raclage de peau sèche en coupe négative.

Figure 9 - 1 - End scraper with traces of scraping dry skins; 2: unretouched blade use to cut and scrap dry skins (> $90^{\circ}$ working angle); 3 fragment of a probable laminar blank with traces referable to scraping dry hides $\left(<90^{\circ}\right.$ working angle) on the pointed edges of the break. 


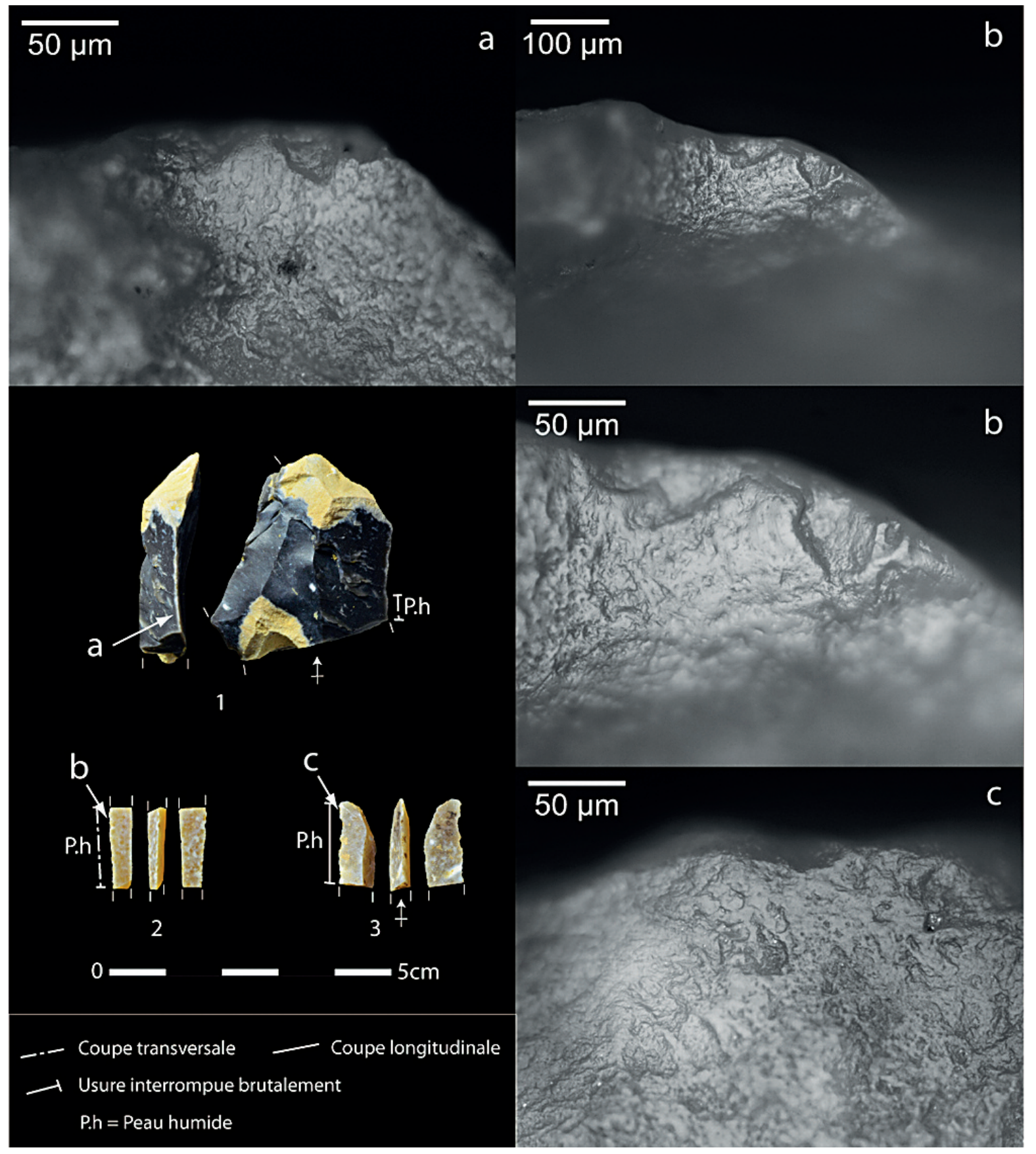

Figure 10 - Exemples d'éléments utilisés au travail de peaux à l'état humide. 1 : fragment distal de support indéterminé présentant des traces de raclage de peau humide entrecoupées d'ébréchures vraisemblablement d'origine accidentelle ; 2 : fragment mésial de chute de burin avec traces de raclage de peau humide ; 3 : fragment distal de chute de burin présentant une usure attribuée à la découpe de peau humide.

Figure 10 - Pieces used to work fresh skins. 1. distal fragment of an indeterminate blank with traces of scraping fresh hides interspersed with probable accidental chipping; 2: mesial fragment of a burin spall with traces of working fresh hide; 3: distal fragment of a burin spall with traces referable to cutting fresh hide. 


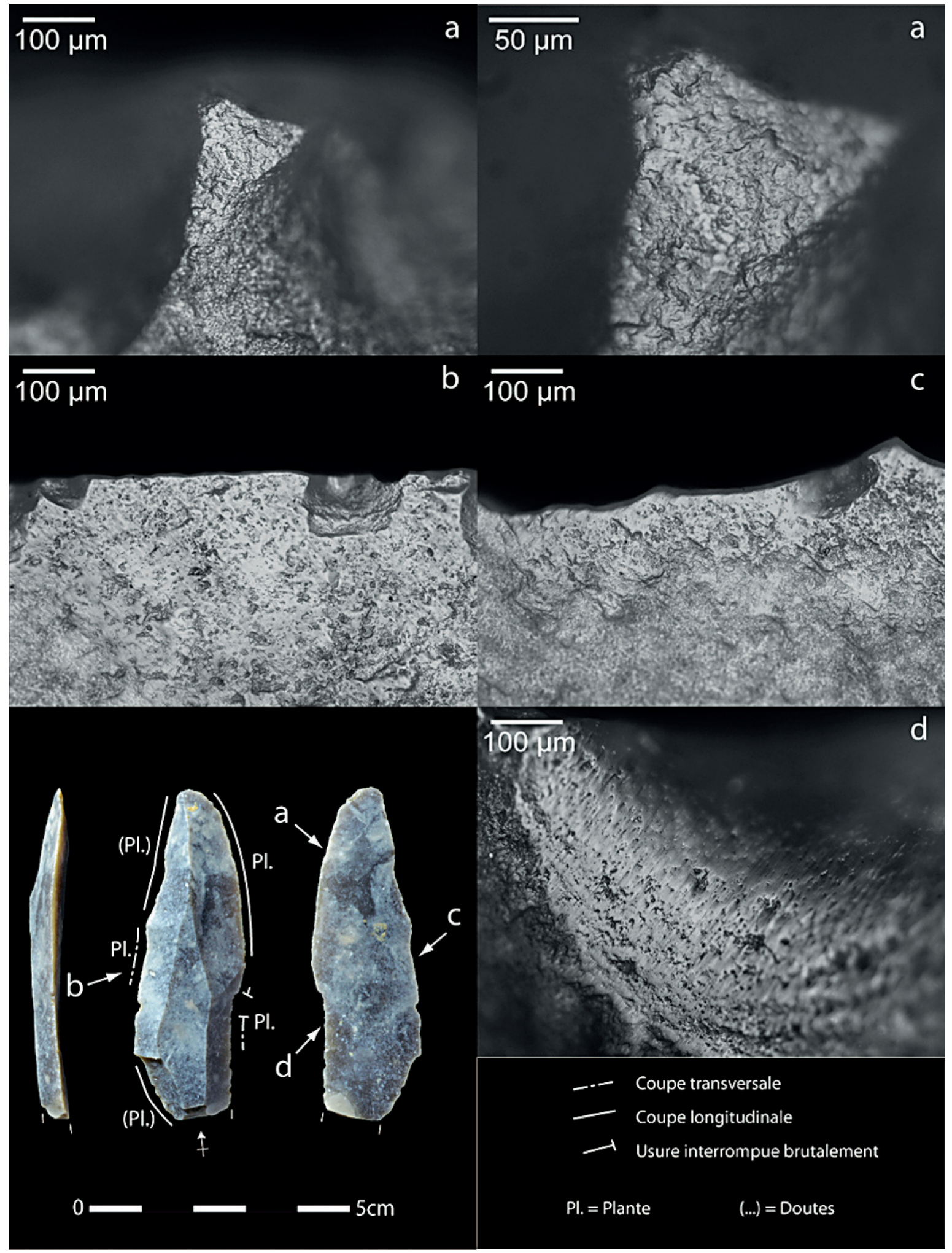

Figure 11 - Lame brute utilisée en coupe transversale (coupe positive oblique) et longitudinale sur une matière végétale non ligneuse indéterminée.

Figure 11 - Unretouched blade used with transversely (oblique $>90^{\circ}$ working angle) and longitudinally on a non-woody plant material. 
microtopographie sans modifier de manière évidente les reliefs (polis fluides) sauf ponctuellement près du fil où le modelé peut être doux lisse (fig. $10, n^{\circ} 1$ ). D'autres polis, comme celui relevé sur le tranchant d'une chute de burin (fig. 10, $\mathrm{n}^{\circ} 2$ ), modifient plus intensément le microrelief.

Le travail des plantes n'est documenté que par un seul outil mais celui-ci a livré cinq zones actives (fig. 11). Deux renvoient à des gestes de raclage et les trois dernières sont attribuables à des actions de découpe. Les deux premières ZU sont courtes et investissent deux zones à délinéation légèrement concave. Les bords présentent un esquillement de faible intensité. Les ébréchures sont bifaciales, espacées et plus nombreuses sur la face en attaque. Ce sont des enlèvements pour l'essentiel initiés en flexion dont la morphologie en plan est variable (principalement semicirculaire à scalariforme). Les micro-usures sont nettement dissymétriques. En effet, sur la face en dépouille (face en contact avec le matériau), le fil présente un large arrondi lisse continu s'estompant progressivement sur la face et prolongé par un micropoli lisse et brillant envahissant et affectant principalement les reliefs. Les stries sont rares - sauf dans un négatif d'enlèvement initié en flexion sur la ZU 2 - mais l'étirement du poli nous indique clairement un geste oblique. Sur la face opposée, l'arrondi du bord est visible mais extrêmement limité et strictement réduit au fil. Le micropoli est moins étendu que sur la face en dépouille mais sa limite semble plus nette. II affecte les reliefs et les creux de la microtopographie et prend un aspect « mou ». Les stries sont absentes mais, comme sur l'autre face, l'étirement oblique est perceptible. Des usures similaires ont été identifiées dans quelques assemblages de la transition Dryas récent / Préboréal du nord-ouest de la France (Jacquier 2014 ; thèse en cours). Ces usures sont également très proches de celles décrites sur bon nombre d'outils appartenant à des assemblages du Mésolithique (Juel Jensen 1994 ; Beugnier 2007 ; Guéret 2013). Les matières travaillées sont vraisemblablement des plantes non ligneuses. Ces outillages pourraient trouver leur place dans des activités liées à la vannerie.

Les grattoirs sont confectionnés tant sur des lames de plein débitage que sur des éclats lamellaires ou des éclats récupérés parmi les déchets de taille (fig. $5, n^{\circ} 3,8-9$; fig. 6, $\mathrm{n}^{\circ}$ 2-3). Comme dans la plupart des contextes archéologiques, les grattoirs de Peyrazet sont impliqués dans le travail de la peau. L'un des exemplaires présente des traces de raclage d'une matière minérale sur son bord latéral mais l'usure est antérieure à la retouche du front. Quatre grattoirs ont été employés au raclage de peau sèche. Les émoussés sont assez bien développés et repérables à faibles grossissements optiques. Ils semblent affecter plus généreusement la face inférieure du support, signalant un angle faible entre cette face et la matière d'œuvre lors du travail. Ils sont toujours plus ou moins centrés sur le front. Les micropolis, très semblables d'un front à l'autre, sont caractérisés par une luisance faible, un aspect grenu et irrégulier du fait de la présence d'abondants arrachements de matière (fig. $9, n^{\circ} 1$ ). Aucune trace d'emmanchement n'a été mise en évidence mais il est difficile d'envisager que des outils si petits et utilisés selon cette cinématique aient pu être maniés efficacement à mains nues.

Deux pièces esquillées présentent des traces de percussion sur matière organique. II s'agit d'un éclat entier épais et d'un fragment mésial de support laminaire (fig. 12). Ils ont vraisemblablement été utilisés en pièces intermédiaires lors d'opérations de percussion lancée contre des matières dures. Ils présentent deux zones marquées par des usures macroscopiques intenses et opposées de part et d'autre du support. Les usures sont caractérisées par des ébréchures superposées, de grandes dimensions à extrémité abrupte. Sur certaines pièces, des accidents « burinants » filent le long des bords. Les zones endommagées sont parfois fissurées en profondeur mais aucune ne présente des écrasements ou des abrasions qui pourraient indiquer le contact contre une matière minérale. Aucune trace microscopique ne permet de préciser la nature des matériaux durs organiques en contact. La question de la fonction de ces éléments reste difficile à traiter.

Deux des cinq burins de la série présentent des traces d'usage sur les parties dégagées par l'extraction des chutes. Tous deux ont été employés contre une matière osseuse indéterminée. Le burin dièdre a été employé au rainurage et l'autre dans une opération de raclage (fig. 13). Les usures observées sont classiques du travail des matières dures animales. Les bords, robustes, présentent de petites ébréchures hertziennes trapézoïdales à extrémité abrupte. Les fils actifs portent un biseau microscopique discontinu, plat et nappé perpendiculairement au bord. Une bande de micropoli brillant, à l'aspect mou caractéristique, affecte les faces d'attaque (fig. 13). L'analyse des burins et des chutes montre également qu'avant d'être transformés en burins, les supports bruts originaux ont été utilisés sous forme de couteau dans des opérations variées : boucherie (fig. $8, \mathrm{n}^{\circ} 3$ ), travail de peaux humides ou sèches (fig. 10, nos 2-3; fig. 14), travail du minéral (fig. 13, $n^{\circ} 1$ ).

\section{Les armatures}

Les armatures du Laborien de Peyrazet regroupent 90 pièces auxquelles on peut ajouter cinq déchets de fabrication ou ébauches (tabl. 5). Trois groupes principaux se distinguent : des pointes à dos étroites (cf. " des Blanchères »; Rozoy 1978); des pointes à dos tronquées et bitroncatures à dos (cf. " de Malaurie » et « rectangle ») et des bitroncatures trapéziformes. La présence d'une pointe à dos courbe sur éclat lamellaire et d'une lamelle à dos appointée de manière inverse signe selon nous plutôt des mélanges avec les niveaux sous-jacents.

Les trois types d'armatures correspondent à des gabarits différents. Les deux bitroncatures sont presque identiques. Pour les pointes à dos, bien que les longueurs soient rarement déterminables du fait de la fragmentation, les quelques pièces entières du type « des Blanchères 》 mesurent entre $22 \mathrm{~mm}$ et $37 \mathrm{~mm}$ de long et les rares pointes entières du type " de Malaurie » autour de 35$40 \mathrm{~mm}$. Les premières présentent des largeurs comprises 


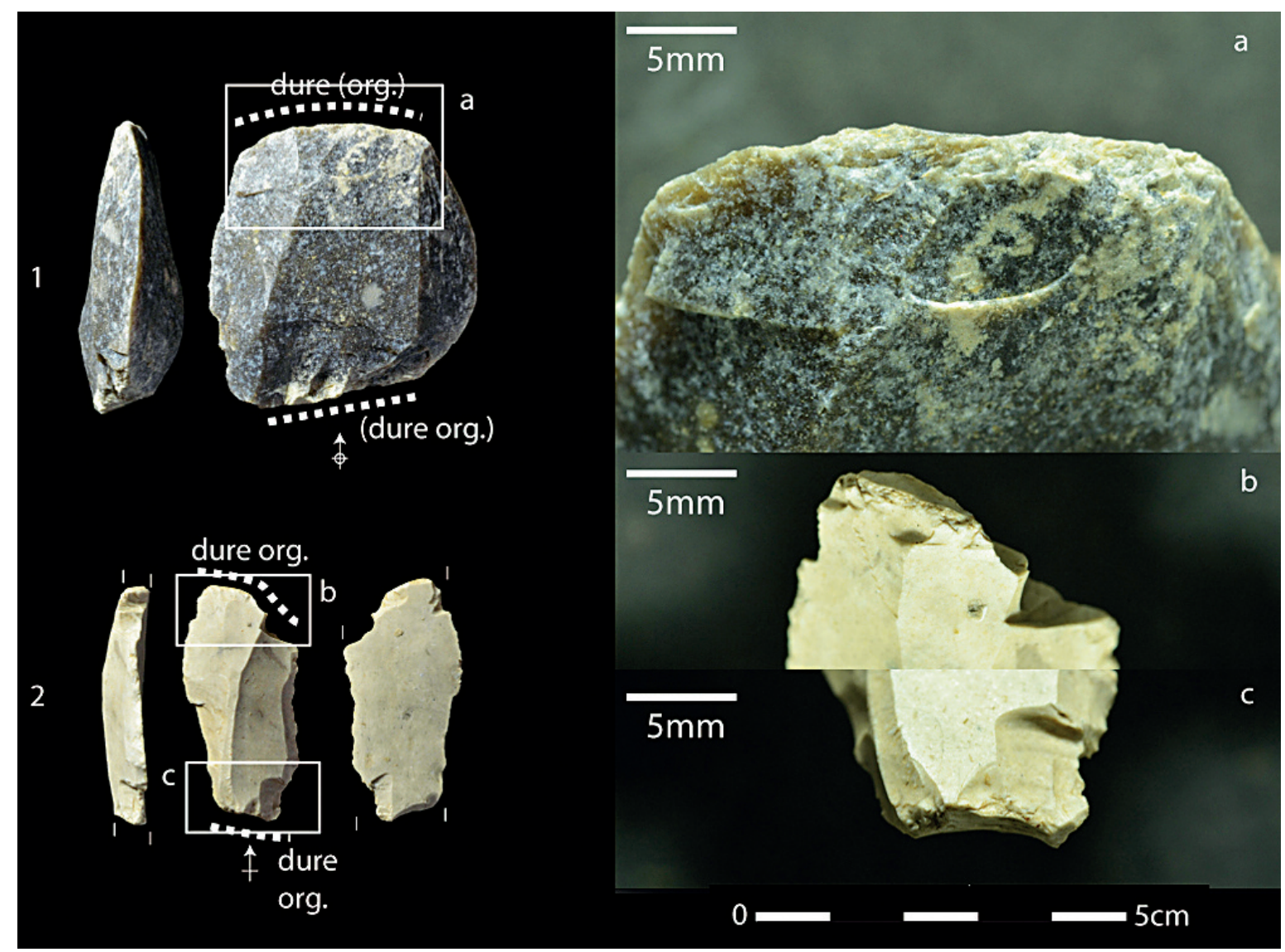

Figure 12 - Pièces esquillées utilisées en percussion lancée directe et indirecte avec traces de percussion sur matière dure organique probable.

Figure 12 - Splintered pieces with percussion traces due to contact with a probable hard organic material using direct and indirect percussion.

\begin{tabular}{|lrrrr|}
\hline \multicolumn{1}{|c}{ TYPES } & LAMELLE & PETITE LAME & ELL & NR \\
\hline fgt LD/PD étroite & 30 & 1 & 1 & $\mathbf{3 2}$ \\
PD étroite \& fgt & 17 & 1 & $\mathbf{1 8}$ \\
Pointe des Blanchères \& fgt & 17 & 1 & $\mathbf{1 8}$ \\
Pointe de Malaurie \& fgt & 1 & 15 & $\mathbf{1 6}$ \\
bitronqué rectangle & 1 & 1 & $\mathbf{2}$ \\
bitronqué trapéziforme & & 2 & & $\mathbf{2}$ \\
$P D$ courbe & 1 & & 1 & $\mathbf{1}$ \\
LD appointée inverse & $\mathbf{6 7}$ & $\mathbf{2 1}$ & $\mathbf{2}$ & $\mathbf{9 0}$ \\
\hline NR & 3 & & & $\mathbf{3}$ \\
ébauche LD/PD & & 1 & 1 & $\mathbf{2}$ \\
déchet fabrication LD/PD & & &
\end{tabular}

Tableau 5 - Décompte des armatures lithiques de l'ensemble supérieur de Peyrazet (PL : petite lame, ELL : éclat lamellaire, fgt : fragment, $L D$ : lamelle à dos, $P D$ : pointe à dos).

Table 5 - Microliths counts for the upper Peyrazet sequence (PL: small blade, ELL: bladelet, fgt: fragment, LD: backed bladelet).

entre 3 et $7 \mathrm{~mm}$ (centrée autour de $5 \mathrm{~mm}$ ) et des épaisseurs de 1-2 mm, tandis que les secondes arborent une plus grande variabilité des largeurs, entre 8 et $13 \mathrm{~mm}$, et des épaisseurs, entre 2 et $4 \mathrm{~mm}$.

Le groupe des armatures étroites réunit 68 pièces (fig. 15, $\left.\mathrm{n}^{\circ} 1-6\right)$. Les pièces munies d'une pointe indiquent une absence de latéralisation préférentielle des dos tant à droite ( 9 cas) qu'à gauche ( 9 cas). En revanche, la pointe est plus fréquemment proximale. Une pointe du type « des Blanchères » présente un enlèvement burinant de $2 \mathrm{~mm}$ environ, initié à la base, qui file le long du tranchant. II pourrait avoir été créé par contrecoup contre la hampe lors 


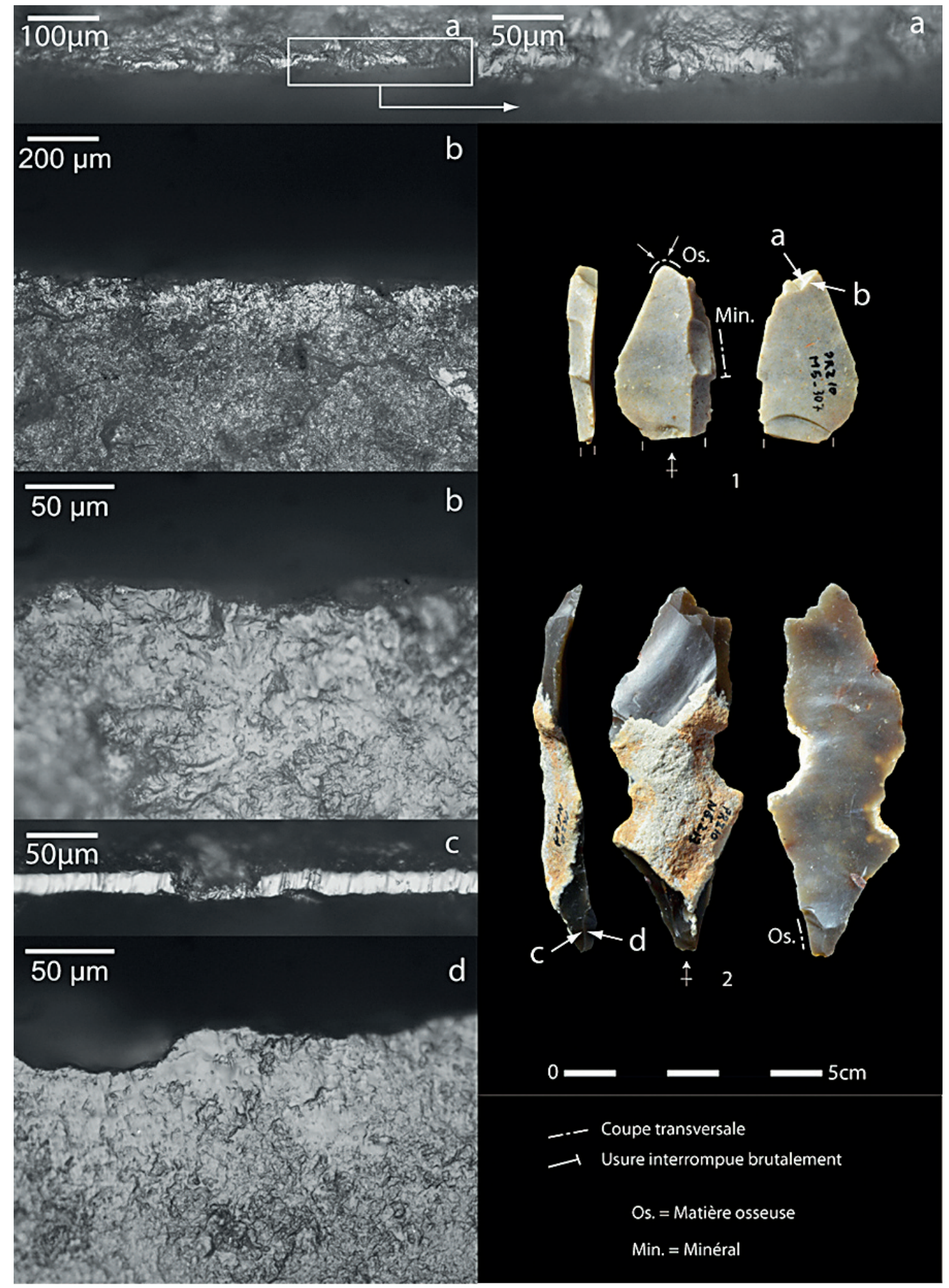

Figure 13 - Outils employés au travail de matières osseuses. 1 : burin dièdre utilisé au rainurage d'une matière osseuse indéterminée et présentant également des traces de raclage d'une matière minérale ; 2 : possible burin sur cassure utilisé au raclage d'une matière osseuse indéterminée.

Figure 13 - Tools used to work osseous materials. 1: dihedral burin used to groove an unidentified osseous material that also bears traces of scraping a mineral material; 2 possible burin on break used to scrape an unidentified osseous material. 


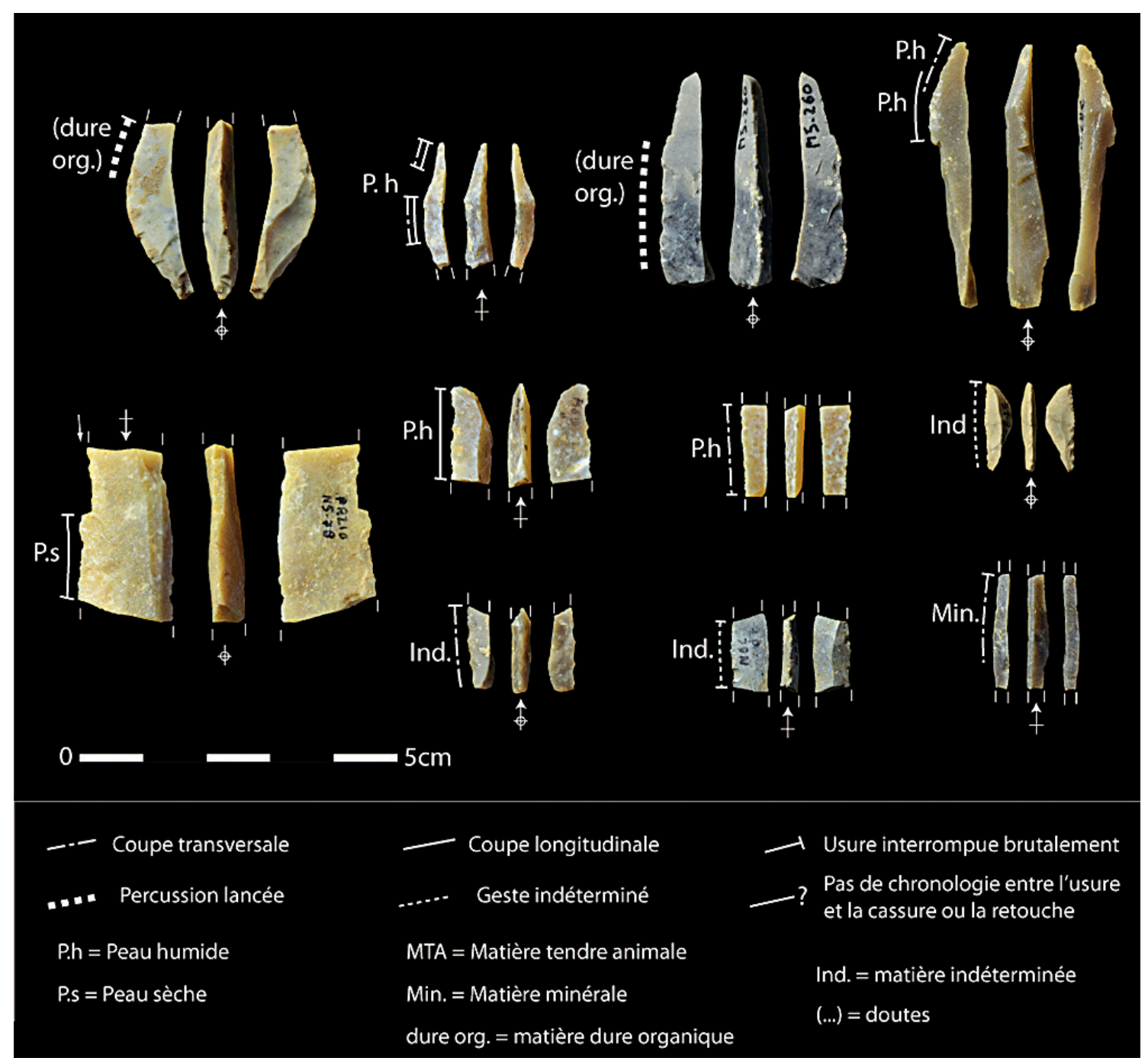

Figure 14 - Exemples de burins et chutes ayant livré des traces d'usage.

Figure 14 - Burins and burin spalls with use-wear traces.

de l'impact. Vers l'apex, le tranchant présente également une série d'ébréchures scalariformes obliques dirigées vers la base et compatibles avec une utilisation en élément perforant sur une arme de jet (fig. 15).

Les pointes à dos tronquées (« de Malaurie ») et les bitroncatures à dos (« rectangles ») sur petites lames réunissent 18 pièces (fig. 16). Elles portent plus fréquemment la pointe en partie distale et les dos peuvent être à droite (13 cas) ou à gauche (8 cas). Deux éléments raccordés, correspondant à un fragment de pointe à dos et base tronquée du type « de Malaurie » (fig. 16, $\mathrm{n}^{\circ}$ 6), présentent des endommagements ambigus. Les trois cassures sont initiées en flexion et arborent des languettes légèrement inférieures à $2 \mathrm{~mm}$ à terminaison abrupte. $\mathrm{La}$ base présente également une large ébréchure inverse. Aucune MLIT (Microscopic Linear Impact Traces ; Odell 1978) n'a été identifiée. Si les cassures ne sont pas véritablement diagnostiques parce qu'un peu courtes, leur association avec l'enlèvement à la base - potentiellement créé lors d'un impact par contrecoup contre la hampe pourrait soutenir l'hypothèse d'une utilisation en armature de projectile. Des stigmates d'impacts diagnostiques ont été repérés sur trois autres pointes « de Malaurie ». La première (fig. $16, n^{\circ} 1$ ) porte une fracture par flexion avec une languette de plus de $10 \mathrm{~mm}$. Les deux autres (fig. $16, \mathrm{n}^{\circ} 7,5 ; 1$ et 2 ) présentent des cassures droites sans languette depuis lesquelles s'initient des ébréchures de type spin-off d'environ $2 \mathrm{~mm}$. Des stries d'impact accompagnent ces endommagements sur une des deux pièces (fig. 16, 2b). Les MLIT observées sur ces éléments sont globalement orientées selon l'axe technologique des pièces. Elles sont parfois légèrement obliques mais permettent de confirmer une utilisation en éléments perforants disposés parallèlement aux fûts. Le seul rectangle étudié (fig. $16, \mathrm{n}^{\circ} 8$ ) n'a pas livré de traces 

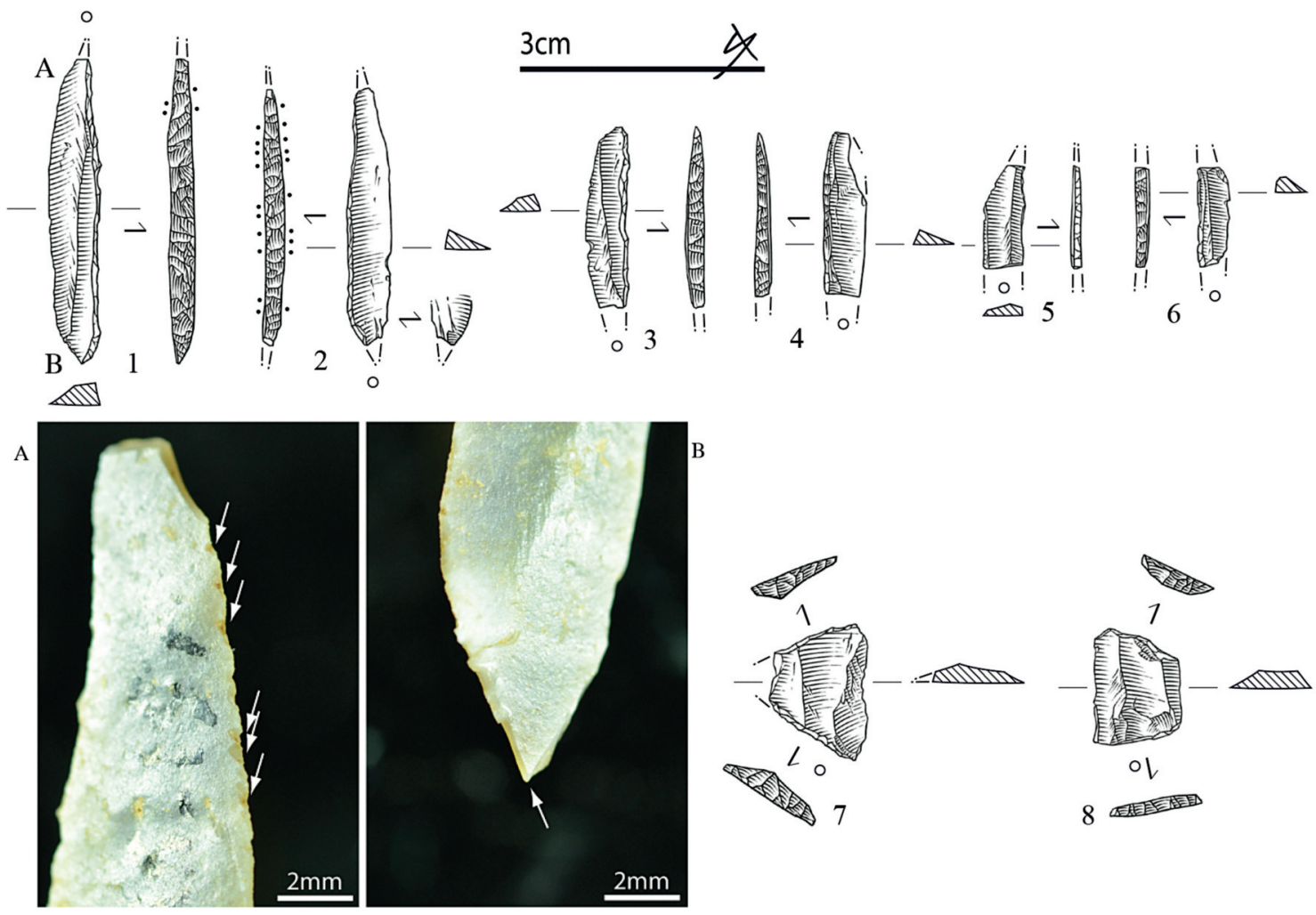

Figure 15 - 1-6: Exemples de pointes à dos étroites type «Blanchères " et fragments. A : ébréchures obliques sur le tranchant en face inverse au niveau de la pointe, $B$ : enlèvement burinant initié sur la base ; 7-8: bitroncatures trapéziformes (dessins S. Ducasse).

Figure 15 - 1-6: Straight-backed Blanchères points and fragments. A: oblique chipping on the ventral surface of an edge near the point, B: burination fracture initiating from the base ; 7-8: Trapazoidal bitruncations (Drawing S. Ducasse).

permettant de discuter de sa fonction. Des observations technologiques effectuées dans d'autres séries suggèrent que ces bitroncatures à dos peuvent correspondre au recyclage de pointes de "Malaurie » (Langlais 2007 ; Langlais et al. 2014b). Sont-elles systématiquement issues d'un tel processus? Qu'est-ce qui motive cette transformation? Une fois transformées, trouvent-elles un rôle dans la sphère cynégétique ou sont-elles employées dans d'autres registres fonctionnels ? Répondre à ces questions nécessitera l'analyse techno-fonctionnelle de nouvelles séries mais cette hypothèse permettrait d'expliquer leur présence variable selon les gisements.

Les bitroncatures trapéziformes $(\mathrm{N}=2)$ correspondent à des segments de petites lames tronqués au niveau des deux cassures délimitant les deux bases tranchantes du trapèze. On ne note pas de latéralisation préférentielle des troncatures ou bases (fig. 15, $n^{\circ} 7-8$ ). L'analyse des deux éléments n'a livré aucun indice permettant de préciser leur rôle au sein du système technique. Pour l'instant, la fonction de ces outils reste incomprise. Les observations réalisées sur d'autres séries n'ont livré que de rares indications. Si l'observation macro et microscopique de la plupart des bitroncatures trapéziformes du site de La Fosse en Mayenne n'a livré aucune trace suggérant une utilisation en élément de couteau, en revanche deux pièces présentent des endommagements plaidant en faveur d'une utilisation en tête de projectile selon un montage en armature tranchante (Naudinot 2013, fig. 2 ; Jacquier thèse en cours). Un exemplaire de La Borie del Rey c. 3 pourrait également alimenter cette hypothèse (Langlais et al. 2014b, fig. 19).

\section{Les modalités de production lamino-lamellaire}

Les multiples fragments et éclats (tabl. 3) proviennent pour la grande majorité des productions lamino-lamellaires (tablettes, aménagements de crêtes et corrections de flanc...). Ils fournissent des supports d'outils d'appoint, en particulier pour les grattoirs (fig. 6, $n^{\circ}$ 2-3). Ces observations valent aussi pour les éclats laminaires qui peuvent être récupérés parmi les déchets de taille. Des lames de mise en forme (« nervuration ») et d'entretien des convexités sont également récupérées, au sein des débitages exécutés dans la grotte, comme supports d'outils (burin, couteaux et lames retouchées). La production laminaire a pour but de fournir des lames régulières de profil rectiligne transformées en outils d'extrémité (burins, grattoirs ; fig. 5) ou utilisés comme couteaux (fig. 7). Dans 


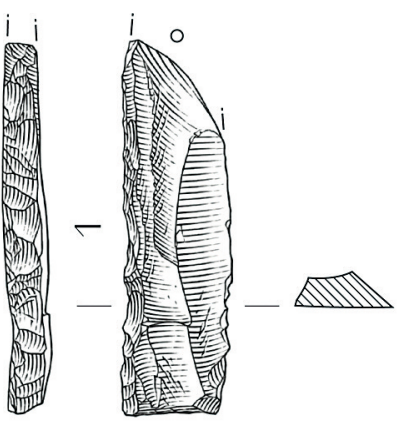

(1)

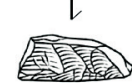

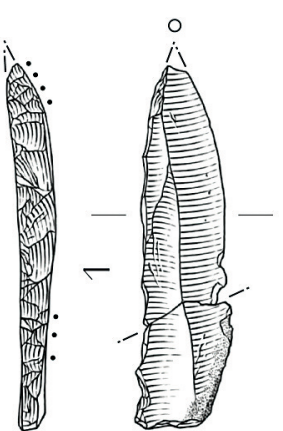

(2)

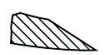

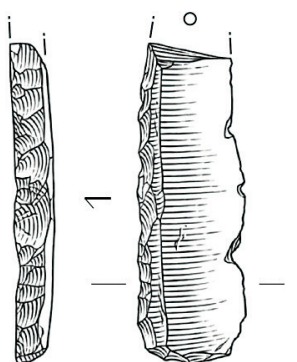

(3)

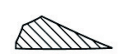

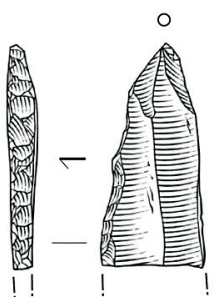

(4)

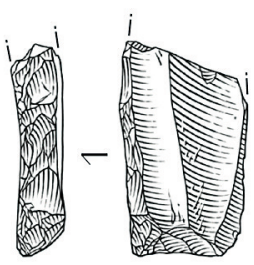

(5)

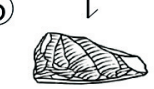

○

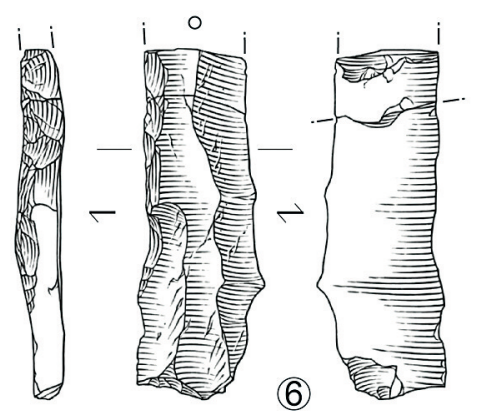

$\Delta$
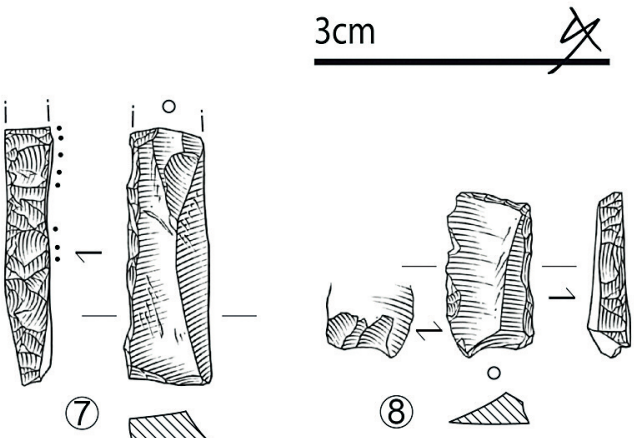

(8) 1 .

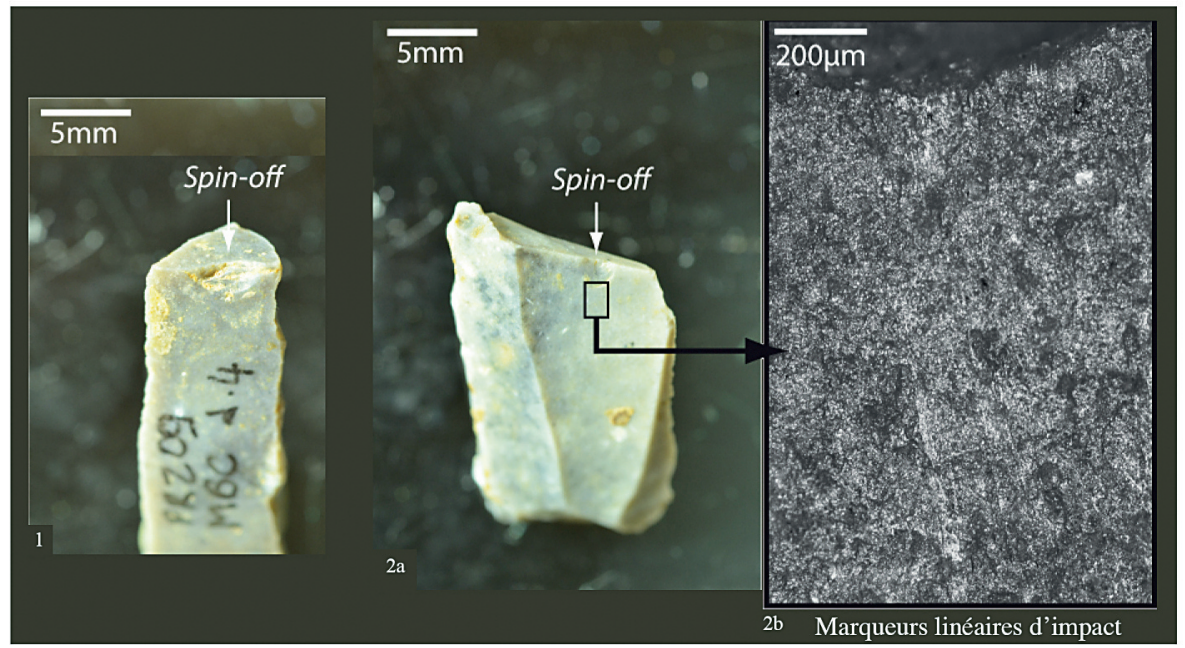

Figure 16 - Exemples de pointes à dos tronquées de type "Malaurie" ( $n^{\circ}$ 1-7) et bitronquée à dos type rectangle ( $\left.n^{\circ} 8\right)$ de l'ensemble supérieur de Peyrazet (dessin S. Ducasse) ; Stigmates d'impact diagnostiques 1 : cassure par flexion droite et ébréchures de type spinoff sur la face ventrale pièce $n^{\circ} 7 ; 2 a$ : cassure par flexion droite avec 1 ébréchure de type spin-off sur la face ventrale, $2 b:$ stries linéaires d'impact pièce $n^{\circ} 5$.

Figure 16 -Truncated-backed Malaurie points (nos 1-7) and a bitruncated backed rectangle ( $n^{\circ}$ 8) from the upper Peyrazet sequence (Drawings S. Ducasse) ; Diagnostic impact fractures 1: straight bending fracture and spin-offs on the ventral surface ( $\left.n^{\circ} 7\right)$; 2a: straight bending fracture with a single spin-off on the ventral surface, $2 b$ : linear impact striations $\left(n^{\circ} 5\right)$. 


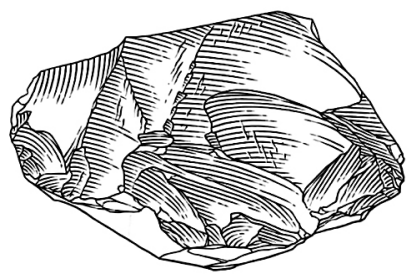

1
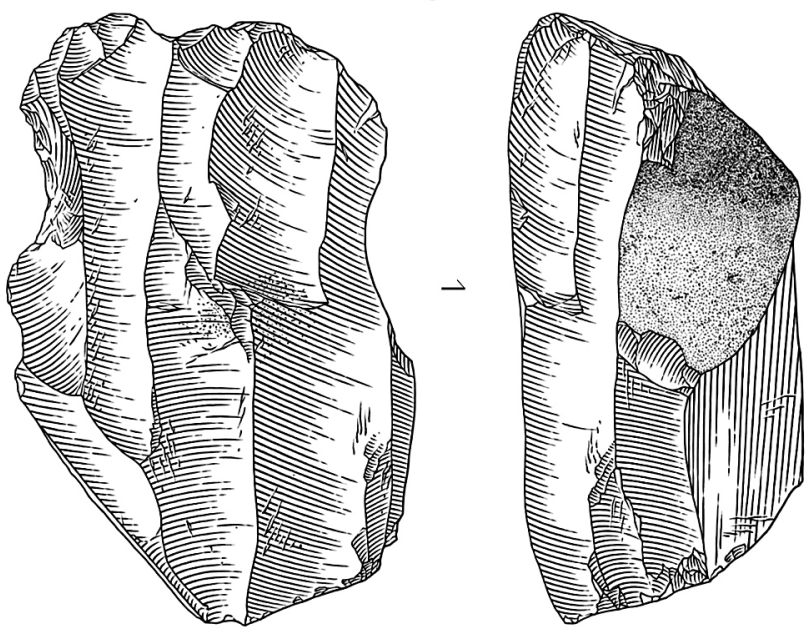

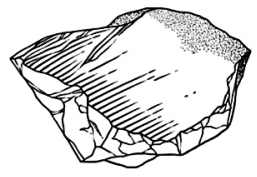

1
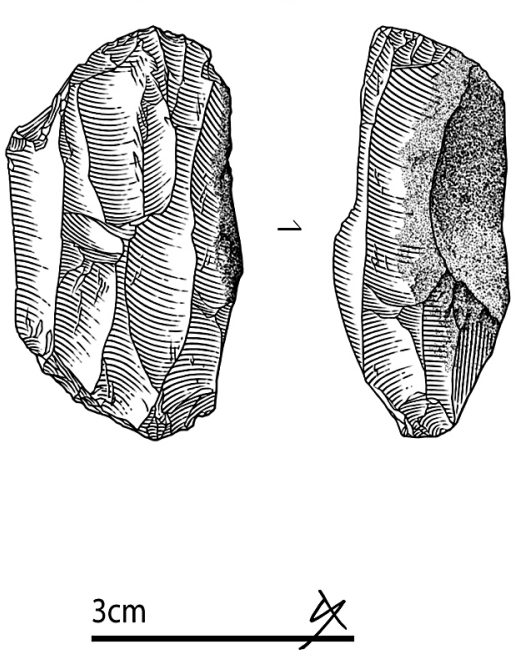

Figure 17 - Nucléus à objectifs lamino-lamellaires (dessin S. Ducasse).

Figure 17 - Blade-bladelet cores (Drawings S. Ducasse).

la continuité des débitages laminaires voire de manière autonome à partir de volumes plus réduits, de petites lames sont transformées en pointes à dos tronquées (« de Malaurie ») et pièces à dos bitronquées (« rectangles ») mais également en bitroncatures trapéziformes et, plus rarement, en outils domestiques (troncature, microperçoir). La présence de supports présentant des négatifs bipolaires dès la mise en forme et au cours du plein débitage indique, comme les deux nucléus de la série (fig. 17), l'emploi successif de deux plans de frappe opposés. La succession de séquences unipolaires entrecoupées de nettoyages opposés ponctuels s'opère depuis l'un ou l'autre plan. Ce principe répond en particulier à la recherche de supports réguliers et plats. En outre, l'emploi d'un percuteur en pierre dans ses diverses variantes de gestes tout au long du débitage participe également au succès de cet objectif, qui en contrepartie entraîne de fréquents réfléchissements qu'il faut ensuite nettoyer. Parallèlement, des aménagements transversaux permettent de conditionner et de maintenir le volume dans des conditions favorables au débitage de supports réguliers et rectilignes. C'est ainsi que le recours aux néocrêtes localisées $(\mathrm{N}=22)$ est très fréquent. La préparation au détachement des lames et lamelles est faite d'une abrasion plus ou moins appuyée afin de favoriser l'extraction de supports à la pierre dans sa version tangentielle principalement.
Les lamelles, extraites en continuité des petites lames ou de manière autonome à partir de petits rognons (notamment en jaspéroïdes), présentent les mêmes caractéristiques techniques que les lames, dans leur régularité et leur profil rectiligne. Elles indiquent néanmoins un plus fort taux d'unipolarité des négatifs qui pourrait relever d'un abandon d'un des plans de frappe ou d'une plus faible nécessité de nettoyer depuis un second plan de frappe, la longueur disponible étant désormais plus facile à gérer depuis un seul pôle. Ces lamelles sont dévolues pour l'essentiel à des pointes à dos plus légères (cf. " des Blanchères »).

Le continuum des gabarits laminaires et lamellaires (entre 20 et $5 \mathrm{~mm}$ de large et 1 à $3 \mathrm{~mm}$ d'épaisseur) ainsi que leur homogénéité technique nous incitent à proposer l'hypothèse d'un continuum conceptuel lamino-lamellaire. Selon les diverses qualités intrinsèques et la dimension initiale des volumes à débiter disponibles, cet enchaînement a pu s'effectuer sur un même volume. L'attribution à une phase précise du Laborien/Épilaborien de cet ensemble techniquement homogène est délicat car nous savons qu'ils sont finalement très proches (Langlais et al. 2014b, fig. 34-35) hormis la nature de leurs armatures (voir infra) et une forte composante lamellaire pour le second (Naudinot 2013). 


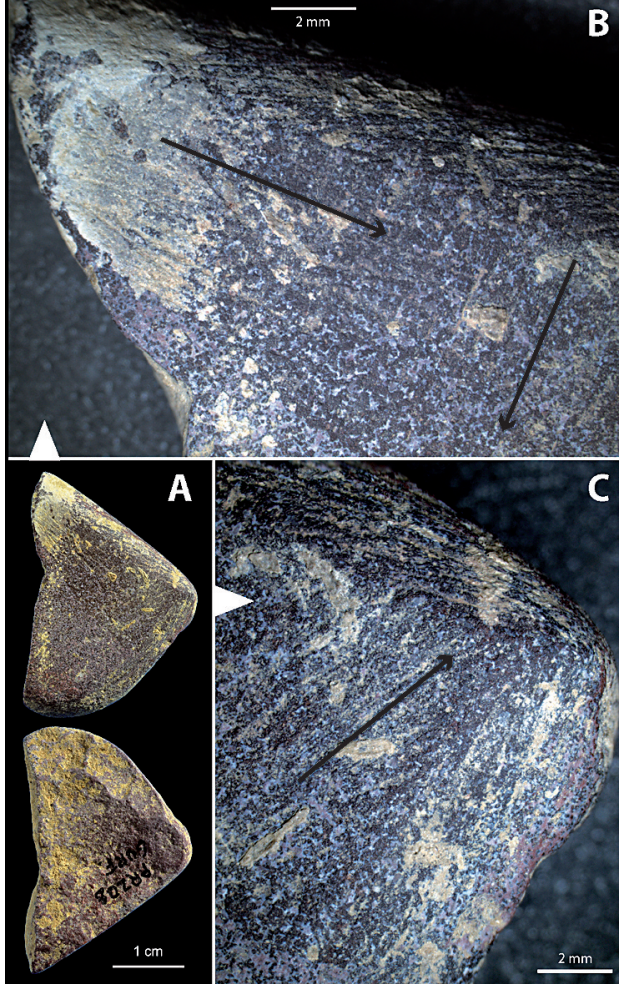

Figure 18 - Le vestige en ocre de Peyrazet.

Figure 18 - Ochre piece from Peyrazet.

\section{Le « crayon d'ocre » de Peyrazet : vestige de production de poudre ou pièce façonnée ?}

Un fragment de roche ferrugineuse rouge portant de nettes traces d'abrasion a été trouvé hors stratigraphie. Son attribution demeure problématique mais sa position en surface dans un secteur où affleurait le niveau supérieur nous a conduit à le considérer comme appartenant vraisemblablement à l'équipement laborien. Cette pièce est tout à fait particulière puisqu'elle présente quatre facettes striées, dont une face large quasi-triangulaire (fig. 18A). La matière première est une roche de type argilite ferrugineuse, composée de kaolinite et d'hématite (d'après une analyse par diffraction de rayons X). Du point de vue morphologique, on peut parler de " crayon » (facettes convergentes), bien qu'elle présente un aspect tabulaire et des tranches fines. Les stries couvrent entièrement la face principale, l'une des tranches, et partiellement une deuxième tranche. Elles sont fines et parallèles, et les facettes planes à plano-convexes, ce qui indique une abrasion sur un support minéral (pas de traces de raclage). La troisième tranche correspond à une fracture ancienne, présentant un possible point d'impact sur la face supérieure striée. La chronologie des traces est difficile à établir en raison de la présence de nombreuses concrétions. Deux directions d'abrasion sont observées sur la face triangulaire ; elles suivent la direction des deux arêtes de part et d'autre de la pointe (fig. 18B), conférant à la face un aspect symétrique. Des pièces facettées tabulaires ont déjà été décrites dans la littérature (Soressi et d'Errico 2007 ; Salomon 2009 ; Watts 2010 ; Rifkin 2011 ; Dayet et al. 2013 ; Hodgskiss 2013). Toutefois la finesse des tranches, les deux directions d'abrasion observées sur une face principale très plane et la position de la fracture distinguent cet objet des pièces facettées produites en général au cours d'un processus de réduction en poudre. Ces particularités pourraient indiquer un début de mise en forme, interrompue en cours de route par la fracturation. Les caractéristiques de la pointe (fig. 18C), ainsi que l'emplacement de la fracture, vont à l'encontre d'une utilisation comme " crayon » pour marquer des surfaces (Salomon 2009). Certaines pièces portant des traces d'usure sur les tranches pourraient être interprétées comme des lissoirs. Cette piste serait alors cohérente avec nos observations. Reste l'hypothèse que la forme ait été recherchée en tant que telle. La finesse des tranches évoque la morphologie de certaines pendeloques en pierre provenant de contextes tardiglaciaires (Rousseau 1933, pl. 5). Ce type d'objet est rare dans le sud-ouest de la France.

\section{Les éléments de parure}

Les couches supérieures ont livré quatre tests de dentales et cinq fragments de nacre. Afin d'identifier l'origine des dentales et de vérifier si les chasseurs-cueilleurs ont sélectionné et modifié ces pièces, une analyse morphométrique et microscopique a été menée. Les dentales de Peyrazet ont été comparés à deux référentiels - une collection moderne composée de 339 Dentalium vulgare récoltée sur les plages du bassin d'Arcachon et un ensemble fossile de 244 Dentalium sp. provenant du falun miocène de Saucats (Vanhaeren 2002). Les mesures enregistrées sur les dentales archéologiques et naturels comprennent la longueur des pièces et le diamètre de leurs ouvertures. De rares modifications postdépositionnelles sont présentes sur les pièces de Peyrazet, incluant quelques puits de dissolution à la surface des pièces. Un des dentales présente une cassure longitudinale. Les dentales complets des référentiels ont une forme conique légèrement courbe et leur longueur est comprise entre 7 et 12 fois leur diamètre maximal (Poppe et Goto 1993). Les mesures enregistrées sur les dentales archéologiques montrent que deux d'entre eux ont une longueur inférieure aux minimales obtenues sur les pièces des référentiels. Les deux autres entrent dans la variabilité des longueurs de l'une ou l'autre des collections de comparaison. Les quatre dentales archéologiques montrent un rapport longueur/diamètre variant entre 1 et 3 . Ces résultats indiquent que les pièces trouvées à Peyrazet sortent de la variabilité métrique des deux référentiels.

$\mathrm{Au}$ sein des dentales naturels, les ouvertures antérieures non fracturées présentent un diamètre proche de $1 \mathrm{~mm}$. Les mesures effectuées à Peyrazet montrent qu'une pièce possède sa partie antérieure tandis que les autres sont plus larges que $2,5 \mathrm{~mm}$. Ceci indique que trois des pièces archéologiques sont des portions provenant de la partie 


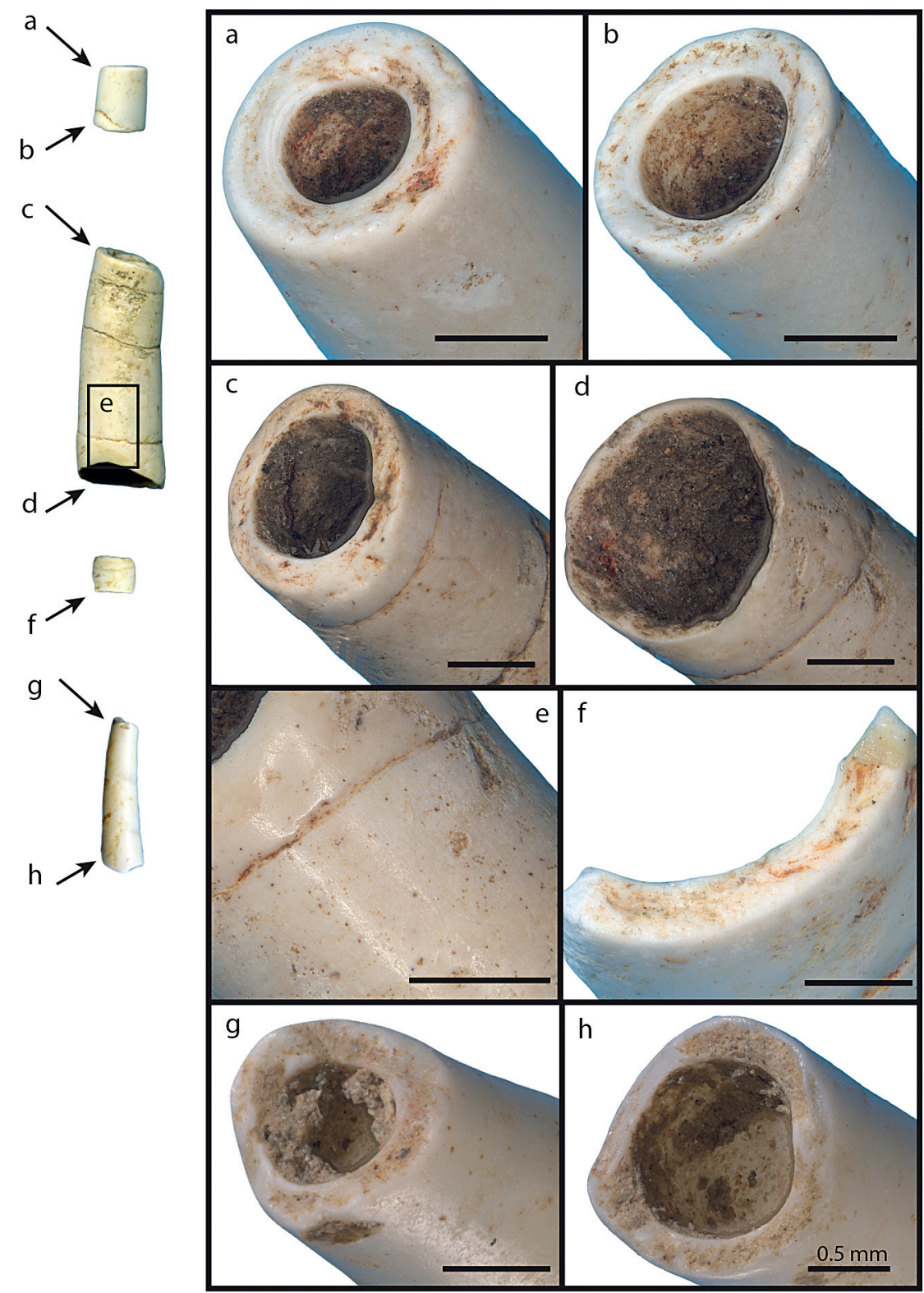

Figure 19 - Les dentales : a, c - extrémités proximales ; $b, d$-extrémités distales ; $e$ usure; $f$ - le fragment est trop court pour identifier les extrémités proximale et distale; $a, b, c, f$ - extrémités fracturées par flexion, $c$ - extrémité intacte.

Figure 19 - Dentallium: a, c-proximal extremity; $b, d$-distal extremity; $e$ - wear; $f$ - the fragment is too short to identify the proximal and distal extremities. centrale ou postérieure des coquilles, la partie absente étant l'extrémité antérieure plus fine. Pour les référentiels, les ouvertures des dentales intactes présentent des bords fins et aigus, perpendiculaires à l'axe du coquillage (Vanhaeren 2002). Cet état est observé uniquement sur le bord postérieur d'une des pièces (fig. 19d). Les autres extrémités des dentales présentent des bords nets, larges, interceptant perpendiculairement le cylindre du coquillage (fig. 19). Cela s'observe sur certaines cassures naturelles ou après fracturation par flexion (ibid.).

Les données de l'analyse morphométrique qui excluent les dentales de Peyrazet des ensembles naturels suggèrent qu'ils ont été volontairement fracturés aux extrémités par flexion afin de conserver leur portion la plus large.
Un poli d'usure est présent sur les bords des ouvertures de plusieurs dentales. Sur le bord postérieur d'une des pièces, cette usure a entraîné l'amincissement et la déformation du test (fig. 19e). La facette d'usure déborde sur la surface du dentale et se développe en une petite plage triangulaire. Ceci indique que les dentales étaient suspendus, probablement cousus sur un vêtement.

L'analyse ne permet pas d'identifier précisément la provenance de ces dentales, cette espèce étant présente autant sur les côtes méditerranéennes qu'atlantiques, mais également dans de nombreuses formations fossiles aquitaines et rhodaniennes. L'absence de dentales fossiles dans l'encaissant naturel du gisement suggère cependant une origine exogène des supports. La présence d'usure sur 
les pièces et l'absence des fragments distaux et proximaux malgré le tamisage fin des sédiments laissent à penser que les dentales ont été importés sur le site déjà transformés en objets de parure et perdus/abandonnés durant l'occupation du site.

Les décors naturels visibles à la surface de cinq fragments de nacre indiquent qu'ils proviennent d'une coquille de bivalve. Ces objets ne présentent aucun stigmate permettant d'expliquer leur origine géographique ni leur éventuelle utilisation.

\section{Synthèse et discussion}

Au sein de l'ensemble supérieur de Peyrazet, nous avons noté des indices très probables de mélanges interstratigraphiques localisés, dus notamment à la présence d'un/de terrier(s) et de différents processus postdépositionnels. Ces processus pourraient expliquer la présence intrusive des quelques restes de renne, de deux armatures lithiques azilienne et magdalénienne, mais aussi de rares tessons de céramique récoltés dans l'ensemble supérieur. En dehors de ces pollutions, fréquentes en contexte de remplissage en grotte, cet ensemble supérieur apporte de nouveaux éléments pour la connaissance du complexe laborien dans la région et ses marges et sur la nature des activités réalisées dans la grotte.

L'attribution à cet ensemble chronoculturel s'appuie principalement sur la composition de l'équipement lithique (production soignée de lames rectilignes réalisée à la pierre, pointes à dos empreints de caractères post-aziliens ; Naudinot 2010 ; Langlais et al. 2014a).

Concernant la nature des occupations laboriennes du gisement, plusieurs points peuvent être soulignés. Nous avons relevé un apport de galets (à vocation de combustion ?) et de différents matériaux siliceux sous forme de volumes et de supports pour la fabrication et l'entretien d'équipements voués aux activités domestiques et à la chasse. L'essentiel de cet approvisionnement provient d'un rayon de $50 \mathrm{~km}$ autour du site et en particulier de gîtes du Sénonien gris-noir. L'introduction de carcasses animales (principalement du cerf), entières ou partielles, a été suivie par de la boucherie et plusieurs opérations techniques liées au prélèvement et au traitement des peaux. Le travail de la peau correspond d'ailleurs à l'activité la mieux documentée. L'identification de raclage de peaux humides ou fraîches suggère la mise en œuvre d'étapes de début de chaîne opératoire. Les travaux sur peaux sèches et notamment par raclage avec des bords anguleux et en découpe plaident pour la réalisation d'étapes de finition et de confection d'objets en peau. Nous avons également noté la production de supports et d'outils en matière dure animale et la mise en œuvre d'un débitage par rainurage longitudinal. Des objets de parure sont introduits sous la forme de tests de dentales. L'utilisation de colorant est également représentée par une pièce façonnée et l'emploi probable de supports lithiques lié au raclage de matières minérales. Le travail de plantes non ligneuses pourrait être mis en relation avec une activité de vannerie.
À côté d'une exploitation marginale du Lièvre, le gibier de prédilection des Laboriens de Peyrazet est le cerf. Ce choix rappelle la couche 3 de La Borie del Rey et le niveau 2 de Port-de-Penne (Langlais et al. 2014b). En revanche, dans d'autres gisements laboriens connus - Le Pont d'Ambon c.2 en Dordogne (Célérier (dir.) 1994 ; Gilbert 1984), La Borie del Rey c.7 et c.5 en Lot-et-Garonne (Langlais et al. 2014b), Manirac dans le Gers (Gilbert op. cit.) et ChampChalatras dans le Puy-de-Dôme (Pasty et al. 2002) l'aurochs constitue la proie privilégiée. Enfin, le niveau 1 de Port-de-Penne livre un spectre dominé par le cheval (Langlais et al. 2014b).

À Peyrazet, les données environnementales issues des différents vestiges fauniques vont dans le sens d'une diversité de biotopes associant des paysages ouverts (prairies/steppes) à fermés (broussailles à futaies) et rupestres. Ceci est à mettre en relation avec la situation de la grotte-abri de Peyrazet à l'interface entre plaine alluviale, falaise et plateau caussenard.

Les conditions de mise en place et de conservation des dépôts archéologiques rendent difficile de trancher entre l'hypothèse d'un site résidentiel dont témoignerait la diversité des activités et une superposition d'occupations aux fonctions plus ciblées mais différentes dans le temps. II paraît dès lors bien délicat de raisonner sur le statut socioéconomique de cette/ces occupation(s). L'hypothèse d'installations logistiques en relation avec la chasse est ainsi difficile à argumenter dans ce contexte, à la différence de ce qui a pu être proposé récemment pour le niveau 2 du site de plein air de Port-de-Penne dans l'Agenais (Langlais et al. 2014b).

Trois dates ${ }^{14} \mathrm{C}$ ont été réalisées sur os de cerf. La première (Ly7828/SacA22775, $9780 \pm 45$ BP) situe au moins certaines occupations de Peyrazet à la transition Pléistocène-Holocène, soit vers 11,5 - $11 \mathrm{Ky}$ cal. BP. Pour les deux autres (Ly9062/SacA28329, $9235 \pm 45$ BP ; Ly11973/SacA40415, $8560 \pm 60$ BP), les laboratoires de Lyon et Saclay notent un faible rendement en collagène $(4 \mathrm{mg} / \mathrm{g})$ qui tend à relativiser ces résultats. Ceux-ci nous paraissent d'ailleurs trop récents par comparaison avec ceux connus pour le Mésolithique ancien régional (fig. 20, tabl. 6).

Pour aborder la question de l'association dans un ensemble laborien de pointes « de Malaurie », « des Blanchères » et de bitroncatures trapéziformes, il est nécessaire d'élargir les comparaisons à plusieurs gisements (voir également Naudinot 2010, tabl. 4.1). Tandis que ce triptyque est également documenté à $\mathrm{La}$ Borie del Rey c. 3, le couple pointes « de Malaurie "pointes « des Blanchères » est présent notamment à La Borie c. 7 et c. 5 et aux Blanchères (Rozoy 1978 ; Valentin 1995 ; Naudinot 2010 ; Langlais et al. 2014b.), deux sites éponymes aux conditions stratigraphiques complexes. Dans d'autres gisements, ces deux types de pointes semblent s'exclure comme vraisemblablement au Cuze de Neussargues (Rozoy 1978 ; Delpuech et al. 1983), et au Closeau (Bodu 2000 ; Teyssandier 2000). La présence à 
OxCal v4.2.3 Bronk Ramsey (2013); r:5 IntCal13 atmospheric curve (Reimer et al 2013)

Fontfaurès $5 \mathrm{~b}$

Rouffignac_5b

Gurp_11b

Gurp_11a

Peyrazet_c2b_cerv

ChpChalatrasloc1

Alizay

Pont d'Ambonc.2

Fontfaurès_6b

Peyrazet_c.2_Cerv

Alizay

ChpChalatrasloc 1

Buholoupc.8

Alizay

Usclades1c5

ChpChalatrasloc2

La Passagère

Alizay

Buholoupbase c.6

Madeleinesep

Usclades $1 \mathrm{c} 6$

ValLastari_3D

PaluEtchen_2T_7

BorieRey_5_Bos

BorieRey_7_Eq

Mallaetes VI

Cogola_19

PortPenne_2_Bos

BusdelaLum

PortPenne_2_Eq

Rochefort_3.1

Cogola_19

Pont d'Ambon canis c.2

Dalmeri_14b

Carneira

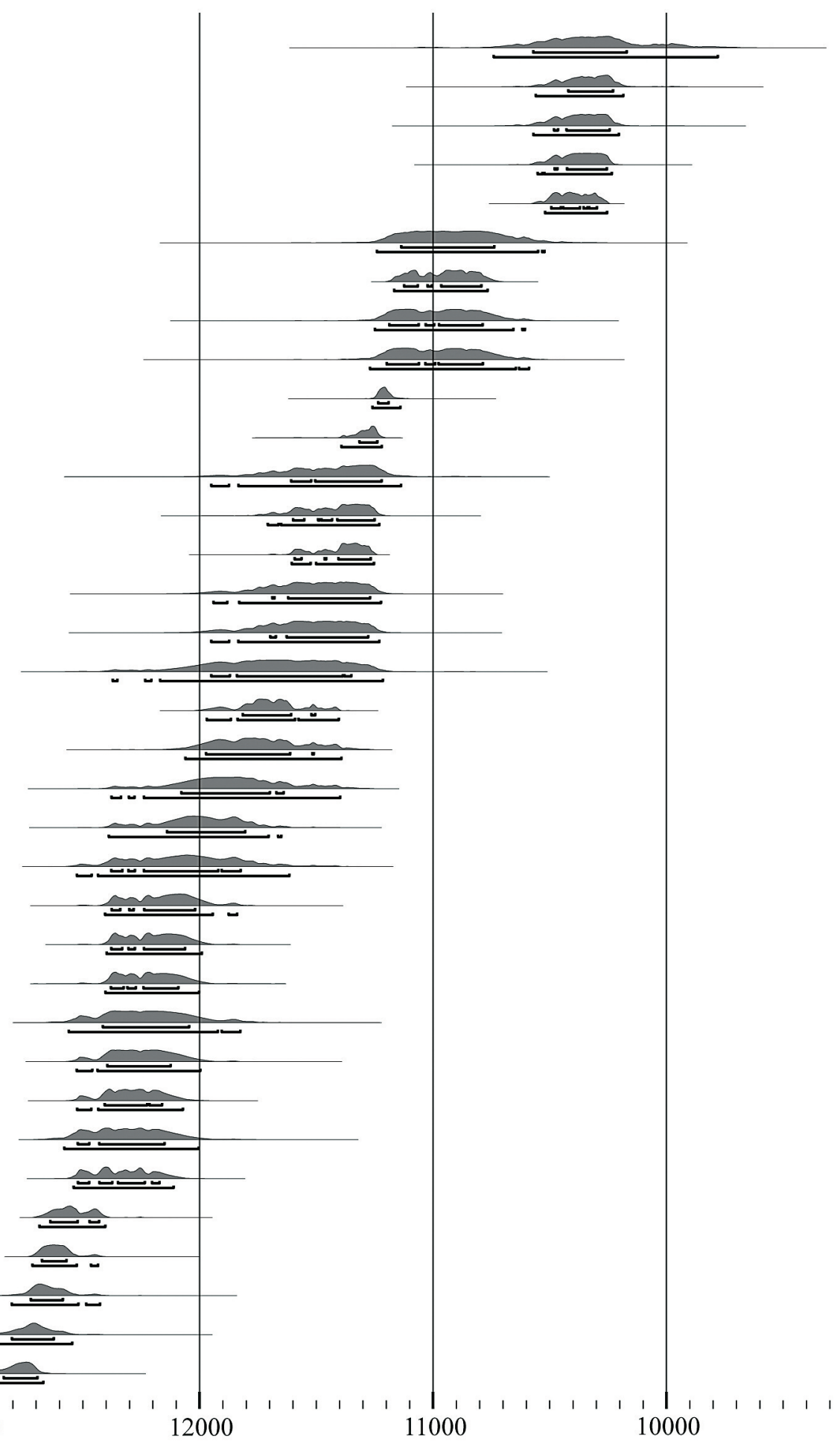

Figure 20 - Dates $14 C$ des sites ayant pour certains livré des pointes de type «Malaurie » (en rouge) ou des bitroncatures trapéziformes (en vert), Sauveterrien ancien (en violet).

Figure 20 - Radiocarbon dates for sites having produced Malaurie points (in red) and or trapazoidal bitrucations (in green), Early Sauveterrian (in purple). 


\begin{tabular}{|c|c|c|c|c|}
\hline SITE & DATE BP & $E C A R T$ & CODE & REFERENCES \\
\hline Fontfaurès_5b & 9140 & 160 & Ly4448 & Barbaza et al. 1991 \\
\hline Rouffignac_5b & 9150 & 90 & GrN5514 & Barrière 1974 \\
\hline Gurp_11b & 9180 & 90 & Ly5321 & Roussot-Larroque 2009 \\
\hline Gurp_11a & 9200 & 70 & Ly5322 & Roussot-Larroque 2009 \\
\hline Peyrazet_c2b_cerv & 9235 & 45 & Ly9062/SacA28329 & cet article \\
\hline ChpChalatras_loc1 & 9580 & 140 & AA43089 & Pasty et al. 2002 \\
\hline Alizay & 9610 & 50 & Beta322721 & Bemilli et al. 2014 \\
\hline Pont d'Ambon_c.2 & 9640 & 120 & Gif3740 & Célérier 1998 \\
\hline Fontfaurès_6b & 9650 & 130 & Ly4449 & Barbaza et al. 1991 \\
\hline Peyrazet_c.2_Cerv & 9780 & 45 & Ly7828/SacA22775 & Langlais et al. 2014b \\
\hline Alizay & 9890 & 40 & Beta317897 & Bemilli et al. 2014 \\
\hline ChpChalatras_loc1 & 9920 & 120 & AA43083 & Pasty et al. 2002 \\
\hline Buholoup_c.8 & 9952 & 69 & Ly1092 & Briois et Vaquer 2009 \\
\hline Alizay & 9960 & 40 & Beta333640 & Bemilli et al. 2014 \\
\hline Usclades1_c5 & 9990 & 100 & Gif8437 & Maury 1999 \\
\hline ChpChalatras_loc2 & 10000 & 100 & AA43085 & Pasty et al. 2002 \\
\hline La Passagère & 10080 & 150 & Ly3647 & Monin 2000 \\
\hline Alizay & 10100 & 40 & Beta333638 & Bemilli et al. 2014 \\
\hline Buholoup_base c.6 & 10131 & 78 & Ly1091 & Briois et Vaquer 2009 \\
\hline Madeleine_sép & 10190 & 100 & GifA95457 & Gambier et al. 2000 \\
\hline Usclades1_c6 & 10250 & 80 & Gif8438 & Maury 1999 \\
\hline ValLastari_3D & 10280 & 110 & $\mathrm{UtC} 2685$ & Peresani et al. 2000 \\
\hline PaluEtchen_2T_7 & 10320 & 60 & $\mathrm{UtC} 13428$ & Mussi, Peresani 2011 \\
\hline BorieRey_5_Bos & 10340 & 50 & Ly-SacA28803 & Langlais et al. 2014b \\
\hline BorieRey_7_Eq & 10350 & 50 & Ly-SacA28804 & Langlais et al. 2014b \\
\hline MallaetesVI & 10370 & 105 & KnI915 & Fortea 1973 \\
\hline Cogola_19 & 10380 & 70 & UtC9286 & Peresani et al. 2000 \\
\hline PortPenne_2_Bos & 10410 & 50 & Ly-SacA28801 & Langlais et al. 2014b \\
\hline BusdelaLum & 10430 & 90 & UtC8912 & Peresani et al. 2000 \\
\hline PortPenne_2_Eq & 10440 & 50 & Ly-SacA28802 & Langlais et al. 2014b \\
\hline Rochefort_3.1 & 10570 & 60 & GrA30689 & Hinguant, Colleter 2005 \\
\hline Cogola_19 & 10640 & 60 & UtC9287 & Peresani et al. 2000 \\
\hline Pont d'Ambon_canis_c. 2 & 10730 & 100 & GifA99102 & Célérier et al. 1999 \\
\hline Gazel_c6_charb & 10760 & 190 & Gif2654 & Sacchi 1986 \\
\hline Dalmeri_14b & 10800 & 110 & R425 & Mussi, Peresani 2011 \\
\hline Carneira & 10880 & 90 & SMU2535 & Zilhao 1997 \\
\hline
\end{tabular}

Tableau 6 - Références des dates $14 \mathrm{C}$ de la figure 36.

Table 6 - References for radiocarbon dates used in figure 36 .

Peyrazet de bitroncatures trapéziformes alimente la question de l'existence de liens interculturels des derniers groupes épipaléolithiques (Langlais et al. dir. 2014, fig. 21). Ces armatures tissent en effet des liens entre l'Aquitaine (ibid.), le nord de la Loire (Naudinot 2010, 2013) et l'est du Rhône (Peresani et al. 2000 ; Duches et al. 2014). Ces pièces (qu'il ne faut pas confondre avec les trapèzes du second Mésolithique) se rencontrent en Aquitaine dans des contextes stratigraphiques délicats : à La Borie del Rey c. 3, au Roc d'Abeille mélangées à de l'Azilien ancien (Champagne et Espitalié 1970), à Roquemissou dans un ensemble à microgravettes (Bobœuf 2003), au Moulin du Roc (Detrain et al. 1996) ou à la Gare de Couze
« associées » à du Magdalénien supérieur (Bordes et Fitte 1964). Au nord de la Loire, les bitroncatures trapéziformes sont associées à des pointes « des Blanchères » comme au Camp d'Auvours et à la Fosse (Naudinot et Jacquier 2009 ; Naudinot 2013). On voit donc bien à travers ces lignes que l'ensemble supérieur de Peyrazet pose de nouvelles questions sur la perduration de la pointe « de Malaurie » au cours du Laborien récent / Épilaborien.

Pour conclure, l'ensemble laborien récent de Peyrazet documente une diversité d'activités domestiques et cynégétiques en contexte de grotte-abri dans une région où ce complexe culturel était mal connu. Plus largement, cette 


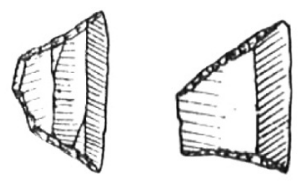

Couze (24)

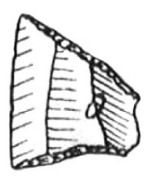

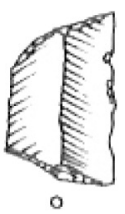
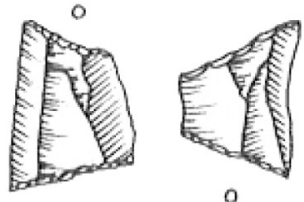

Moulin du Roc (24)
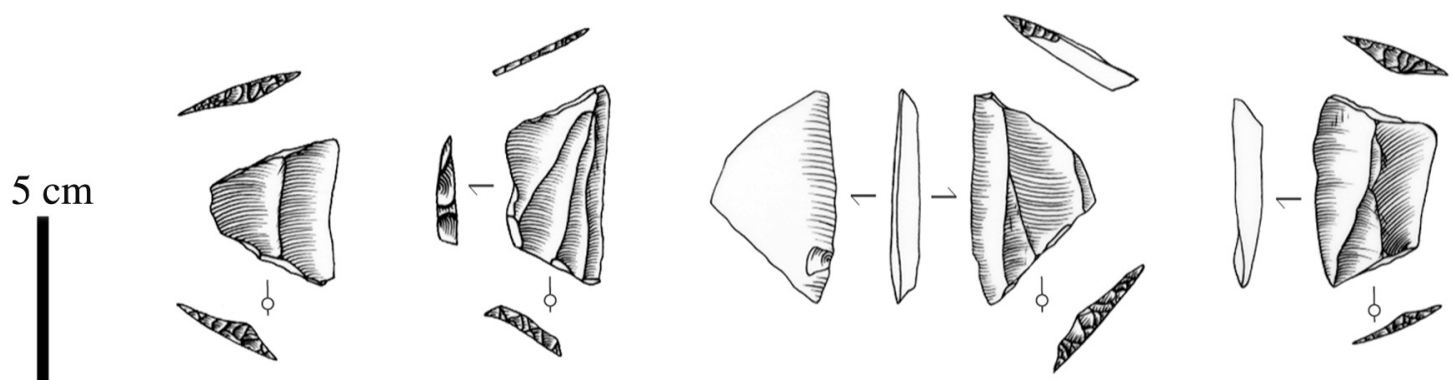

La Borie del Rey (47)
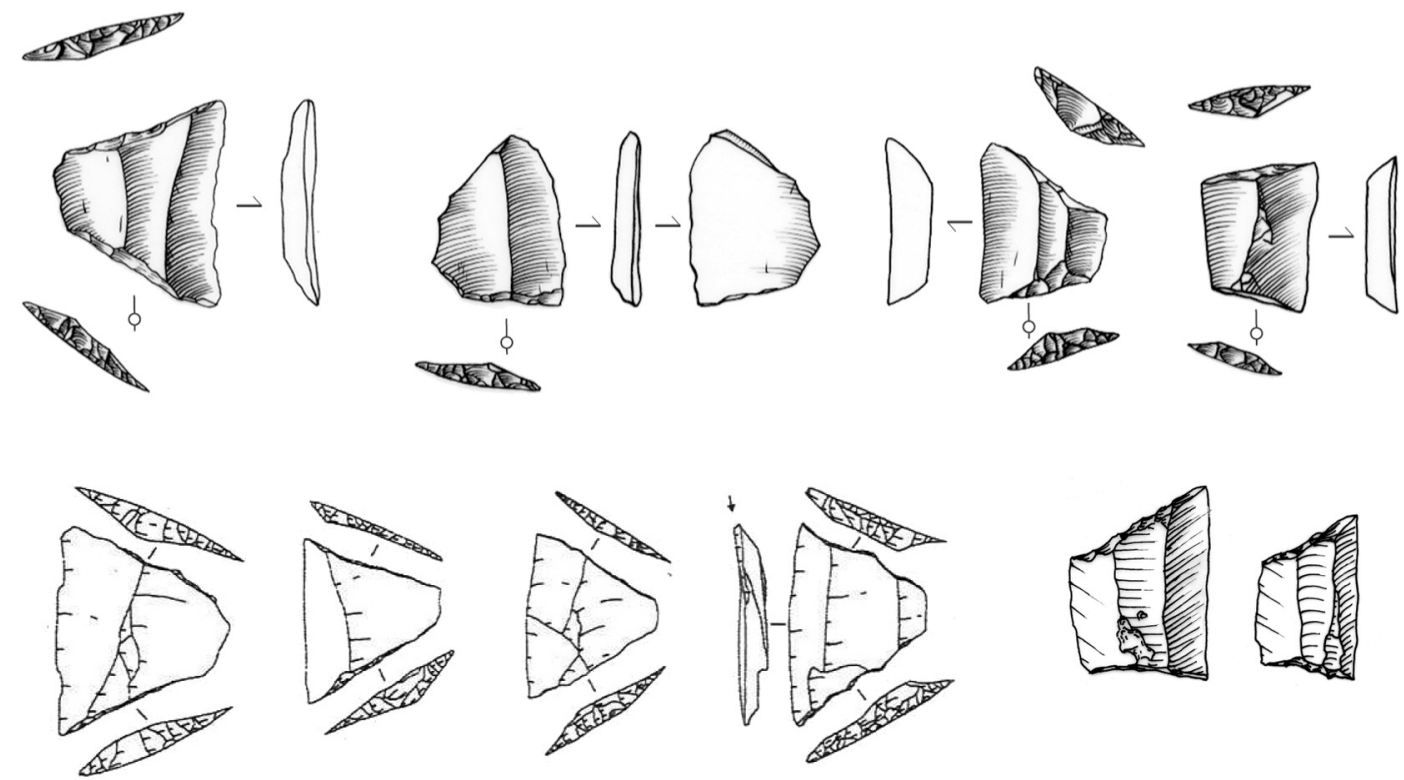

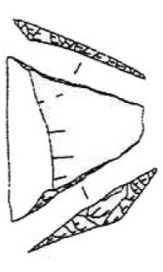

La Fosse (53)
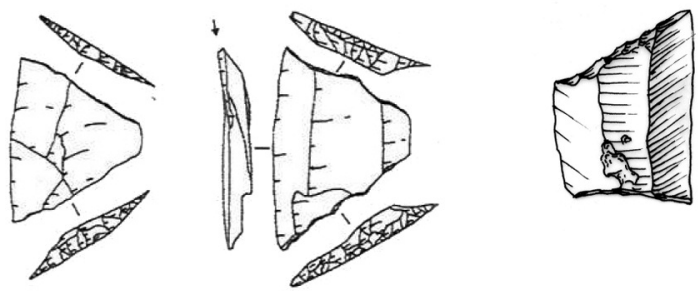

Palu Etchen (Italie)

Figure 21 - Exemples de bitroncatures trapéziformes épilaboriennes (Couze, d'après Bordes et Fitte 1964 ; Moulin du Roc, Dordogne, d'après Detrain et al. 1996 , La Borie del Rey, Lot-et-Garonne, dessins C. Fat Cheung), "épilaboro-ahrensbourgienne " (La Fosse, Mayenne, d'après Naudinot et Jacquier 2009) et épigravettiennes (Palu Etchen, Italie, d'après Duches et al. 2014).

Figure 21 - Epilaborian trapazoidal bitruncations (Couze, after Bordes and Fitte 1964; Moulin du Roc, Dordogne, after Detrain et al. 1996, La Borie del Rey, Lot-et-Garonne, Drawings C. Fat Cheung), "Epilaboro-Ahrensbourgian" (La Fosse, Mayenne, after Naudinot and Jacquier 2009) and Epigravettian (Palu Etchen, Italy, after Duches et al. 2014).

série s'intègre au débat sur la mosaïque européenne des groupes culturels de la transition Pléistocène - Holocène. Elle alimente ainsi le questionnement sur les rythmes d'évolution du contenu lithique des carquois et l'organisation socio-économique des groupes humains à cette période.

\section{Remerciements}

Les auteurs remercient la DRAC Midi-Pyrénées, en particulier le Service Régional de l'Archéologie, et le Conseil Général du Lot pour l'aide financière apportée à ce projet. Nous remercions également P.-L. Lasfargues et 
P. Jardel pour leur autorisation à accéder au site de Peyrazet et y réaliser nos travaux depuis 2008. Un grand merci à G. Delfour qui avait entamé l'étude géoarchéologique, à N. Cantin (IRAMAT-CRPP2A, université de Bordeaux Montaigne) pour les analyses par diffraction de rayons $X$ réalisées sur la pièce d'ocre, à L. Bruxelles pour les données géomorphologiques contextuelles, à G. Saint-Sever pour son examen des céramiques trouvées en surface de l'abri et dans les premiers décapages, à $\mathrm{C}$. Oberlin et $\mathrm{D}$. Roux pour les datations Artémis, à $F$. Echassériaud (association Archéologies), à G. Bariviera (sté TSM), à S. Ducasse pour la réalisation de certaines planches de dessins lithiques (contrat Archéologies-CG 46), à B. Gravina pour la traduction du résumé et des légendes. Nous remercions également les deux relecteurs de cet article, B. Valentin et L. Detrain pour leurs commentaires constructifs ainsi que C. Boussat pour son travail éditorial. Enfin, nous adressons un grand merci aux bénévoles venus participer chaque été à cette expérience archéologique.

\section{Références bibliographiques}

BARBAZA M., VADEYRON N., ANDRE J., BRIOIS F., MARTIN H., PHILIBERT S., ALLIOS D., LIGNON E. 1991 Fontfaurès en Quercy, contribution à l'étude du Sauveterrien, Toulouse, Archives d'Ecologie Préhistorique, 11, $271 \mathrm{p}$.

BARRIÈRE C. 1973-74 - Rouffignac. L'archéologie. Travaux de l'institut d'Art Préhistorique, université de Toulouse le Mirail, 15, p. 65-160; 16, p. 3-47; 17, p. 3-83

BEMILLI C., BIARD M., CHAUSSE C., DONNART K. 2014 - Une partie de chasse à l'Aurochs, il y a 10000 ans. Le Locus 28704 d'Alizay (Eure, France). In : S. Costamagno (dir.) : Histoire de l'alimentation humaine : entre choix et contraintes, actes du $138^{\circ}$ congrés des Sociétés historiques et scientifiques, Rennes avril 2013, Paris, Ed. Du CTHS, p. 170-187.

BERTRAN P. 2004 - Dépôts de pente continentaux: Dynamiques et faciès. Quaternaire Hors-Série (1). Paris, Maison de la géologie, $258 \mathrm{p}$.

BEUGNIER V. 2007 - Préhistoire du travail des plantes dans le nord de la Belgique. Le cas du Mésolithique ancien et du Néolithique final en Flandre, in V. Beugnier, P. Crombe (dir.), Plant Processing from a Prehistoric and Ethnographic Perspective. Proceedings of a workshop at Ghent University (Belgium) November 28, 2006, Oxford, British Archaeological Reports, Archaeopress (BAR International Series 1718), p. 23-40

BODU P. 2000 - Les faciès tardiglaciaires à grandes lames rectilignes et les ensembles à pointes de Malaurie dans le sud du Bassin parisien : quelques réflexions à partir de l'exemple du gisement du Closeau (Hauts-de-Seine), in $\mathrm{P}$. Crotti (dir.), Epipaléolithique et Mésolithique « Méso 97 », actes de la table ronde de Lausanne, novembre 1997, Cahiers d'archéologie romande 81, p. 9-28.
BORDES F. et FITTE P. 1964 - Microlithes du Magdalénien supérieur de la gare de Couze (Dordogne). In Miscelanea en homenaje al abate Henri Breuil, Instituto de Prehistoria y Arqueologia, Barcelona, p. 259-267.

BRIOIS F. et VAQUER J. 2009 - L'abri de Buholoup, de l'Epipaléolithique au Néolithique ancien dans le piémont central des Pyrénées, in Collectif, De la Méditerranée et d'ailleurs, Mélanges offerts à Jean Guilaine, Archives d'Ecologie Préhistorique, Toulouse, p. 141-149.

CAUX S. 2014 - A new piece within a larger puzzle: characterisation of 'grain de mil' flint from the CharenteMaritime, a central resource for the reconstruction of Palaeolithic territories in south-western France. In A. Garcia, J. Garcia, A. Maximiano, J. Rios-Garaizar (ed.), Debating spatial archaeology, international workshop, Santander, juin 2012, IIIPC Ed., p. 143-152.

CÉLÉRIER G. dir. 1994 - L'abri-sous-roche de Pont d'Ambon à Bourdeilles (Dordogne). Le milieu biologique. Gallia Préhistoire, 36, p. 96-106.

CÉLÉRIER G. 1996 - L'abri-sous-roche de Pont d'Ambon à Bourdeilles (Dordogne). L'industrie osseuse et la parure. Gallia Préhistoire, 38, p. 69-110.

CÉLÉRIER G. 1998 - L'abri sous roche de Pont d'Ambon à Bourdeilles (Dordogne). Perspective synthétique. Paleo 10, p. 233-264.

CÉLÉRIER G., TISNERAT N., VALLADAS H. 1999 Données nouvelles sur l'âge des vestiges de chien à Pont d'Ambon, Bourdeilles (Dordogne), Paleo 11, p.163-165.

CHAMPAGNE F., ESPITALIE R. 1970 - L'abri du Roc d'Abeilles à Calviac (Dordogne), Gallia Préhistoire 13, p. 1-23.

COCHARD D. 2004 - Les léporidés dans la subsistance paléolithique du Sud de la France, Université Bordeaux 1, $354 \mathrm{p}$.

COSTAMAGNO S., LAROULANDIE V., LANGLAIS M., COCHARD D. 2009 - Exploitation du monde animal sur le versant nord des Pyrénées durant le Tardiglaciaire. In J.M. Fullola, N. Valdeyron et M. Langlais (dir.), Els Pirineus i les àrees circumdants durant el Tardiglacial. Mutacions $i$ filiacions tecnoculturals evolucion paleoambiental, Actes du $\mathrm{XIV}^{\mathrm{e}}$ Colloque international d'Archéologie de Puigcerdà, Hommage à G. Laplace, novembre 2006, p. 185-209.

COULONGES L. 1963 - Magdalénien et périgordien postglaciaires : la grotte de La Borie del Rey (Lot-et-Garonne), Gallia Préhistoire 7, p. 1-29.

DAYET L., TEXIER P.-J., DANIEL F., PORRAZ G. 2013 Ochre resources from the Middle Stone Age sequence of Diepkloof Rock Shelter, Western Cape, South Africa. Journal of Archaeological Science, 40, 9, p.3492-3505.

DELPUECH A., FERNANDES P., RAYNAL J.-P., PAQUEREAU M.-M., DAUGAS J.-P. 1983 - Eléments de chronostratigraphie pour les niveaux épipaléolithiques du 
Cuze de Neussargues (Cantal), Bull. Soc. Préhist. Fr. 80 (4), p. 100-102.

DETRAIN L., GUILLON M. ; KERVAZO B., MADELEINE S., MORALA A., TURQ A. 1996 - Le Moulin du Roc à SaintChamassy (Dordogne). Résultats préliminaires. Bull. Soc. Préhist. Fr., 93 (1), p. 43-48.

DRUCKER D.G., MADELAINE S., MORALA A. 2011 - Les derniers rennes de Dordogne: nouvelles données chronologiques et environnementales par l'étude isotopique du collagène $\left({ }^{13} \mathrm{C},{ }^{14} \mathrm{C}\right.$ et $\left.{ }^{15} \mathrm{~N}\right)$, Paleo 22, p. 85-100

DUCHES R., AVANZINI M., BASSETTI M., FLOR E., NERI S., DALMERI G. 2014 - Évolution de la mobilité épigravettienne durant le Dryas récent : quelles nouvelles informations pour l'ttalie nord-orientale. In M. Langlais, N. Naudinot, M. Peresani (dir.), Les groupes culturels de la transition Pléistocène - Holocène entre Atlantique et Adriatique, Table-ronde de Bordeaux, mai 2012, Séances de la SPF, vol. 3, p. 185-204

FORTEA J. 1973 - Los complejos microlaminares y geometricos del Epipaleolitico mediterr neo espanol. Memorias del Seminario de Prehist. y Arqueologia 4, 550 p.

GASSIN B. 1996 - Évolution socio-économique dans le Chasséen de la grotte de l'Église supérieure (Var). Apport de l'analyse fonctionnelle des industries lithiques, Paris, CNRS (Monographie du CRA, 17), 328 p.

GILBERT A. 1984 - Contribution à l'étude des faunes de la fin des temps glaciaires et au début des temps postglaciaires, thèse de doctorat, université de Bordeaux 1, 322 p.

GUÉRET C. 2013 - Identité et variabilité de l'outillage lithique du Premier Mésolithique en Belgique et dans le Nord de la France. Les apports de l'approche fonctionnelle, in B. Valentin, T. Ducrocq, J.-P. Fagnart, F. Seara, B. Souffi, C. Verjux (dir.), Palethnographie du Mésolithique: recherches sur les habitats de plein air entre Loire et Neckar, séances de la SPF, vol. 2, novembre 2010, Paris, p. 147-167.

HENRY-GAMBIER D., VALLADAS H., TISNERATLABORDE N., ARNOLD M., BESSON F. 2000 - Datation de vestiges humains présumés du Paléolithique supérieur par la méthode du carbone 14 en spectrométrie de masse par accélérateur. Paleo 12, p. 201-212.

HERNANDEZ FERNANDEZ M. 2001 - Bioclimatic discriminant capacity of terrestrial mammal faunas. Global Ecology and Biogeography, 10, 2, p. 189-204.

HERNANDEZ FERNANDEZ M. 2006 - Rodent paleofaunas as indicators of climatic change in Europe during the last 125,000 years. Quaternary Research, 65 (2), p. 308-323.

HERNANDEZ FERNANDEZ M., PELAEZ-CAMPOMANES P. 2003 - The bioclimatic model: a method of palaeoclimatic qualitative inference based on mammal associations. Global Ecology and Biogeography, 12 (6), p. 507-517.
HERNANDEZ FERNANDEZ M., PELAEZ-CAMPOMANES P. 2005 - Quantitative palaeoclimatic inference based on terrestrial mammal faunas. Global Ecology and Biogeography, 14, 1, p. 39-56.

HODGSKISS T. 2013 - Ochre use in the Middle Stone Age at Sibudu, South Africa: grinding, rubbing, scoring and engraving. Journal of African Archaeology, 11, 1 p. 75-95.

JACQUIER J. 2014 - Analyse fonctionnelle des outillages lithiques et interprétations socio-économique du statut des sites tardiglaciaires du Buhot à Calleville (Eure) et de la Fosse à Villiers-Charlemagne (Mayenne), In : M. Langlais, N. Naudinot, M. Peresani (dir.), Les groupes culturels de la transition Pléistocène - Holocène entre Atlantique et Adriatique, Table-ronde de Bordeaux, mai 2012, Séances de la SPF, vol. 3, p. 221-246.

JEANNET M. 2010 - L'écologie quantifiée. Essai de description de l'environnement continental à l'aide des microvertébrés. Préhistoires Méditerranéennes, 1, p. 11-34.

JUEL JENSEN H. 1994 - Flint tools and plant working. Hidden traces of stone age technology. A use wear study of some danish mesolithic and TRB implements, Aarhus, University Press, $263 \mathrm{p}$.

LANGLAIS M. 2007 - Dynamiques culturelles des sociétés magdaléniennes dans leurs cadres environnementaux. Enquête sur 7000 ans d'évolution de leurs industries lithiques entre Rhône et Ėbre. Thèse de doctorat en cotutelle avec les universités de Toulouse-Le Mirail et Barcelone, $550 \mathrm{p}$.

LANGLAIS M., LAROULANDIE V. avec la collaboration de BRUXELLES L., CHALARD P., COCHARD D., COSTAMAGNO S., DELFOUR G., KUNTZ D., LE GALL O., PETILLON J.-M., QUEFFELEC A. 2009 - Les fouilles de la grotte-abri de Peyrazet (Creysse, Lot) : nouvelles données pour le Tardiglaciaire quercinois. Bull. Soc. Préhist. Fr. 106 (1), p. 150-152.

LANGLAIS M., NAUDINOT N. et PERESANI M. dir. 2014 Les groupes culturels de la transition Pléistocène - Holocène entre Atlantique et Adriatique, Séance de la SPF, Bordeaux, mai 2012, Séances de la SPF, vol. 3, 246 p.

LANGLAIS M., COSTAMAGNO S., LAROULANDIE V., PETILLON J.M., DISCAMPS E., MALLYE J.B., COCHARD D., KUNTZ D. 2012 - The evolution of Magdalenian societies in South-West France between 18,000 and 14,000 cal BP: Changing environments, changing tool kits. Quaternary International 272-273, p. 138-149.

LANGLAIS M., BONNET-JACQUEMENT P., DETRAIN L., VALDEYRON N. 2014a - Le Laborien : ultime sursaut technique du cycle évolutif paléolithique du Sud-Ouest de la France ? In S. Michel et N. Naudinot (org.), session G, in J. Jaubert, N. Fourment, P. Depaepe (dir.) Transitions, ruptures et continuités en Préhistoire, Actes du

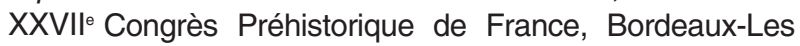
Eyzies, juin 2010, Mémoire de la SPF, p. 417-430. 
LANGLAIS M., DETRAIN L., FERRIÉ J.-G., MALLYE J.-B., MARQUEBIELLE B., RIGAUD S., TURQ A., BONNETJACQUEMENT P., BOUDADI-MALIGNE M., CAUX S., FAT CHEUNG C., NAUDINOT N., MORALA A., VALDEYRON N., CHAUVIĖRE F.-X. 2014b - Réévaluation des gisements de La Borie del Rey et de Port-de-Penne : nouvelles perspectives pour la transition Pléistocène - Holocène dans le sud-ouest de la France ; in M. Langlais, N. Naudinot, M. Peresani (dir.), Les groupes culturels de la transition Pléistocène - Holocène entre Atlantique et Adriatique, Table-ronde de Bordeaux, mai 2012, Séances de la SPF, vol. 3, p. 83-128.

LE LOUARN H. et QUÉRÉ J.-P. 2003 - Les rongeurs de France : faunistique et biologie. Editions Quae, $260 \mathrm{p}$.

LENOBLE A. 2005 - Ruissellement et formation des sites préhistoriques: référentiel actualiste et exemples d'application au fossile. Archaeopress BAR, Oxford, 216 p.

LE TENSORER J.M. 1981 - Le Paléolithique de l'Agenais, Cahiers du Quaternaire 3, CNRS, 526 p.

LLOVERAS L., MORENO GARCIA M., NADAL J. 2009 - Butchery, Cooking and Human Consumption Marks on Rabbit (Oryctolagus cuniculus) Bones: An experimental Study, Journal of Taphonomy 7, 179-201.

LORBLANCHET M. 1972 - Aperçu sur le Magdalénien moyen et supérieur du Haut-Quercy. In : CPF, XIX ${ }^{\ominus}$ session, Auvergne, 1969, Soc. Préhist. Fr., p. 256-283.

LORBLANCHET M. 1989 - Caractères originaux du Magdalénien du Quercy. In J.-P. Rigaud (dir.), Le Magdalénien en Europe, Colloque de Mayence, 1987, ERAUL 38, p. 239-252.

LORBLANCHET M. 1996 - Du Magdalénien à l'Azilien en Quercy. In La vie préhistorique, Ed. Faton, p. 282-285.

MALLYE J.-B. 2007 - Les restes de Blaireau en contexte archéologique : Taphonomie, archéozoologie et éléments de discussion des séquences préhistoriques. Thèse de Doctorat, Université Bordeaux 1, $547 \mathrm{p}$.

MARQUET J.-C. 1993 - Paléoenvironnement et chronologie des sites du domaine Atlantique français d'âge Pléistocène moyen et supérieur d'après l'étude des rongeurs. Tours, Les Cahiers de la Claise, Supplément 2, $345 \mathrm{p}$.

MAURY J. 1999 - Le groupe épipaléolithique des Usclades (Nant, Aveyron), Bull. Soc. Préhist. Fr. 96 (4), p 505-528.

MONIN G. 2000 - Apport de la technologie lithique à l'étude de séries anciennes. Les assemblages tardiglaciaires des chasseurs de marmottes des grottes de Colomb et de la Passagère à Méaudre (Vercors, Isère), in G. Pion (Ed.), Le Paléolithique supérieur récent: nouvelles données sur le peuplement et l'environnement, Table ronde de Chambéry, 1999, Mém. SPF 28, p. 271-287.
MUSSI M., PERESANI M. 2011 - Human settlement of Italy during the Younger Dryas, Quaternary International 242 ; p. $360-370$

NAUDINOT N. 2010 - Dynamiques techno-économiques et de peuplement au Tardiglaciaire dans le Grand-Ouest de la France, thèse de doctorat, université Rennes 1, 735 p.

NAUDINOT N. 2013 - La fin du Tardiglaciaire dans le Grand-Ouest de la France. Bull. Soc. Préhist. Fr. 110 (2), p. 233-255.

NAUDINOT N., JACQUIER J. 2009 - Un site tardiglaciaire en place à la Fosse (Villiers-Charlemagne, Mayenne) : premiers résultats et implications chronoculturelles. Bull. Soc. Préhist. Fr. 106 (1), p. 145-149.

NIEDERLANDER A., LACAM A., SONNEVILLE-BORDES D. de 1956 - L'abri Pagès à Rocamadour et la question de l'Azilien dans le Lot, L'Anthrop. 60 (5-6), p. 417-446.

ODELL G.-H. 1978 - Préliminaires d'une analyse fonctionnelle des pointes microlithiques de Bergumermeer (Pays-Bas), Bulletin de la Société Préhistorique Française 75: p. 37-49.

PASTY J.F., ALIX Ph., BALLUT C., GRIGGO C., MURAT R. 2002 - Le gisement épipaléolithique à pointes de Malaurie de Champ-Chalatras (Les Martres d'Artière, Puyde-Dôme), Paleo 14, p. 101-176.

PERESANI M., BERTOLA S., DE STEFANI M., DI ANASTASIO G. 2000 - Bus de la Lum and the Epigravettian occupation of the Venetian Pre-Alps during the Younger Dryas, Rivista di Scienze Preistoriche L, p. 103-132.

PLISSON H. 1985 - Étude fonctionnelle d'outillages lithiques préhistoriques par l'analyse des micro-usures : recherche méthodologique et archéologique, thèse de doctorat, université Paris 1 - Panthéon-Sorbonne, 353 p.

POPPE G.T., GOTO Y. 1993 - European Sea shells. (Scaphopoda, Bivalvia, Cephalopoda). Hemmen, Wiesbaden.

RIFKIN R.F. 2012 - Processing Ochre in the Middle Stone Age: Testing the Inference of Prehistoric Behaviours from Actualistically Derived Experimental Data. Journal of Anthropological Archaeology, 31, 2, p. 174-195.

ROUSSEAU L. 1933 - Le Magdalénien dans la Vienne. Découverte et fouille d'un gisement du Magdalénien à Angles-sur-l'Anglin (Vienne). Bull. Soc. Préhist. Fr., 30 (4), p. 239-256.

ROZOY J.G. 1978 - Les derniers chasseurs L'Epipaléolithique en France et en Belgique - Essai de synthèse. Bull. Soc. Arch. Champ., 3 vol.

SEMENOV S. A. 1964 - Prehistoric Technology, an Experimental Study of the Oldest Tools and Artifacts from 
Traces of Manufacture and Wear, Londres, Cory, Adams and Mackay, $211 \mathrm{p}$.

SÉRONIE-VIVIEN M.-R. dir. 2001 - La grotte du Sanglier à Reilhac (Lot). Du Magdalénien au Néolithique ancien, Préhistoire du Sud-Ouest, suppl.4, 182 p.

SÉRONIE-VIVIEN M.-R. dir. 1995 - La grotte de Pégourié, Caniac-du-Causse (Lot). Périgordien-Badegoulien-AzilienAge du Bronze, quercynoise, suppl. 2, 334 p.

SACCHI D. 1986 - Le Paléolithique supérieur du Languedoc occidental et du Roussillon. Gallia Préhistoire XXle suppl., Ed. du CNRS, Paris, 284 p.

SALOMON H. 2009 - Les matières colorantes au début du Paléolithique supérieur : sources, transformations et fonctions. Université Bordeaux I, Thèse de doctorat, $427 \mathrm{p}$.

SIMONNET R. avec la collaboration de BON F., BORDES J.-G., PRIMAULT J. 2007 - Le silex « Grains de Mil ». Localisation des gîtes. In N. Cazals et X. Terradas (dir.), Frontières naturelles et frontières culturelles dans les Pyrénées préhistoriques, Table ronde de Tarascon/Ariège, 2004, Publican Ediciones universidad de Cantabria, Santander, p. 101-102.

SORESSI M., D'ERRICO F. 2007 - Pigments, gravures, parures : les comportements symboliques controversés des Néandertaliens, in B. Vandermeersch, B. Maureille (Eds.), Les Néandertaliens, biologie et cultures, Ed. CTHS, Documents préhistoriques 23, Paris, p. 297-309.

SZMIDT C., LAROULANDIE V., DACHARY M., LANGLAIS M., COSTAMAGNO S. 2009 - Harfang, Renne et Cerf : nouvelles dates ${ }^{14} \mathrm{C}$ par SMA du Magdalénien supérieur du Bassin aquitain au Morin (Gironde) et Bourrouilla (Pyrénées-Atlantiques). Bull. Soc. Préhist. Fr. 106 (3), p. 583-587.

TEYSSANDIER N. 2000 - Un gisement belloisien sur les bords de la Seine : le Closeau à Rueil-Malmaison (Hautsde-Seine), Bull. Soc. Préhist. Fr. 97 (2), p. 211-228.

TURQ A. 2000 - Le Paléolithique inférieur et moyen entre les vallées de la Dordogne et du Lot. Paleo, supplément $n^{\circ}$ 2, avril 2000, $456 \mathrm{p}$.

TURQ A., MORALA A. avec la collaboration de M.-R. SERONIE-VIVIEN et M. SERONIE-VIVIEN 2014 - Inventaire des silicifications du Quercy, de ses marges et des marqueurs lithologiques du nord-est aquitain : synthèse des données, in M. Jarry, J.P. Brugal, C. Ferrier (dir.), Modalités d'occupation et exploitation des milieux au Paléolithique dans le sud-ouest de la France : l'exemple du Quercy, suppl. Paleo $\mathrm{n}^{\circ} 4, \mathrm{XV}^{\mathrm{e}}$ congrès de l'IUSPP, Lisbonne, session C67, septembre 2006, p. 159-180.
VALDEYRON N., BOSC-ZANARDO B., BRIAND T., HENRY A., MARQUEBIELLE B., MICHEL S. 2011 - Le gisement du Cuzoul de Gramat (Lot, France) : présentation des nouveaux travaux et résultats préliminaires. Sénépart I., Perrin T., Thirault E., Bonnardin S. (dir.), Marges, frontières et transgressions. Actes des $8^{\mathrm{e}}$ Rencontres Méridionales de Préhistoire Récente, Marseille, novembre 2008, Archives d'Ecologie Préhistorique, Toulouse, p. 197-211.

VALENTIN B. 1995 - Les groupes humains et leurs traditions au Tardiglaciaire dans le Bassin parisien. Apports de la technologie lithique comparée, Thèse de Doctorat, université de Paris 1, 3 vol., 1106 p.

VAN GIJN A. L. 1989 - The Wear and Tear of Flint: Principles of Functional Analysis Applied to Dutch Neolithic Assemblages, Leyde, University of Leiden, Institute of Prehistory (Analecta Praehistorica Leidensia, 22), 181 p.

VANHAEREN M. 2002 - Les fonctions de la parure au Paléolithique supérieur : de l'individu à l'unité culturelle. Thèse de doctorat, Université de Bordeaux 1, Talence.

VIGNE J.-D., MARINVAL-VIGNE M.-C. 1983 - Méthode pour la mise en évidence de la consommation du petit gibier, in Clutton-Brock J., Grigson C. (Eds.), Animals and Archaeology. 1: Hunters and their prey, Archaeopress BAR, p. 239-242.

VIGNE J.-D., MARINVAL-VIGNE M.-C., DE LANFRANCHI F., WEISS M.-C. 1981 - Consommation du «Lapin-rat» (Prolagus sardus Wagner) au Néolithique ancien méditerranéen Abri d'Araguina-Sennola (Bonifacio, Corse), Bull. Soc. Préhist. Fr. 78, p. 222-224.

WATTS I. 2010 - The Pigments from Pinnacle Point Cave 13B, Western Cape, South Africa. Journal of Human Evolution, 59, 3-4, p. 392-411.

WYE KR. 1990 - Coquillages. Paris: Arthaud

ZILHAO J. 1997 - O Paleolitico Superior da Estremadura portuguesa, vol.1, Ed. Colibri. 